\title{
EXPERIMENTAL CAUSATION OF CONGENITAL SKELETAL DEFECTS AND ITS SIGNIFICANCE IN ORTHOPAEDIC SURGERY*
}

\author{
P. K. Duraiswami, Baltimore, Maryland, United States of America \\ Formerly Research Fellow, Department of Orthopaedic Surgery, University of Liverpool
}

The frequency of anomalies of development is much greater than one would be inclined to suggest from an examination of the records of hospitals. According to Stockard (1909) congenital malformations of various types and degrees cause " the death of about 23 per cent of the human race before or shortly after the time of birth and handicap a certain proportion of the survivors throughout their lives." MacGregor (1946), who reviewed 1,053 stillbirths and neonatal deaths, found that 20 per cent of stillbirths and 10 per cent of neonatal deaths were directly attributable to gross congenital malformations. Mall's careful studies in 1908 led him to conclude that the great majority of aborted foetuses were malformed, and that out of every hundred pregnancies not more than eighty terminated in the birth of normal infants at full term.

The pathology of the human foetus is a relatively unexplored subject, though over half a century ago Ballantyne of Edinburgh $(1895,1904)$ made a notable beginning to the solution of at least some of its problems with his classical books: The Diseases and Deformities of the Foetus and The Manual of Antenatal Pathology and Hygiene. Since but little is known of the detailed histology of the early human embryo, histological examination in cases of perverted growth is limited mainly to aborted foetuses which, unfortunately, tend to present varying degrees of post-mortem degeneration before accurate histological methods can be applied. It is precisely in this field that experimental work can offer valuable help. According to Mall (1917) and others, the pathological changes that take place in human foetuses and those obtained experimentally in animals are not merely " analogous or similar but identical."

During the past few decades the discovery of genetic factors leading to congenital malformations has attracted a great deal of attention, while research in the field of environmental teratogenic factors has lagged behind. The importance of environmental causes of human malformations has not received as much emphasis as it should have done. From recently published surveys of the works on the subject (Macklin 1936, Murphy 1947, Steindler 1950) it might be concluded that abnormal genes are the cause of practically all congenital malformations. However, the association of developmental anomalies such as cataract, cardiac septal defects, patent ductus arteriosus, deaf-mutism, dental defects, and microcephaly with epidemics of rubella, noted first in Australia by Gregg $(1941,1945)$ and attributed to maternal infection in the early months of pregnancy by Swan and others (1946) demonstrates clearly enough that changes in the germplasm cannot always be invoked as the cause of congenital abnormalities. It will be of great interest to the geneticist to know that types of congenital malformations which are sometimes genetically determined, such as microphthalmos, cleft palate, and certain skeletal abnormalities, can be induced in the offspring not only by maternal nutritional deficiencies (Warkany and Nelson 1941) and by $\mathrm{x}$-radiation (Bagg and Little 1924) but also, at least in some animals, by the deliberate introduction of certain substances such as insulin into the environment of the embryo during its development.

In 1943, while investigating the role of glycogen granules in hypertrophic cartilage cells in chick embryos during endochondral ossification (Harris 1932), I made an accidental observation as a result of which $I$ became interested in the insulin-induced skeletal

\footnotetext{
* Essay based on work done while Research Fellow in the Department of Orthopaedic Surgery, University of Liverpool (1949-51), for which the Robert Jones Medal and the British Orthopaedic Association Prize for 1951 were awarded. 
abnormalities in developing chick embryos. Having confirmed the observation of Harris that the "region of senescent or hypertrophied cartilage cells in the zone of calcification showed the discrete distribution of the particles of glycogen " I proceeded to investigate the effect, if any, of hypoglycaemia-induced in the chick embryos by injections of various doses of insulin into the eggs-on the glycogen granules in the hypertrophic cartilage cells and also on the endochondral ossification in general. I was then aware that Hanan (1925), Vladimirov (1931) and others had induced hypoclycaemia experimentally in chick embryos by injections of insulin into eggs but, to the best of my knowledge, they had not recorded anything about the teratogenic properties of insulin. In the course of my first series of experiments I injected five units of insulin into hens' eggs at various intervals after the beginning of incubation and, to my surprise, noticed that some of the chicks showed radiographic appearances resembling osteogenesis imperfecta in the human. Some of them had developed abnormalities such as spina bifida, partial or complete supression of development of one or more vertebrae, while others showed various deformities in the limbs. Since then a variety of congenital abnormalities have been induced not only with insulin but also with " synthalin," thallium salts, sulphonamide compounds, 3-acetyl-pyridine and cortisone. In this paper I propose to deal only with insulin-induced abnormalities.

\section{REVIEW OF PREVIOUS WORK ON EXPERIMENTAL TERATOGENESIS}

An acquaintance with the achievements of the past will not only stimulate independent thinking but also put a check on those tiresome rediscoveries of old facts and observations which only too frequently find their way into modern literature as supposedly new ideas.

\section{NINETEENTH CENTURY-BEGINNING OF EXPERIMENTAL TERATOGENESIS}

Not only was far greater progress made during the nineteenth century in embryology, foetal physiology and pathology than in any previous century, but also a new type of research was conducted by great pioneers such as Geoffrey Saint-Hilaire, Liharzik, Valentin, Gerlach, Lombardini and Dareste in an attempt to establish on a scientific basis the branch of experimental pathology known as " teratogenesis or the artificial production of malformations or monstrosities." Most of the experiments were carried out on chick embryos during incubation, natural or artificial. Saint-Hilaire (1839) attempted to produce anomalies in the chick by disturbing its development in different ways during the early days of incubation. Various methods were employed such as shaking the eggs, pricking them at various points, keeping them in a vertical position and partly covering them with wax or varnish. These resulted in anomalies like triocephaly, atrophy of the eyes, eventration and spina bifida. Other observers seem to have repeated these experiments with or without modification.

According to Ballantyne (1904), during the fifty years that followed these researches only Camille Dareste stood out supreme in the field of experimental teratogeny. Between 1855 and 1891 he carried out an enormous amount of research and embodied the results of his experiments in a long series of monographs and articles. It was primarily due to him that experimental teratogenesis existed as a special branch of biology. From his numerous experiments conducted by varying the temperature during incubation and careful examination of the monstrous chicks thus produced, Dareste was able to draw important conclusions. $\mathrm{He}$ believed that teratogeny was always the consequence of a deviation from normal embryonic development. He regarded almost all malformations of the single embryo as explicable by arrest of development, thus forestalling Stockard's (1907) observations made two decades later. " He differentiated between hemiterata, in which the arrest of development was quite local and was due to a mild teratogenic influence, and the monstrosities proper, in which a stronger teratogenic agent affected a whole region. There were many other interesting questions in teratogenesis which were opened up or cleared up by Dareste but the most important conclusion

Vol. $34 \mathrm{~B}$, No. 4, NOVEMBER 1952 
he drew from his numerous experiments was that the congenital malformations and monstrosities met with in the chick resembled closely those found in mammalia, especially in the human subject. In this observation Dareste found the germ of the hope that the cause that was active in the chick in teratogenesis might yet be found to apply to the human subject and that human teratology might likewise be elucidated." (Ballantyne 1904).

In 1894 Fére began his series of experiments with hens' eggs. They were divided into three groups. The first group consisted of experiments in which the conditions outside the egg were altered. He repeated many of the experiments of Dareste and others with alterations of temperature, mechanical shaking and varnishing of the egg shell before incubation. He also tried the effect of gases capable of penetrating the shell. Fére placed some eggs in atmospheres containing vapours of turpentine, musk, mercury, phosphorus, ammonia, ether, chloroform, alcohol and tobacco before incubation. The second group consisted of those in which substances in solution were injected into the yolk or albumen of the egg. In this way Fére tested solutions of an incredible variety of substances such as chemicals, microbic toxins, alkaloids, essential oils, various alcohols and other organic substances. "Despite the lack of an intelligent plan the results of Fére's experimental work were very striking. He found, for instance, that there was a direct relation between the teratogenic and toxic powers of poisons " (Needham 1931). Ballantyne (1904) summed up his appreciation of Fére's work in the following words: "Fére has, to my mind, greatly advanced the science of experimental teratogeny by breaking down the dividing wall which was felt to exist in consequence of the particular nature of the supposed exciting causes of monstrosities . . Another good result followed Fére's work: it gave teratogeny a clinical aspect. If the causes of disease were likewise the causes of monstrosity, then it might be expected that in parents, and especially in the mother, of malformed foetuses, some traces of such morbid causes might be found. The question then arose whether malformed offspring were more common in the alcoholic parents or those suffering from syphilis, tubercle, infectious fevers and the like." (My italics.)

\section{EXPERIMENTAL TERATOGENESIS DURING THE PRESENT GENTURY}

In view of the large number of experiments that have been conducted during the first half of the present century in different parts of the world, it is proposed to touch upon only the more important among the various investigations, grouping them under certain headings for purposes of convenience instead of following the usual chronological order.

Mechanical injury-According to Needham (1931), teratogenesis by mechanical injury has not been studied so much during this century as in the past, because " the accurate grading of mechanical shocks to living material is a very difficult matter." Scott (1903) investigated the capacity of the eggs of the worm amphitrite to develop, without segmenting, into ciliated swimming structures after agitating them mechanically by squirting through a pipette or by other means. Hein (1907) conducted an interesting series of experiments by subjecting the eggs of the trout salmo fario to various injuries at different moments in their development. $\mathrm{He}$ observed that the period of greatest susceptibility was between thirteenth and seventeenth day of development; for he noticed that both before and after that time the same amount of injury hardly produced the same degree of damage. Hata (1927) repeated Hein's work on two Japanese fishes onchroryncus mason and a kind of trout. He employed a " standard vibration treatment" and observed a definite maximum of susceptibility about the sixteenth day of development. Landauer and Bauman (1943) have shown that " rumplessness" can be produced in chickens by mechanical shaking of the eggs. They found that the genetic constitution of the mother played an important part in the extent of the response to mechanical injury. According to them injury to the blastoderm was responsible for " rumplessness." 
Thermal injury--Morgan (1904) studied the morphological effect of injury by cold on the eggs of rana palustria and came to the conclusion that during post-fertilisation and early cleavage stages the embryos were very susceptible but later their resistance increased. Hein (1911) observed that there were marked differences in susceptibility of trout eggs to temperature changes during their development, and also that the greatest prenatal susceptibility to developmental malformations occurred about the fifteenth day of development or almost exactly at the same time as the susceptibility to mechanical and electrical agents. Higurashi and Nakai (1925) concluded from their experiments with the eggs of a Japanese fish plecoglossus altivelis that at first the eggs were very susceptible to teratogenic influences of temperature but became more resistant after the appearance of the "eye-spots" in the embryo.

Teratogenesis by abnormal gas concentrations and anoxia-By far the largest number of researches in ontogenetic susceptibility variations in relation to teratogenesis have been conducted with oxygen lack or carbon dioxide excess, primarily because a given atmosphere is readily prepared, and its effects can be easily observed. Lyon (1902) investigated the effect of placing echinoderm eggs in hydrogen at varying intervals after fertilisation and observed that the embryos were more susceptible during certain phases of development (" critical periods") than others. Morgan (1905) found that the critical period to anoxia in the development of the frog's egg was after fertilisation and before the first cleavage. If anoxia occurred during this critical interval there was a high incidence of spina bifida, ring embryos and failures of segmentation. Hall (1924) conducted certain experiments on the eggs of the toad bufo Americanus with variations in oxygen tension and changes in $\mathrm{pH}$ and showed that the first cleavage and gastrulation were again the "critical periods of susceptibility."

Ingalls, Curley and Prindle (1950) submitted pregnant mice to anoxia inside a bell-jar and demonstrated that differences in the degree of anoxia determined not only the frequency of embryonic deaths but also the kind of abnormal offspring of the exposed mice. During an experiment, a vacuum pump continuously exhausted the bell-jar while entrance of the air into the system was restricted by means of an adjustable glove valve. Anencephaly resulted from exposures to " simulated atmospheres " of 25,000 feet and was not found among progeny of animals exposed to 27,000 feet or maintained at " sea level." They have also drawn attention to the "influence of timing of the maternal insult " on the causation of intra-uterine deaths and congenital anomalies. They observed that the specific effects depended on the stage of foetal development and the sites involved when maternal insult occurred. Anencephaly of the foetus was caused by systemic anoxia, obviously with focal involvement of cephalic structure on the eighth day of gestation and cleft-palate resulted in the offspring when the mothers were subjected to anoxic insult on the fourteenth day of gestation. These workers state: "It is reasonable to infer that certain rapidly differentiating cephalic structures are more vulnerable to anoxia on that day than resting cells of fully differentiated tissues." I believe that these experimental observations may have clinical application; and future research may show that during pregnancy maternal anoxia, not necessarily of the rare " anoxic" type but also the commoner "anaemic" and "stagnant" types, may play a significant part in the causation of foetal deaths and congenital defects.

Teratogenesis by $x$-rays, radium and ultra-violet light-There are a great number of papers on this subject in the literature, $\epsilon$ ven if the discussion is confined to the period of embryonic growth, but many can be disregard€d because the experiments were conducted without adequate attention to dosagr .

Loeb and Bancroft (1911) used x-rays and radium in treating the common fruit fly drosophila. They published a meagre report of their work but they made an important observation that among the radium-irradiated group certain abnormal offspring were noticed in the second generation which bred true, whereas none of the controls showed any of the

VOL. $34 \mathrm{~B}$, No. 4 , NOVEMBER 1952 
abnormalities. In 1922 Mavor observed that irradiation might modify the germplasm and he obtained in drosophila a considerable number of abnormal daughters by submitting the mothers to x-rays before mating (Mavor 1922). A certain proportion of these abnormal daughters alone were fertile but they bred true without themselves undergoing any $\mathrm{x}$-ray treatment.

In 1918 Bagg began his classical experiments to investigate the effects of various types of irradiation on animals. He used x-rays, radium emanation and injections of radioactive solutions. He studied the pathological and metabolic changes produced in rats and dogs by injections of radioactive solutions (Bagg 1920); and later the effect of such agents and gamma rays of radium emanation on the functional activity of the ovary and reproduction in the rat (Bagg 1922). Breeding female mice were treated with radioactive solutions of radium emanation at various periods both before and after mating with normal untreated males. In another series of experiments, pregnant rats were irradiated with comparatively heavy doses of gamma-rays. The most constant finding in these animals was the occurrence of characteristic subcutaneous haemorrhagic areas of extravasation in the head region, especially around the eye, and in the feet of the developing embryos irradiated in utero. In the case of three litters, similar blood-vascular disturbances were observed in the offspring of mothers irradiated several days (in one case twenty-two days) before mating with a normal male. Marked pathological changes were noted in the brain, which showed evidence of arrest of development, and there were also cataracts and other abnormalities of the eyes in embryos irradiated in utero with gamma rays. The prevalence of vascular lesions in the head regions of the embryos, especially in the area surrounding the eye, apparently accounted for the abnormal incidence of eye defects. The abnormalities of the limbs were mainly expressed in various forms of club foot, syndactylism, hypodactylism, congenital amputations and polydactylism. Various combinations of these defects were frequently found in the same limb. Blindness and less severe anatomical defects of one or both eyes, the absence of one or both kindeys and hydronephrosis, usually of one kidney, were the most frequent defects that were associated with abnormalities of the limbs.

Murphy has reviewed the records of 106 women who received therapeutic amounts of pelvic $\mathrm{x}$-radiation during pregnancy. These patients gave birth to seventy-five children at full term, and thirty-eight abnormal children from this group were examined carefully. In twenty-eight, maternal irradiation appeared to be the only factor responsible for their abnormalities. Twenty out of the twenty-eight children suffered from " severe distrubances of the central nervous system." Sixteen had microcephaly. The rarity of microcephaly in the general population (one in 10,000 or more births) suggests that maternal pelvic irradiation was most probably the cause. According to Murphy (1947), maternal pelvic irradiation before conception does not influence the growth of the offspring subsequently conceived. He believes that the small amounts of $x$-radiation employed for diagnostic radiography of the mother's pelvis during pregnancy have no adverse effects on the developing foetus.

Teratogenesis by bacterial toxins and viral infections in experimental animals-Gray and Worthing (1947) produced in chick embryos a localised destruction of the anterior end of the central nervous system with tetanus toxin. They believed that an enzyme inhibitor in the tetanus toxin was probably responsible for the destruction. Blattner and Williamson (1951) have studied the teratogenic action of Newcastle disease virus on developing chick embryos. Virus and control inoculations were made forty-five hours after the beginning of incubation of the eggs. The virus inoculum consisted of allantoic fluid from a twelve-day chick embryo inoculated twenty-four hours previously with Newcastle virus disease. Control inoculum consisted of allantoic fluid from a normal twelve-day embryo. A dose of 0.01 millilitres of inoculum was injected beneath the vitelline membrane over the blastoderm near the edge of the area pellucida, the flow from the needle being directed towards the embryo. They observed that the lens and auditory sac showed defective development or were completely 
missing in 42 per cent of the 150 infected chick embryos. In the 150 control embryos inoculated with normal allantoic fluid neither defect was found. They have recorded that in their subsequent experiments the specific abnormalities were found in 80 to 90 per cent of the embryos after inoculation with the virus. Preliminary histological studies of the lens defects revealed findings very similar to those observed by Cordes and Barber (1946) and by Swan (1944) in their studies of human foetuses aborted by mothers who had contracted rubella during the first trimestre of pregnancy-namely, retardation in the development of the lens (Cordes and Barber 1946) and necrosis and degeneration of varying degrees in the lens fibres (Swan 1944, Tondury 1951).

Teratogenesis by chemical and hormonal agents-Undoubtedly the most important teratogenic studies during the first two decades of the present century were made by Stockard (1907-21). He carried out most of his experiments in teratogeny with the eggs of the common minnow fundulus heteroclitus. He was able to induce a variety of deformities not only by changing the temperature and oxygen content of the environment but also by introducing alcohol and various anaesthetics into the environment. Most of the valuable conclusions which he drew from his long series of experiments have since been confirmed repeatedly by many workers experimenting with different materials.

According to Stockard (1920), the rate of development of an embryo is not uniform throughout the entire process, but periods of rapid progress alternate with those of slow rate or almost quiescence. Such a conception of discontinuity of development led Stockard to the view that there were certain critical points in the development of the embryo at which more damage was caused by an environmental disturbance than at any other time. He also concluded from his experimental observations that the primary action of all teratogenic agents was to inhibit the rate of development. The type of deformity which resulted depended upon the developmental moment at which the interruption occurred. Stockard had located several developmental moments at which rather definite defects of particular organs might be induced. He believed that these were the moments during which the organs were most rapidly proliferating. (It will be seen later how these observations have been confirmed in the case of congenital anomalies induced in chickens by insulin.)

Riddle (1922) was one of the earliest workers to study the suppression of ovulation in adult ring doves by subcutaneous injections of insulin, soon after the successful extraction of the hormone by Banting and Best in 1922. He observed that insulin " blocked ovulation by preventing the ova from beginning their final period of growth and by causing them to be reabsorbed after having entered this stage of growth." In the course of his experiments he showed that the adult birds were highly resistant to the hypoglycaemic effects of insulin, and could survive a dose of the hormone nearly thirty times that which would easily kill a rabbit. Hanan (1925) observed from his own experiments that this resistance to insulin was established early in the embryo. Cassidy, Dworkin and Finney (1926) injected subcutaneously various doses of insulin, ranging from four to 130 units per kilogram body weight, into domestic fowls to determine the effects of severe hypoglycaemia induced by insulin. They noticed that although the extent of the fall of blood sugar after insulin administration in fowls was greater than in mammals, convulsions did not occur and, even after massive doses of insulin ( 130 units per kilogram), the blood sugar of adult fowls returned to normal autogenously. Vladimirov (1931) studied the effects of injection of water, certain sugar solutions, adrenaline, and insulin into hens' eggs and also the result of filling the air-space in the eggs with carbon dioxide. None of the above-mentioned research workers made any mention of the teratogenic effects of insulin in their published papers.

In 1945, W. Landauer, Professor of Genetics in the University of Connecticut, published a paper entitled " Rumplessness of Chicken Embryos produced by the injection of Insulin and other Chemicals," in which he said: "Incidental to other investigations it was observed that the injection of solutions of certain chemicals into unincubated chicken eggs led to the

vol. 34 B, No. 4, NOVember 1952 
appearance of increased numbers of rumpless embryos and chicks." (It is noteworthy that Landauer's observation of the " morphogenetic effects" of insulin was accidental as was my own.) As a geneticist, Landauer was obviously interested in comparing the " morphological appearance of the distal end of the spine in insulin-induced rumplessness " with the sporadically occurring mutations. He was, therefore, content with the naked-eye examination of the chick embryos "which had died between fourteen and eighteen days and between eighteen and twenty-two days of incubation " as well as hatched chicks. Landauer and his associates were not, apparently, concerned with the radiological and histological investigations of the various skeletal abnormalities in embryos of all ages and hatched chickens, all of which would, obviously, be of the greatest interest to orthopaedic surgeons interested in the etiology and pathology of congenital malformations. In 1947 Landauer, in a further paper, described the deformities of the beak, eyes and extremities (" micromelia ") induced by insulin.

Ancel and Lallemand (1942) who injected over ninety different substances into hens' eggs with a view to inducing malformations succeeded in producing " micromeiia " and beak abnormalities in the embryos with only two-namely, eserine sulphate and sulphonamide. In the course of a study of the effects of various agents such as 2-6-diaminopurine (Karnofsky, Patterson and Ridgway 1949), anti-vitamin B6 (Karnofsky, Stock, Ridgway and Patterson 1950), thallium (Karnofsky, Ridgway and Patterson 1950) and cortisone acetate, Karnofsky and his colleagues observed "achondroplasia" in chick embryos treated with thallium and "striking inhibition of growth" with cortisone acetate. Ackermann and Taylor (1948) investigated the results of injection of 3-acetyl-pyridine (structural analogue of nicotinamide, acting, however, as its " antagonist ") into hens' eggs. They found that " some of the symptoms associated with the toxicity were undersized deformed legs and a general oedematous-like condition." These effects were reversed by injection of nicotinamide after the administration of 3-acetyl-pyridine. Unfortunately, radiological and histological investigations were not made. (As it was obvious, from the radiological and histological investigations I had made on the very first series of insulin-induced skeletal abnormalities in chick embryos in 1943, that " micromelia" could be due to a generalised developmental disturbance of bone resembling osteogenesis imperfecta in the human, and not necessarily to "achondroplasia" or " chondrodystrophy," as has been suggested by these research workers, I have repeated the experiments with sulphonamides, thallium salts, cortisone and 3-acetyl-pyridine, in order to compare the histological and radiographic appearances of the deformities induced by these substances with those of insulin-induced abnormalities.)

\section{EXPERIMENTAL TERATOGENESIS IN MAMMALS}

This is a much more complicated problem because, in the first place, the ovum develops within the uterus; secondly, the placenta is interposed between the foetal and maternal environments; and lastly, experimental treatments cannot be applied to mammals without disturbing the uterus and foetal membranes which, more often than not, leads to abortion. Despite these handicaps, congenital defects have been induced in mammalian embryos by the application of $x$-rays to the mother during pregnancy as described already (Bagg 1920). Indirect evidence that a perverted metabolism in pregnant women can have serious consequences for the offspring was made available by the valuable contributions of some investigators to the problem of endemic go tre and pellagra (Lavinder and Babcock 1910, Harris 1919). The diversity of factors which, on occasion, can evoke defects in the offspring of man and other mammals have been carefully examined in two excellent reviews by Warkany $(1945,1947)$.

Gillman and his associates (1948) have induced in rats congenital abnormalities such as hydrocephalus, spina bifida, eye and ear defects, and malformations of the tail by subcutaneous injections of trypan blue to the mothers during gestation. The total number of 100 female rats they used in their experiments was composed of two series. Every rat in both series 
received an injection of one millilitre of 1 per cent aqueous solution of trypan blue during gestation but the rats in the second series had received, in addition, a variable number of injections before conception. In the series of rats receiving injection treatment during gestation (on the eighth or ninth day after conception) only 3 per cent of the offspring showed congenital malformations. In the second series of rats, which received injections before conception and during gestation, the incidence of abnormal offspring was much higher, ranging between 65 and 80 per cent.

Corda (1932) observed that pregnant rabbits injected with insulin aborted or produced young ones that were undersized. Lichtenstein, Guest and Warkany (1951) found that protamine zinc insulin, when administered in suitable doses to pregnant albino rats throughout the period of gestation, had significant effects on foetal development. The average weight of the foetuses of the insulin-treated rats was lower than that of the controls and the number in each litter was less owing to foetal deaths and resorption. They also noticed certain skeletal abnormalities such as a " decreased number or complete absence of ossification centres in the sternum." In some of the foetuses of the insulin-treated rats the long bones, such as the femur and the humerus, seemed "short in relation to the body size" and showed irregularities in ossification at their ends. Some of these foetuses showed "wavy ribs." (It is indeed gratifying that some of my observations on insulin-treated skeletal abnormalities in chickens have been paralleled in mammals.)

\section{TERATOGENESIS BY MATERNAL NUTRITIONAL DEFICIENCIES}

In recent years a number of publications have appeared, indicating that congenital malformations in the offspring of animals may be due to a faulty maternal diet. Ivanovsky (1923), in a report on the physical modification of the population of Russia under famine, remarked: "The number of children either prematurely born or stillborn, monsters, and children with different anomalies considerably increased during the famine." According to Murphy (1947) the diets of mothers who gave birth to children with congenital deformities were " significantly lacking in adequate amounts of calcium, phosphorus, iron, and vitamins B, C and D." Iodine deficiency during pregnancy results in the birth of defective offspring or foetal deaths. Cretins are usually born of goitrous mothers in endemic mountainous areas. Manifestations of prenatal iodine deficiency have also been described in horses, cattle, pigs and lambs. The thyroid of the offspring is enlarged, hyperaemic and poor in iodide. According to Smith (1917), one million pigs were lost in the United States in 1917 because of prenatal iodine deficiency. Such pigs were born hairless, and their skin was myxoedematous. Smith showed that these defects could be prevented by the administration of potassium iodide or thyroid of sheep.

Hale (1935) reported that sows fed on rations deficient in vitamin A gave birth to piglets with blindness or without eye-balls. In addition, microphthalmos, misplaced kidneys, cleft palate, hare-lip and other abnormalities were noticed. Hale showed that genetic factors could be ruled out as the cause of these malformations. Moore, Huffman and Duncan (1935) observed that calves born to vitamin-A-deficient cows were blind. Andersen (1941) reported a high incidence of congenital diaphragmatic herniae in the offspring of rats fed on a vitaminA-deficient diet. Ross and his co-workers (1944) noticed in swine congenital malformations of nutritional origin such as syndactylism, " talipes," kinked tail and ocular defects.

Warkany and his associates (1948) have shown that a syndrome of multiple congenital anomalies can be induced in the progeny of rats reared and bred on a vitamin-A-deficient diet. They were as follows: ocular anomalies such as retrolenticular membrane replacing the vitreous, coloboma and folding of the retina, rudimentary development of the lungs and pleural cavities, cardiac septal defects, anomalies of the aortic arch, diaphragmatic hernia, tracheo-oesophageal fistula, and a variety of congenital defects in the genito-urinary system.

Warkany and co-workers $(1940,1942,1943)$ found that female rats reared and bred on a

VOL. 34 B, NO. 4, NOVEMBER 1952 
diet deficient in riboflavin gave birth to offspring a third of which had congenital skeletal abnormalities. The malformations consisted of shortening of the mandible, tibia, fibula, radius and ulna, cleft palate and fusion of the ribs. According to Silberberg and his colleagues (1948), deficiency of vitamin B-complex in growing rats causes retardation and finally cessation of growth of cartilage and bone, associated with " serous atrophy" of the bone marrow. They found that after refeeding with a stock diet containing an adequate amount of vitamin B-complex, skeletal growth was resumed at an intensified rate, resulting in early restoration of the normal condition. Byerly and his associates (1935) obtained short-legged embryos from eggs laid by chickens reared and bred on a deficient diet whose effects were reversed by wheatgerm, liver and whey. Romanoff and Bauernfeind (1942) demonstrated in chickens that riboflavin deficiency gave rise to "micromelia" and beak deformities in the progeny. Couch and his co-workers (1948) obtained similar abnormalities with biotin deficiency. Lyons and Inkso (1937) observed that a diet deficient in manganese also gave rise to "micromelia" and beak deformities in the offspring.

This new knowledge in the field of nutrition deserves special attention, since it demonstrates clearly the effect of vitamin deficiencies upon the earliest processes of growth and differentiation.

\section{EPIDEMIOLOGICAL IMPLICATIONS OF DEVELOPMENTAL ARRESTS} AND OTHER RELEVANT OBSERVATIONS

Rubella-Epidemiological events in the past decade have demonstrated that the broad principles that govern the disturbances of growth and differentiation in lower animals can be applied, with suitable modifications, to human developmental arrests and malformations. From time to time the possibility that maternal intercurrent infections may cause congenital defects in the foetus has been discussed and the role of syphilis has long been recognised. However, it was not until Gregg (1941) drew attention to the association of developmental anomalies in the offspring such as cataract and cardiac septal defects with maternal rubella in the early months of pregnancy, that it became an established fact. A masterly review by Swan (1949) has surveyed the evidence against rubella upon more than 558 recorded cases in which there appeared to be a definite relationship between maternal intercurrent infection and the development of congenital malformations. Swan concluded from his survey that a woman who had contracted rubella during the first four months of pregnancy had a three to one chance of giving birth to a congenitally deformed infant.

Although there can be little doubt from the formidable array of statistics so far accumulated that maternal rubella is in some way causally related to congenital abnormalities in infants, it is still not certain whether these statistics reflect the true situation. According to Fox et al. (1948) rubella "increases the risk of congenital anomalies from the usual figure of 0.9 per cent to about 15 per cent." These observers have also made a report on the possible role of measles, mumps and chicken-pox in the causation of congenital malformations. Parsons (1946) suggested that in mammals " the embryonic cells are more susceptible to virus infections than adult tissues; more severe changes, therefore, should be seen in the foetus and these should be especially marked at the period of greatest embryonic activity, viz., the early weeks of pregnancy." From his survey of the Australian and American literature, Wesselhoeft (1947) compiled a list of major malformations seen in infants born to mothers contracting rubella at some stage during pregnancy. The congenital anomalies included eye defects, deafness, heart lesions, microcephaly, dental defects, mental retardation and pyloric stenosis. To this list may be added hydrocephalus (Fox and Bortin 1946), congenital obliteration of the bile ducts, mongolism, imperforate anus, myelocele, " bilateral talipes," spina bifida occulta, spastic diplegia, cleft palate, unilateral Horner's syndrome and hemiparesis, umbilical hernia, strabismus, cryptorchidism, buphthalmos, hypospadias and genu valgum (Swan et al. 1943, 1946). Moreover, stillbirths, premature births and abortions were commoner (Goar and Potts 1946). 
Time relationship between the maternal rubella and the type of malformation-Aycock and Ingalls (1946) tried to correlate the month of infection during pregnancy with the occurrence of a particular congenital malformation in the infant after taking into account all the recorded findings of various authors, and stated: "The average period of pregnancy when rubella occurred was as follows: for cataract, six weeks; for deafness, nine weeks; for cardiac anomalies, five to ten weeks; for deformed teeth, six to nine weeks." Swan and Tostevin (1946) have made the following observations of the time relationship: "The obvious conclusion, however, is that in man the primordia of the various organs have relatively long so-called ' critical moments.' Our experience suggests that in general the 'critical moment ' of the optic cup is the first three months of pregnancy, and that of the cochlear anlage is the second, third and fourth months. We believe, moreover, that averages such as we have drawn above may indicate the period of greatest susceptibility of the anlage of a particular organ, for example, lens or cochlea to the virus of rubella."

According to Tondury (1951), who reviewed Bourquin's statistics (1948) based on 146 cases of congenital cataract due to maternal rubella, the maximal incidence of this developmental anomaly was observed when the mother contracted the infection during the fourth and fifth weeks of pregnancy; after this period its incidence became less frequent up to the twelfth week, when it disappeared almost entirely. It may be recalled that at the end of the fourth week or the beginning of the fifth week (twenty-eighth to thirtieth day) the crystalline plate appears in the epidermis which covers the ocular cuticle. Between the thirtieth and thirty-fifth days, the crystalline vesicle becomes isolated and at the end of the sixth week (fortieth to forty-second day) the first crystalline fibres begin to differentiate. The " critical period" for the formation of a congenital cataract would therefore appear to coincide with the processes of differentiation of the embryonic crystalline lens.

Tondury (1951) had an opportunity to examine the malformed lenses of five aborted foetuses. The maternal intercurrent rubella infection was during the first trimester of pregnancy in all the five. He noticed in a 21-millimetre embryo (the youngest in his series) that " the disposition of the lens was normal, but the fibres during differentiation showed a vacuolar deformation." An embryo of 64 millimetres had a central degeneration of the lens and, in addition, it could be seen that this destructive process had reached the fibres of the lens which were formed secondarily. He observed the same type of degeneration of the lens fibres in a foetus of 32 centimetres, as well as in a stillborn infant. (It is significant that Tondury observed evidences of degeneration in the lens fibres which had apparently developed normally up to a certain stage in all the five foetuses. Analogous degenerative changes are induced by insulin in cartilage models which have developed normally up to a particular stage, depending on the time of injection of the hormone, as will be seen later.)

Mongolism-By epidemiological methods an association has been observed between mongolism in the offspring and a variety of maternal uterine or systemic diseases present or operating between the seventh and ninth weeks of foetal life (Ingalls 1947). This observation has been confirmed by Lowe's (1949) studies of the eyes of fifty-two mongoloid children. Lenticular opacities were among the earliest consistent ocular abnormalities. Because of their position within the nuclear part of the lens, Lowe came to the conclusion that their genesis lay in relation to an abnormal capsulo-pupillary vessel during early foetal life, " a critical stage of development corresponding to a foetal length of $\mathbf{3 5}$ millimetres or a foetal age of 8.5 weeks." According to Ingalls (1947), " diverse causative agents are involved in the pathogenesis of mongolism and foetal anoxia may be an important pathogenic mechanism."

Bleyer (1938) plotted the ages of 2,822 mothers who gave birth to mongoloid infants against the ages of more than two million mothers in the United States who gave birth to normal infants during 1934. He observed that a significantly high percentage of the mothers who gave birth to mongoloid offspring were about forty years old. Thus he was able to show 
a definite association between mongolism and relatively advanced age of the mother. Other factors which have been identified in the causation of mongolism are: gestational haemorrhage; mechanical disorders of the uterus; and intercurrent infection such as rubella, influenza, mumps and purulent otitis media (Ingalls and Gordon 1947).

Encephalo-ophthalmic dysplasia-Epidemiological methods applied to encephaloophthalmic dysplasia (retrolental fibroplasia) have confirmed Terry's (1943) observation that it is related to prematurity and multiple pregnancy. Thirteen out of twenty-six children whose birth weights were recorded weighed under three pounds at birth. It was found that eleven out of seventy-seven mothers were multiparae, eight had intercurrent infections, three had toxaemia of pregnancy, two had placenta praevia, and eighteen had suffered from gestational haemorrhage (Ingalls and Gordon 1947). The association between the malformations and the maternal condition was indicated by the frequency of toxaemia of pregnancy, multiple births, and placenta praevia, as compared with chance expectancy, and also by the grouping of haemorrhages and intercurrent infections during or shortly after the second trimester of pregnancy.

Congenital oesophageal atresia with tracheo-oesophageal fistula-Ingalls and Prindle (1949) reviewed the records of 107 infants with congenital atresia of the oesophagus and it is noteworthy that they found no case in this series in which the defect had appeared in successive generations or in other members of the family. One hundred and two of these infants had associated tracheo-oesophageal fistulae. They also observed other co-existing congenital anomalies in the cardiovascular, gastro-intestinal, respiratory and skeletal systems. On the basis of the morphology of the tracheo-oesophageal defect, and that of the associated arrests, they postulated that the syndrome is acquired during early foetal life at about the fifth or sixth week of intra-uterine development. In the course of a study of the possible maternal factors responsible for the congenital anomalies they observed that there were four twin-pregnancies, six mothers had antepartum haemorrhages (five in the first or second months of pregnancy) and six had suffered from acute infections or metabolic disturbances in the first trimester of pregnancy (Ingalls and Prindle 1949). On the basis of these and other relevant observations they put forward a hypothesis that "oesophageal atresia, tracheo-oesophageal fistula and certain other commonly associated defects represent departures from normal development about the fifth or sixth week of embryonic life, caused by agents acting through the mother and placenta."

Toxoplasmosis-Since toxoplasma infection in man was first recorded by Wolf, Cowen and Paige $(1939 a, 1939 b)$ it has become recognised in many countries, but the frequency of the infection is still unknown. The protozoon causes a low-grade inflammation in the foetal tissues, particularly in the nervous system. Its clinical manifestations in the early months after birth are numerous, the most frequent being meningo-encephalitis, microphthalmos, bilateral chorio-retinitis in the central area of the fundus, and hydrocephalus or microcephalus (Capon 1950). Intracranial calcification may be observed radiologically and the child is often retarded mentally and liable to have convulsions. Few opportunities have arisen in Britain for studying a series of cases for less than a dozen cases had been reported up till the middle of 1950 (Lancet, 1950, ii, 578). Most of the available information on the subject has come from Sabin and Feldman (1949) in the United States. Only future research can prove whether or not congenital toxoplasmosis is a common cause of developmental abnormalities. However, it has been demonstrated clearly that the infection can pass through the "placental barrier" in the same way as rubella and cause a low-grade inflammation in the foetal tissues. This, in itself, is a significant observation.

Congenital malaria-Another protozoal infection, malaria, may perhaps be a cause of congenital defects among children of non-immune mothers who move into endemic areas. Very few genuine cases have, however, been reported in recent literature, and even these have not been investigated thoroughly. This problem should be explored completely because it 
has been shown that the immunity to malaria varies a great deal even among the local inhabitants in tropical countries, not to speak of non-immune mothers moving into highly malarial areas.

Maternal iso-immunisation-Much attention has been given in recent years to the subject of maternal iso-immunisation by antigens present in the blood of the foetus (inherited from the father) though lacking in the mother's blood (Mollison, Mourant and Race 1948, Cappell 1948, Allott and Holman 1949). Maternal Rh iso-immunisation may interfere with normal foetal development and result in extensive abnormalities of the central nervous system. According to Yannet (1950) the most common clinical picture includes the following features: severe mental deficiency, asymmetric hypertonicity and weakness of the extremities, neck and back, and choreo-athetosis. Yannet states: "In practically all cases it should be possible to obtain a neonatal history compatible with erythroblastosis foetalis and an Rh set-up in mother and child consistent with this diagnosis."

Yannet and Lieberman (1948) have reported an ABO mother-child incompatibility and suggested the possibility that certain cases of congenital mental deficiency may be the result of maternal $\mathrm{AB}$ iso-immunisation. According to them, the "infrequency of a significant history of erythroblastosis foctalis in these cases, the normal incidence of the first-born, and complete absence of specific neurological disorder suggest that the pathogenesis in these cases may be different from that present in Rh iso-immunisation."

\section{FOETAL ABNORMALITIES ASSOCIATED WITH MATERNAL ENDOCRINE DISORDERS}

Diabetes mellitus-In recent years the role of maternal diabetes in teratogenesis has been studied. The foetal and neonatal mortality rate of infants of diabetic mothers is abnormally high. In the pre-insulin era, diabetic women often had amenorrhoea and were frequently sterile. White (1940) showed that with the introduction of insulin the fertility of diabetics improved and the maternal mortality dropped to levels comparable with non-diabetic women. However, the early and late foetal deaths fell only from $\mathbf{4 4}$ to 38 per cent.

In diabetes mellitus there is very definitely a higher incidence of congenital abnormalities than normally. Oakley and Peel (1949) reviewed 142 cases examined at King's College Hospital, London, and found that in addition to minor blemishes such as skin naevi, which were particularly common among these cases, there were more serious abnormalities-an incidence of 6.3 per cent as compared with a general incidence of 0.94 per cent in 4,829 deliveries in normal mothers. They noted the following congenital anomalies in their series: internal hydrocephalus, congenital heart defects, hemi-vertebrae, imperforate anus, congenital dislocation of the hip, cleft palate, renal tract deformities, absence of sacrum and coccyx, and talipes equino-varus.

Joslin and co-workers (1940) observed that four infants out of fifty-one in their series were malformed: the first had a club foot, claw hand, webbed toes and missing fingers; the second showed a congenital heart lesion; the third had congenital dislocation of both hip joints; and the left hand of the fourth infant had no fingers.

Miller (1946) found that in nineteen consecutive necropsies on infants born to diabetic mothers seven had one or more malformations which included: anecephaly; bicuspid pulmonary valve; cor biventriculare, hypoplasia of the aorta; double left ureter, hydro-ureter, hydronephrosis; persistent pupillary membrane; agenesis of the urinary bladder and kidneys, malformation of ureters; harelip, agenesis of the gall-bladder, bicornuate uterus, septate vagina, hypoplasia of the right humerus and femur, agenesis of the left femur and fibula, syndactylism, and agenesis of the thoracic vertebrae. Miller states that these congenital malformations were reviewed by G. W. Corner, Director of Carnegie Institute of Embryology. Corner concluded from his examination that in all instances the malformations were present before the end of the third month of intra-uterine life. The actual mechanism of causation of the various congenital anomalies, which include orthopaedic deformities, is not known at

Vol. 34 B, NO. 4, NOVEMEER 1952 
present. I believe that chorionic gonadotropin may play a part in their causation, and future research on these lines may be rewarding. It is known that chorionic gonadotropin begins to rise on the thirty-fifth day after the last menstrual period and reaches its peak between the fifteth and seventy-fifth day of pregnancy. This period corresponds significantly with the "critical periods" of the various organs and tissues showing the above-mentioned congenital anomalies. Corner's belief that all the malformations originated before the end of three months supports this hypothesis.

This hormonal conception of the problem of pregnancy with diabetes mellitus is the natural outcome of our knowledge that many abnormal pregnancies have an abnormal endocrine background. The first suggestion of a possible hormone imbalance in diabetic pregnancies was made in 1933 by Murphy who reported that the chorionic gonadotropin excretion of two diabetic women exceeded the normal. Excess of chorionic gonadotropin, or deficiency of oestrin and progestin after the fifth month of pregnancy, may be followed by toxaemia and premature deliveries resulting in high foetal mortality (Joslin et al. 1940). Substitutional oestrin and progestin therapy has controlled the rise of serum gonadodropin and as a result late foetal mortality has fallen from 32 per cent to 6 per cent or nearly to the level of non-diabetic pregnancies-3.4 per cent (Joslin et al. 1940). However, treatment given in the third trimester of pregnancy could hardly be expected to influence the incidence of congenital malformations since they are most probably determined in the first trimester. (On the basis of the hypothesis put forward above, I would like to suggest that the substitutional oestrin and progestin therapy should be started in diabetic women almost immediately after any missed period, instead of waiting till the fifth month of pregnancy.)

Recent studies have shown that striking changes often occur in many of the tissues of children born to diabetic mothers. In addition to increased body weight and hyperplasia of the islets of Langerhans, both of which have been recognised for many years, it has been shown that these infants sometimes have, at birth, cardiac hypertrophy, extramedullary erythropoiesis (Miller and Wilson 1943), adrenal hyperplasia (Miller et al. 1944), increase in the eosinophil cells of the anterior hypophysis (Bauer and Royster 1937), and hyperplasia of the genital organs in the female (Smyth and Olney 1938). In the course of their studies of infants born to diabetic mothers Miller and Wilson observed that many of these changes were present in infants born to mothers who did not show any evidence of diabetes during pregnancy, but developed it at varying periods after delivery (Miller 1945). The birth weight of such infants is also greater than the average normal and the total foetal mortality rate in such pregnancies is greater, as in the case of infants of mothers who actually suffer from diabetes during pregnancy. These findings lead us to conclude that, even in the pre-diabetic phase, there is an endocrine imbalance in these women which may interfere with the normal development of the foetus in utero.

\section{MATERIAL AND METHODS}

My experiments were conducted with eggs from brown leghorn and light Sussex flocks which were known to be free from genetic abnormalities. The riboflavin and manganese contents of the eggs were found to be adequate from routine testing at fairly frequent intervals.

I have used a simple apparatus (Fig. 1) not only for testing the fertility of an egg before injection, but also for transilluminating it while drilling a hole into the shell and injecting into the yolk. In this way, I have avoided injuring the embryo and its chorionic blood vessels, which very often causes the death of the embryo. A fine dental drill held in a small chuck has been used to make a hole in the egg-shell manually in order to avoid any possible trauma to the embryo by the mechanical vibrations of an electric drill. A tuberculin syringe fitted with the finest hypodermic needle 2 centimetres long has been found most suitable for making the injection into the yolk. 


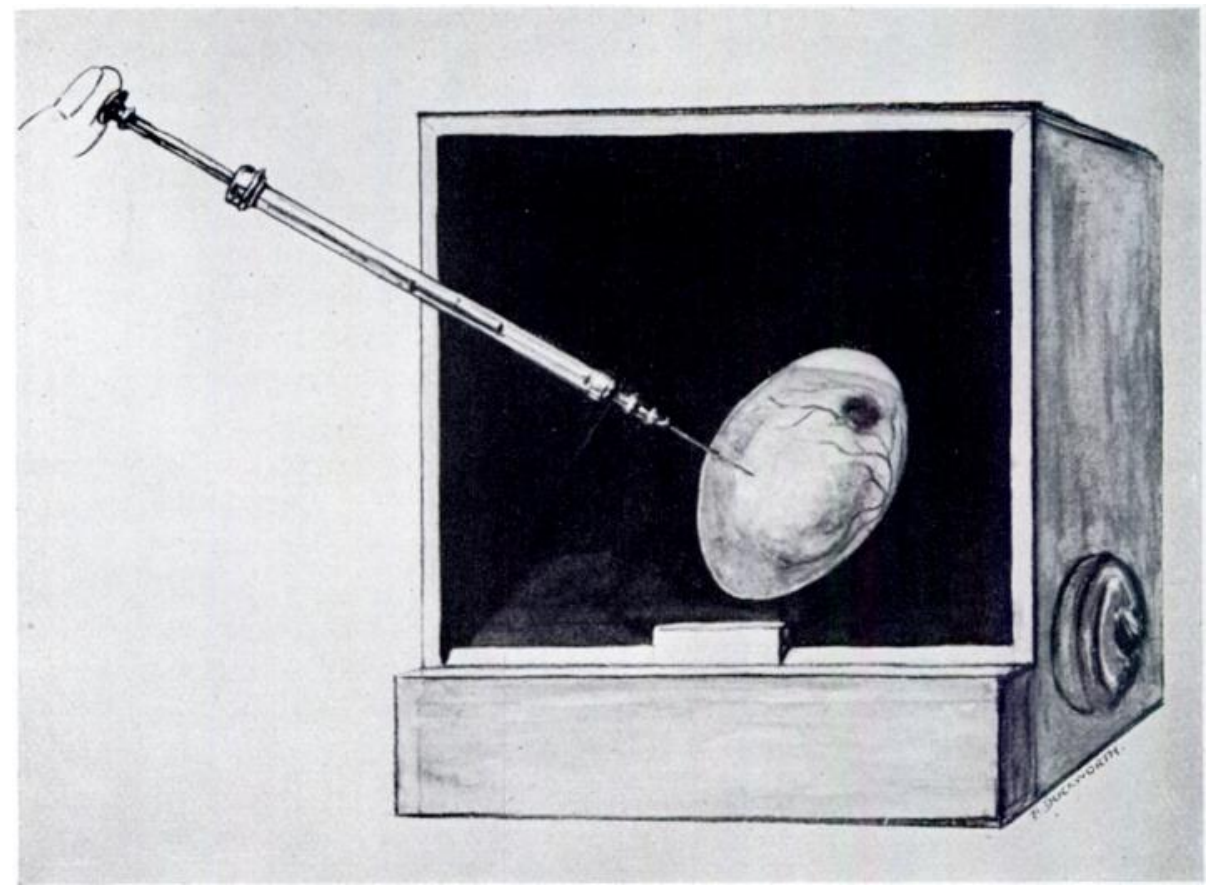

FIG. 1

Apparatus for transilluminating the egg during injection to avoid injury to the embryo and the chorionic blood ressels.

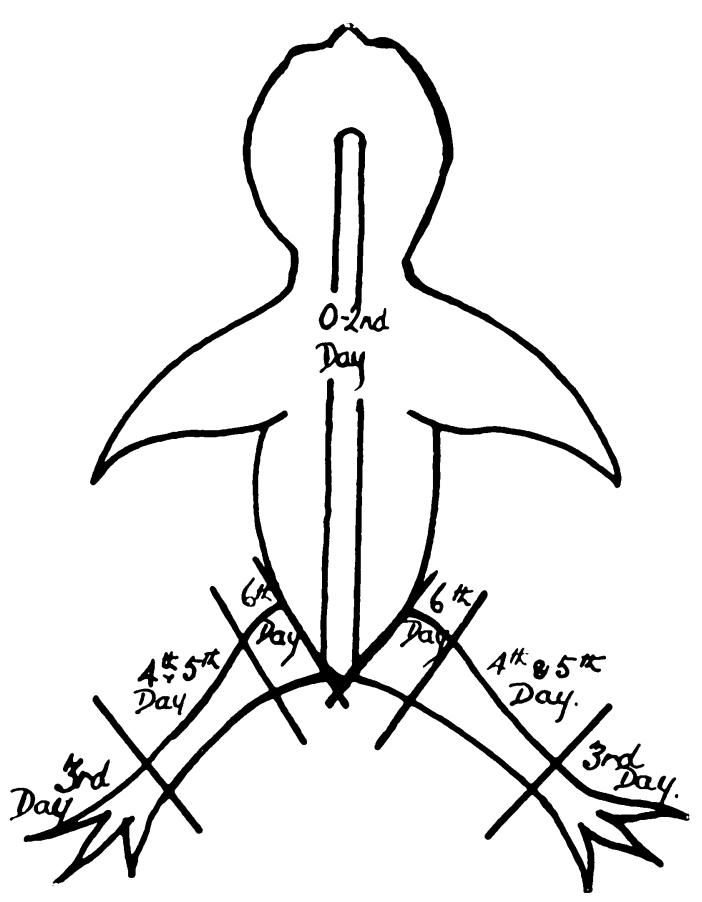

FIG. 2

Site of deformity induced by insulin related to time of injection into the egg after incubation.

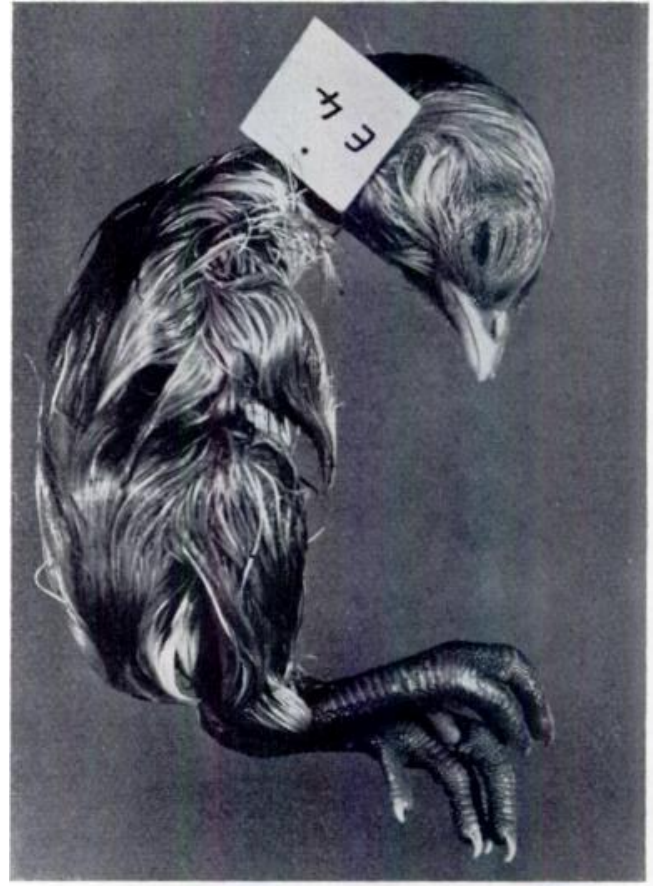

FIG. 3

Normal twenty-days-old embryo extracted from the shell before hatching.

vol. $34 \mathrm{~B}$, No. 4, NOVEMBER 1952 
I have employed solutions of crystalline insulin made up to a strength of $\mathbf{4 0}$ units in each millilitre. The doses ranged between 0.05 and 6 units, and the injections were made at different intervals after the beginning of incubation. Calculated on the basis of the human dose, these doses may be considered distinctly excessive. However, as has already been mentioned, Riddle (1923) and others have shown that birds are highly resistant to insulin and can survive a dose thirty times as strong as that which would kill a rabbit. Whenever the volume of the solution injected has exceeded $0 \cdot 05$ millilitres, an additional hole has been drilled into the egg-shell in the region of the air sac in order to prevent undue increase of pressure inside the egg. I should perhaps make it clear, at this stage, that only one injection of insulin is made into the egg and no more is given either during the remaining period of incubation or after hatching.

After injection, the needle is carefully removed and the hole in the egg-shell is sealed and the egg returned to the incubator. With the same technique, control injections, such as physiological saline, and substances which are known to play a part in ossification, such as calciferol, parathormone and radioactive phosphorus, have been injected into eggs incubated in the same incubator. Care has been taken to eliminate, as far as possible, known teratogenic factors such as fluctuations of temperature and humidity during incubation. Physical conditions of incubation may be accepted as satisfactory since hatches averaged 85 per cent of fertile " uninjected " eggs. In all experiments equal numbers of control eggs were placed in the same incubator in which eggs treated with insulin were incubated. Embryos have been removed at varying intervals after injection for histological and other investigations. Chicks that survived fourteen days after the beginning of incubation and those that hatched out alive either by themselves or with help, as in the case of deformed ones, have been radiographed. All the chicks, insulin-treated as well as controls, have been fed on a nutritious diet containing adequate amounts of vitamins and essential minerals such as calcium, phosphorus and manganese, and reared under equal conditions in every way. It should be noted that nearly all the chicks treated with insulin are more "delicate" than the controls so that they have to be reared with special care.

It has been observed that a certain percentage of the insulin-treated fowls, both male and female, are sterile, but the remaining fertile males and females showing insulin-induced abnormalities such as "osteogenesis imperfecta" and "club foot" were mated and the eggs resulting from these matings have been incubated without any treatment whatsoever. Some of these eggs have been opened and embryos removed at various stages for histological, radiological and other investigations. The hatched chicks were reared on the same nutritious diet as the rest for further breeding, if possible, through successive generations. (Though some of the insulin-induced abnormalities seem to have been passed on to their offspring by the insulin-deformed parents (Figs. 41 to 49), I do not propose to discuss this aspect of the problem in the essay, as it is essential to ascertain whether the abnormalities are transmitted to the descendants of the third and subsequent generations, as is being done now, before any conclusions are drawn from these experiments.)

\section{ESTIMATION OF BLOOD SUGAR IN INSULIN-TREATED AND CONTROL CHICK EMBRYOS}

Blood sugar estimations were made by the Hagedorn-Jansen method (modified) at different intervals after the injection of insulin to study the degree and course of hypoglycaemia. Similar estimations were conducted on appropriate controls for comparison. A volume of 0.02 millilitres of blood was collected with the help of a haemoglobinometer pipette from the vitelline or the allantoic veins, depending on the stage of growth of the embryos. In the case of the early ones, six or seven days old, pooling of blood from two embryos which had been treated with the same dose of insulin had to be resorted to.

\section{HISTOCHEMICAL METHODS}

l have employed Lison's histochemical technique (Lison 1935) for staining the mucopolysaccharide complexes (chondroitin-sulphuric acid complexes) in cartilage with a basic 
metachromatic aniline dye such as toluidine blue. Lison has presented evidence to show that the metachromatic staining reaction is specific for the mucopolysaccharide complexes, the affinity of which for the dye is so great that even in very high dilutions $(1$ in 250,000$)$ the cartilage containing the mucopolysaccharides is stained deep purple red (metachromatic) while the other tissues stain blue (orthochromatic). By using this technique I have observed that the cartilaginous skeleton in the insulin-treated embryos exhibits less affinity for the dye than the controls and also shows degenerative changes and deformities (Figs. 31 to 33 ).

In addition to toluidine blue stain I have emploved another histochemical reaction for polysaccharides. This is the periodic acid-leucofuchsin technique, first introduced by McManus (1946) and later improved by Hotchkiss (1948). It is regarded by most workers in the field as a highly specific test for polysaccharides such as chondroitin-sulphuric acid complexes and glycogen. It is easy to distinguish between the two polysaccharides because the glycogen granules are within the cartilage cells whereas the mucopolysaccharide is stained in the intercellular matrix. Further, only the glycogen particles disappear after treatment with saliva or diastase. According to Rubin and Howard (1950), by making use of both these histochemical methods, one can demonstrate the localisation of both the polysaccharides with considerable assurance.

\section{TISSUE CULTURE EXPERIMENTS}

The main aim of this aspect of my research was to investigate the possible mechanism involved in the induction of developmental abnormalities by insulin, by growing limb buds and cartilaginous models (of bones developed from cartilage such as the femur and the tibia) in vitro and in vivo, in the presence of varying concentrations of insulin. It is, however, not proposed to include details of these investigations in this essay.

\section{OBSERVATIONS}

Broadly speaking, insulin seems to affect primarily the part of the body or tissue that is in the most active stage of growth or differentiation at the time of injection. Table I and Figure 2 indicate the type of deformity that has been induced by insulin in relation to the time of injection after the starting of incubation of the egg. Figure 3 shows a normal twenty-days-old chick embryo; examples of the abnormalities that have been induced (mostly by insulin, a few by other agents) are shown in Figures 4 to 50.

TABLE I

Insulin-induced Skeletal Abnormalities

\begin{tabular}{|c|c|}
\hline $\begin{array}{c}\text { Day of injection after } \\
\text { starting of incubation }\end{array}$ & $\begin{array}{c}\text { Part of the body primarily } \\
\text { affected by insulin }\end{array}$ \\
\hline First and second days & Vertebral column \\
Third day & Feet \\
Fourth and fifth days & Himbs; beak \\
Sixth day & $\begin{array}{c}\text { Generalised developmental } \\
\text { disturbances of bone as } \\
\text { seen in osteogenesis } \\
\text { Third to sixth days } \\
\text { (high doses of insulin } \\
\text { imperfecta, achondroplasia, } \\
\text { chondro-osteo-dystrophy, etc. }\end{array}$ \\
\hline
\end{tabular}

Relationship between the dose of insulin and the incidence and severity of the deformity-Within the range of 0.05 to 6 units of insulin that I have injected, the incidence and severity of the deformities seem to increase with the dose of the hormone (Tables II and III). These should be compared with Table IV, which shows the incidence of abnormal foetuses in untreated groups.

vol. 34 B, No. 4, NOVEMBER 1952 
TABLE II

Relationship Between the Dose of Insulin and the Incidence of all Types of Deformities of the Vertebral Column

(The injection of insulin into the yolk was made twenty-four hours after the beginning of incubation)

\begin{tabular}{|c|c|}
\hline Dose of insulin & $\begin{array}{c}\text { Percentage of all types } \\
\text { of deformities of the } \\
\text { vertebral column }\end{array}$ \\
\hline 1 unit & $18 \cdot 1$ \\
$1 \cdot 5$ units & $20 \cdot 6$ \\
$5 \cdot 5$ units & $25 \cdot 2$ \\
6 units & $31 \cdot 0$ \\
Conits & $36 \cdot 3$ \\
same volume of saline & $1 \cdot 3$ \\
\hline
\end{tabular}

TABLE III

Relationship Between the Dose of Insulin and the Incidence of all Types of Deformities of the Limbs

(The injection of insulin was made 120 hours after the beginning of incubation)

\begin{tabular}{|c|c|}
\hline Dose of insulin & $\begin{array}{c}\text { Percentage of all types of } \\
\text { deformities of the limbs }\end{array}$ \\
\hline 1 unit & $26 \cdot 3$ \\
$1 \cdot 5$ units & $32 \cdot 2$ \\
$5 \cdot 5$ units & $46 \cdot 0$ \\
6 units & $\mathbf{8 5 \cdot 0}$ \\
& $\mathbf{8 9 \cdot 6}$ \\
\hline Controls injected with the & $2 \cdot 2$ \\
same volume of saline & \\
\hline
\end{tabular}

TABLE IV

Table Drawn up by Hut and Greenwood (1929) of the Spontaneously Occurring Monsters and Congenital Defects in a Survey of 12,000 Chick Incubations

(For comparison with insulin-induced deformities as given in Tables II and III)

\begin{tabular}{|c|c|c|}
\hline & $\begin{array}{l}\text { Percentage of } \\
\text { total chicks }\end{array}$ & $\begin{array}{l}\text { Percentage of } \\
\text { total anomalies }\end{array}$ \\
\hline Hyperencephaly (absence of eye-cups, cranial roof, etc.) & 1.52 & 41 \\
\hline $\begin{array}{c}\text { Exencephaly (failure of skull formation-brain } \\
\text { extrudes through meninges) }\end{array}$ & $0 \cdot 84$ & 23 \\
\hline $\begin{array}{l}\text { Microphthalmia and anoph thalmia (eye-cups } \\
\text { abnormally small or entirely absent). }\end{array}$ & $0 \cdot 81$ & 22 \\
\hline Exencephaly and microphthalmia . & $0 \cdot 25$ & 7 \\
\hline $\begin{array}{l}\text { Miscellaneous (including ectopic viscera, malformed } \\
\text { limbs, otocephaly, complete absence of the head } \\
\text { and various duplicities) }\end{array}$ & $0 \cdot 25$ & 7 \\
\hline
\end{tabular}




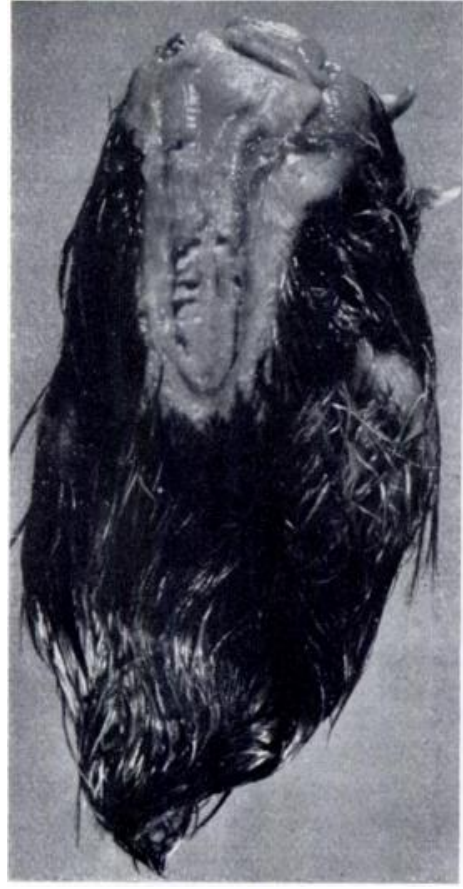

FIG. 4

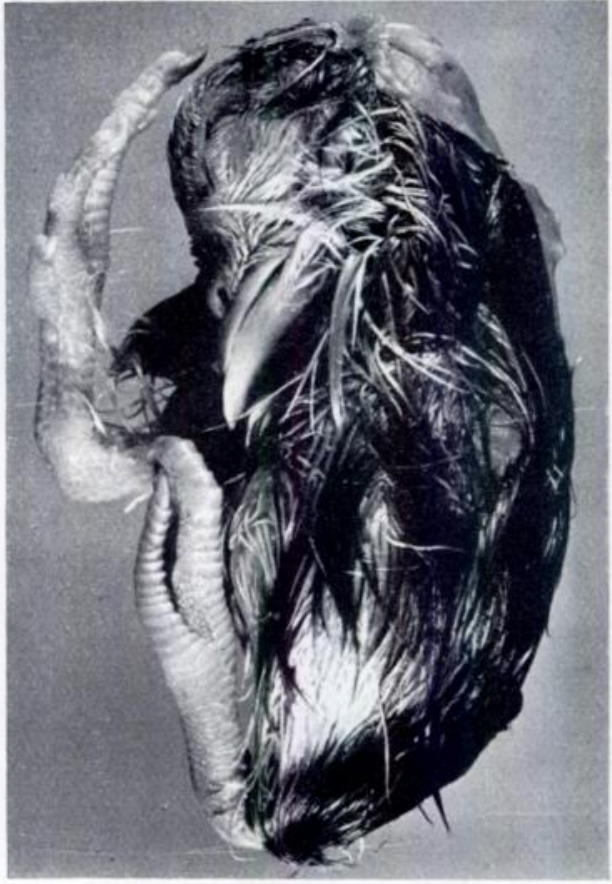

FIG. 5

Spina bifida in an embryo treated with insulin twenty-four hours after incubation and removed from the shell alive on the twentieth day of incubation. Figure 4-Posterior view. Figure 5-Lateral view. Note the anophthalmos and short upper beak.

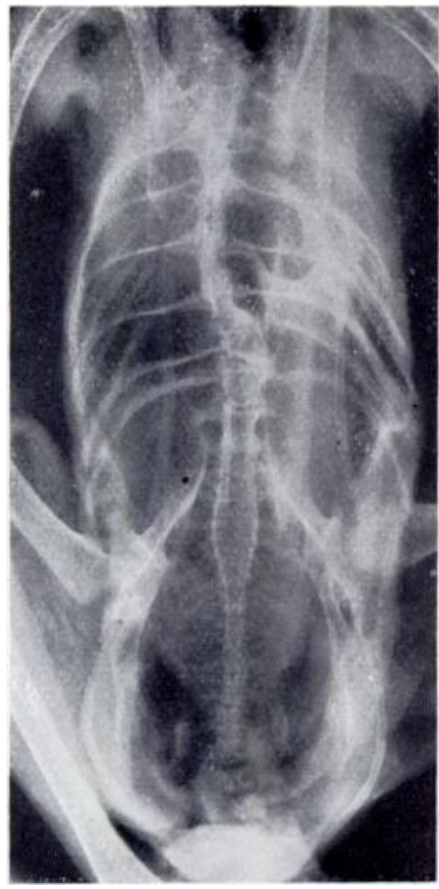

FIG. 6

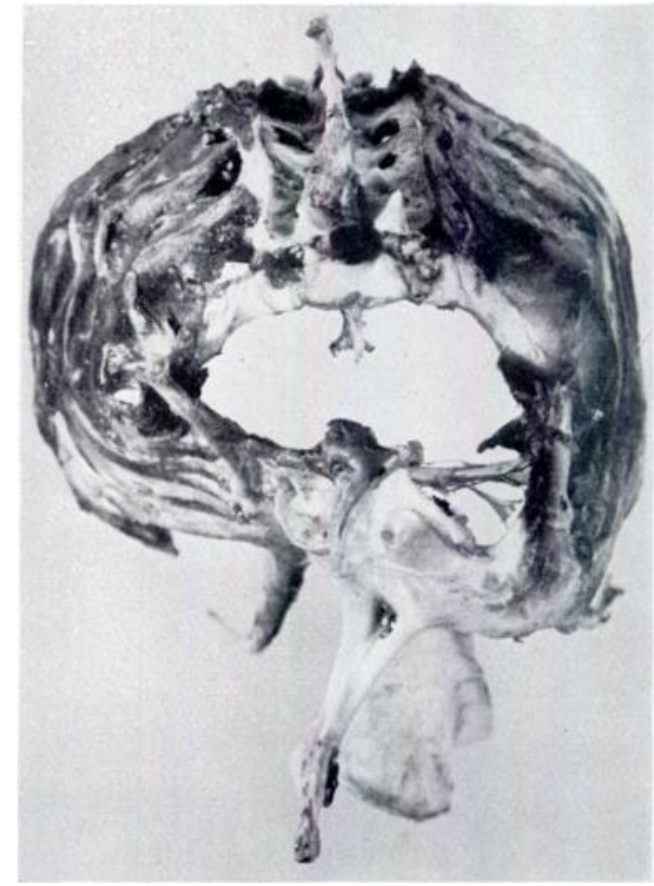

FIG. 7

Figure 6-Scoliosis in an insulin-treated chick four months old. When hatched the chick appeared to be normal. Figure 7-Photograph, taken from above, of the thoracic cage removed from a chicken eight months old with scoliosis, to show the secondary deformities produced by rotation of the vertebrae.

vol. $34 \mathrm{~B}$, No. 4, November 1952 


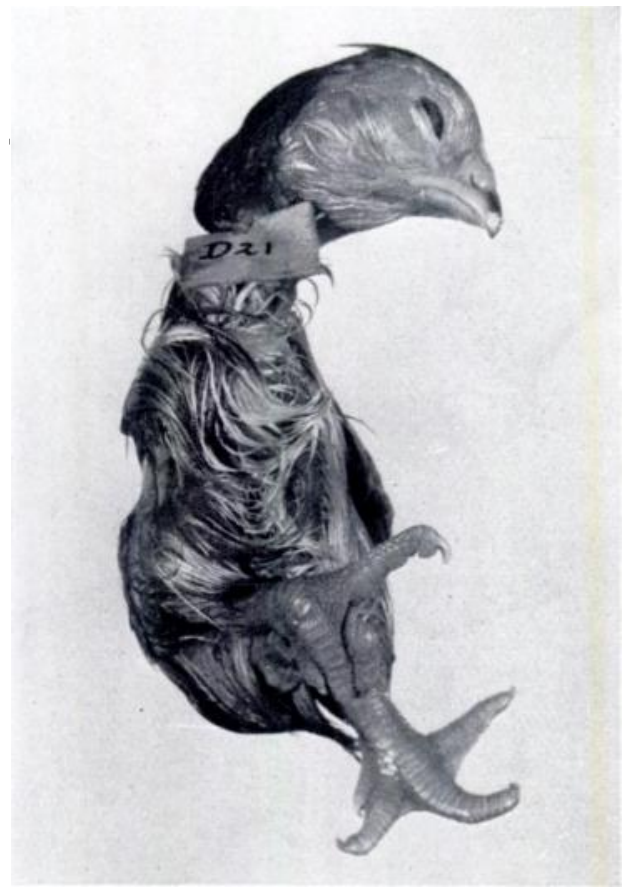

FIG. 8

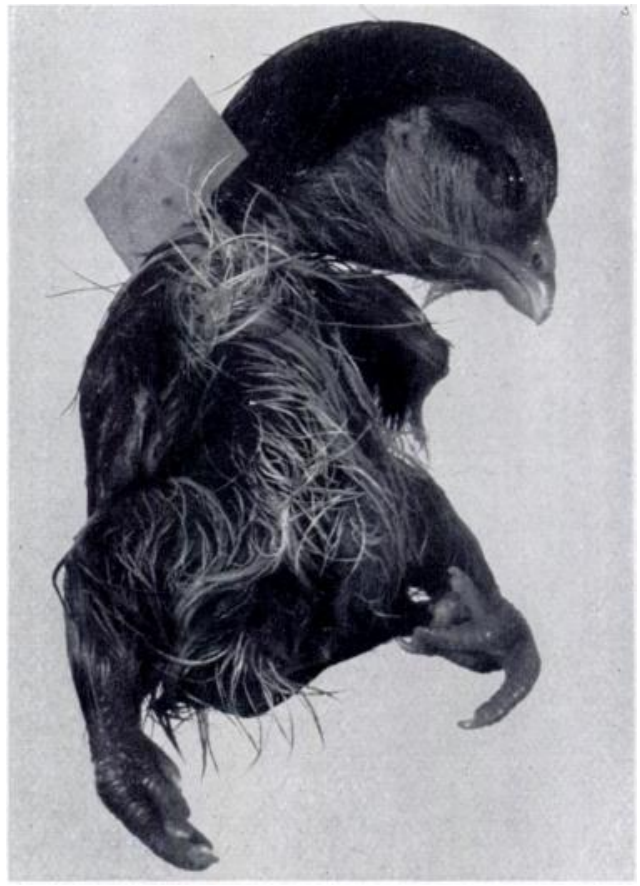

FIG. 9

Figure 8- "Lobster" claw in a twenty-days-old chick embryo injecied with two units cf insulin on the third day of incubation. Note the "parrot" beak. Figure 9-Club feet associated with arthrogryposis in a twenty-days-old embryo treated with 0.05 millilitres of a 10 per cent solution of a sulphonamide compound (Soluseptasine) on the fourth day of incubation.

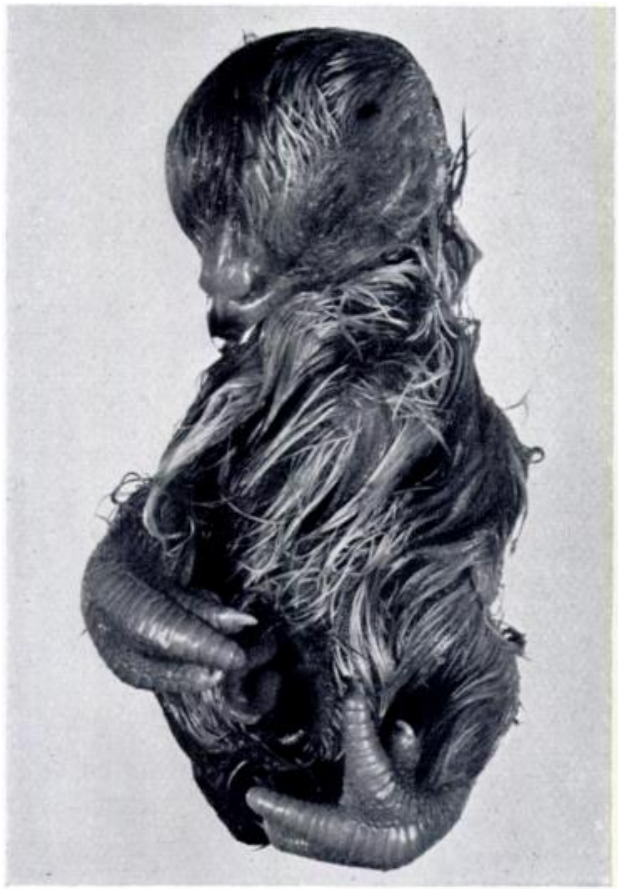

FIG. 10

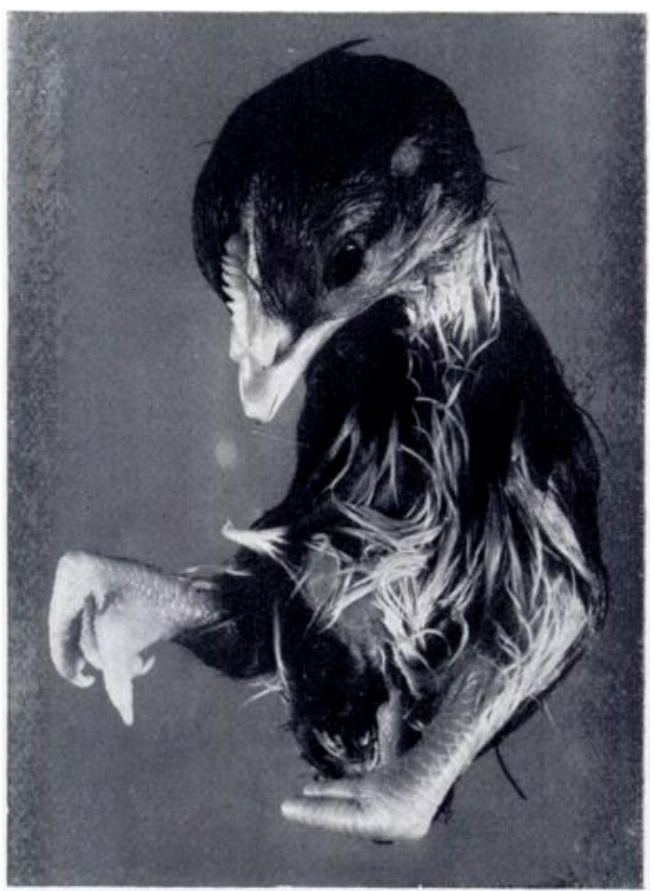

FIG. 11

Figure 10-Club feet in a twenty-days-old embryo. Three units of insulin had been injected on the third day of incubation. Figure $11-$ Club feet associated with arthrogryposis in a twenty-days-old embryo. Compare with Figure 10. (Three units of insulin on fifth day.) 


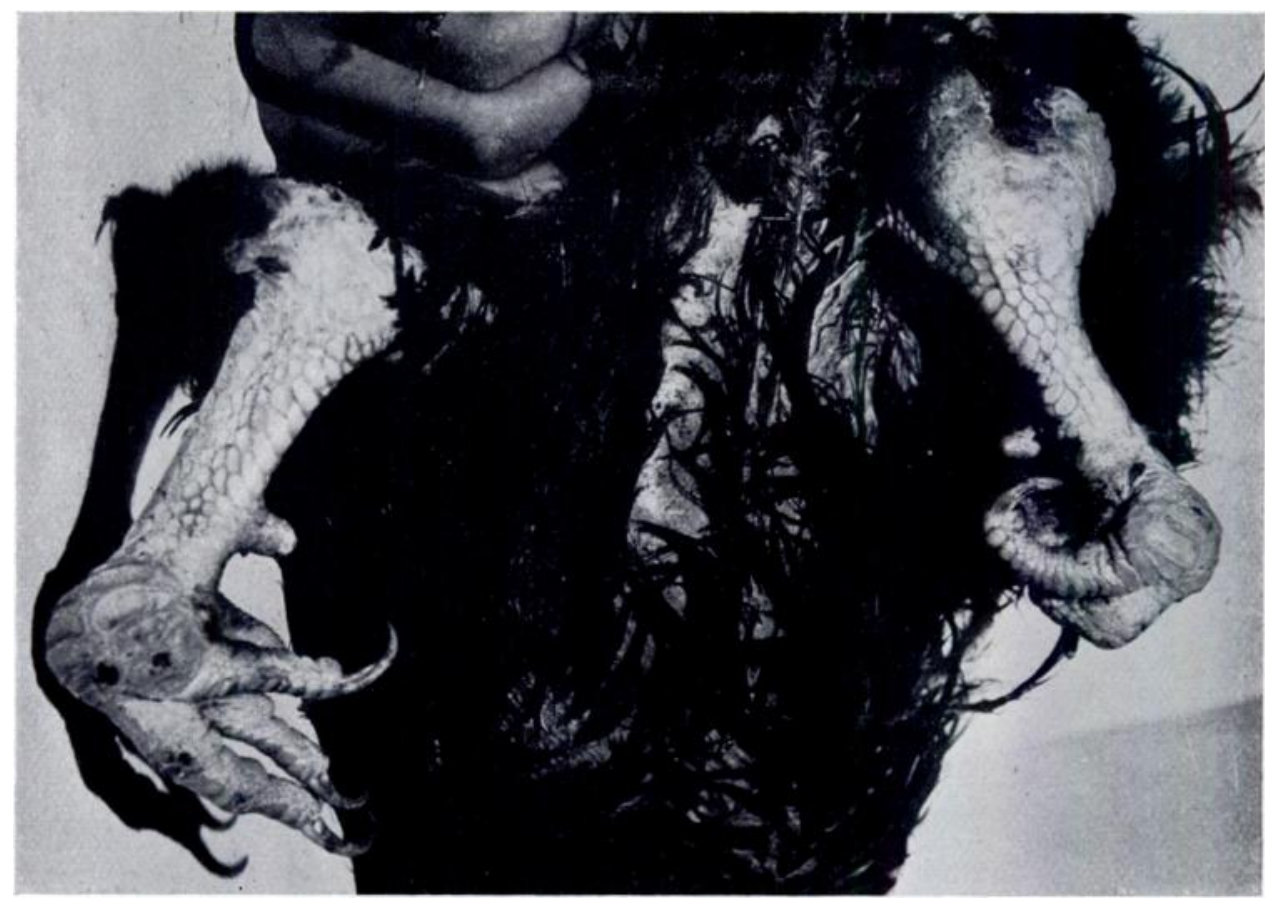

FIG. 12

Club feet in a chicken eight months old. Note the adventitial bursae in the feet.

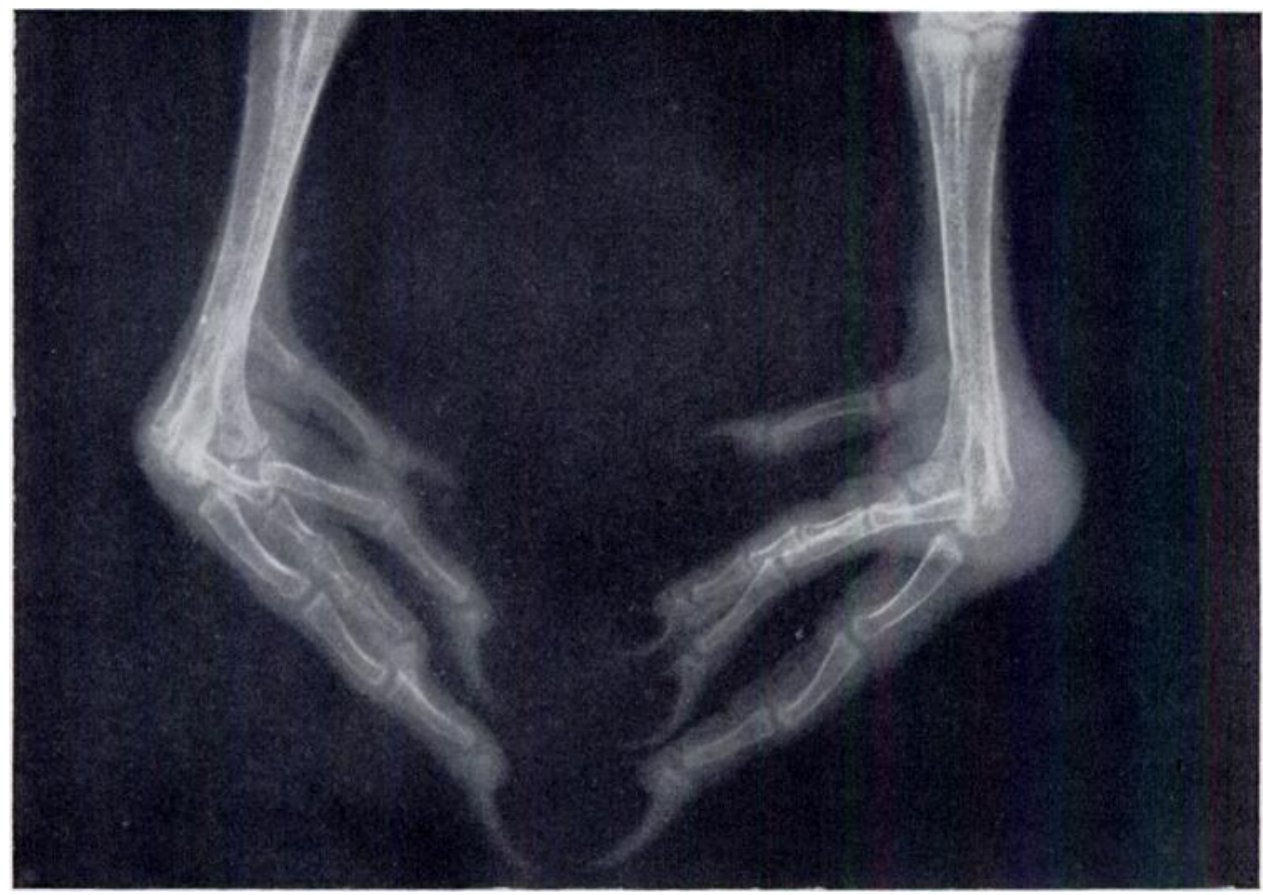

FIG. 13

Radiograph of the club feet of the same chicken seen in Figure 12. Note the soft-tissue shadow cast by the adventitial bursa of the left foot.

Vol. $34 \mathrm{~B}$, No. 4 , NOVEMBER 1952 


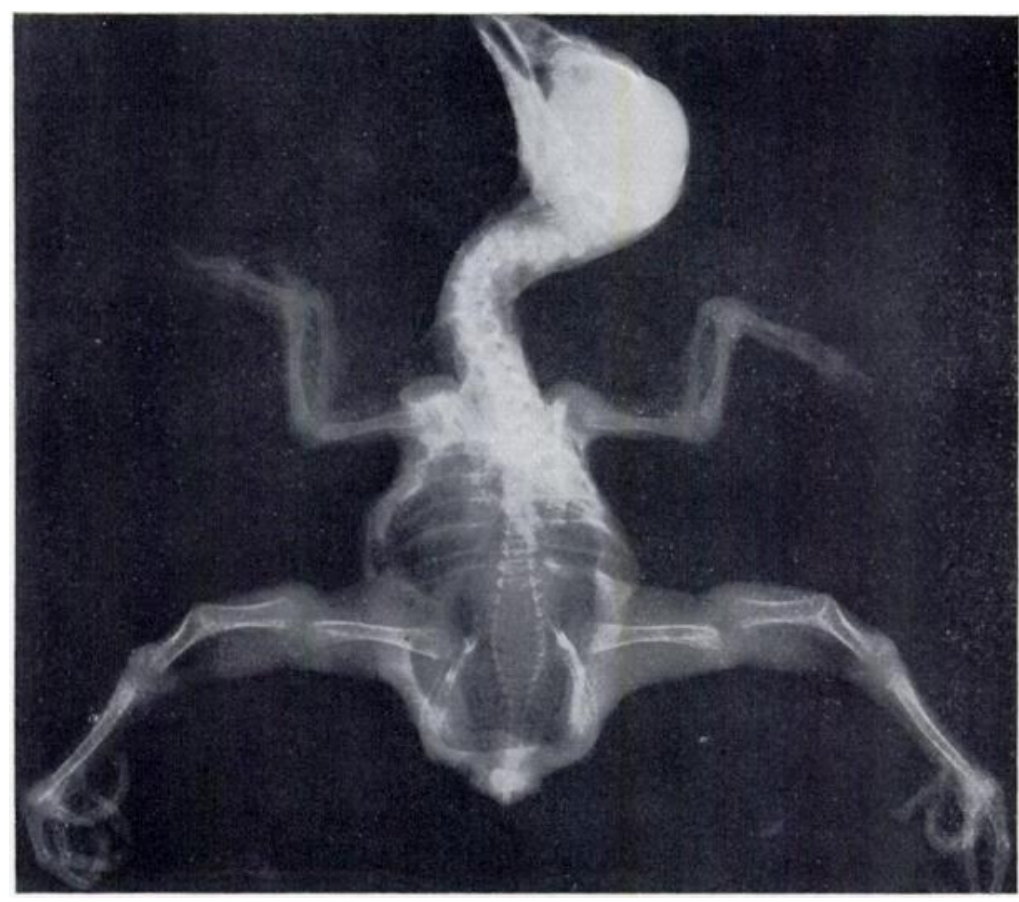

FIG. 14

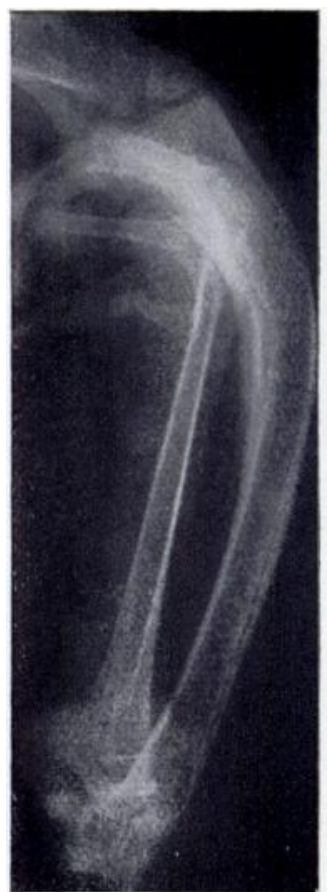

FIG. 15

Figure 14-Radiograph of a three-weeks-old insulin-treated chick with bilateral dislocation of the knees. Note the bilateral angulations of the tibiae ("tibial kyphosis") at the junctions of the middle and lower thirds - the level at which pseudarthrosis usually occurs. Figure 15 Congenital bowing of the tibia in a six-months-old insulin-treated chicken. Bowing affects upper third, whereas in "tibial kyphosis" the angulation is at the junction of the middle and lower thirds, as in the corresponding human deformities.

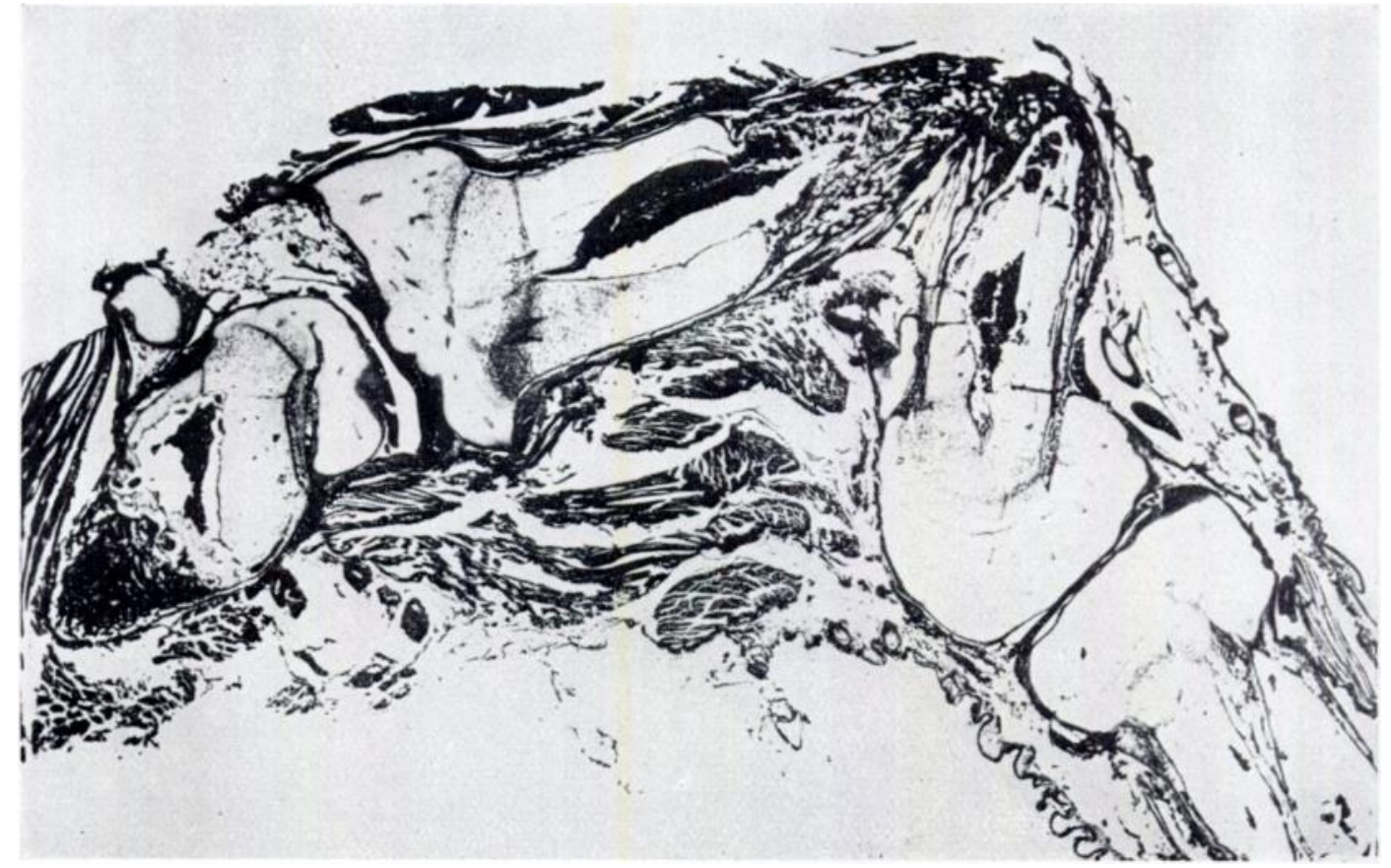

Fis. 16

Sagittal section of a tibia from a twenty-days-old embryo showing pseudarthrosis. Note that the whole tibia is abnormal, with poor subperiosteal bone formation. 


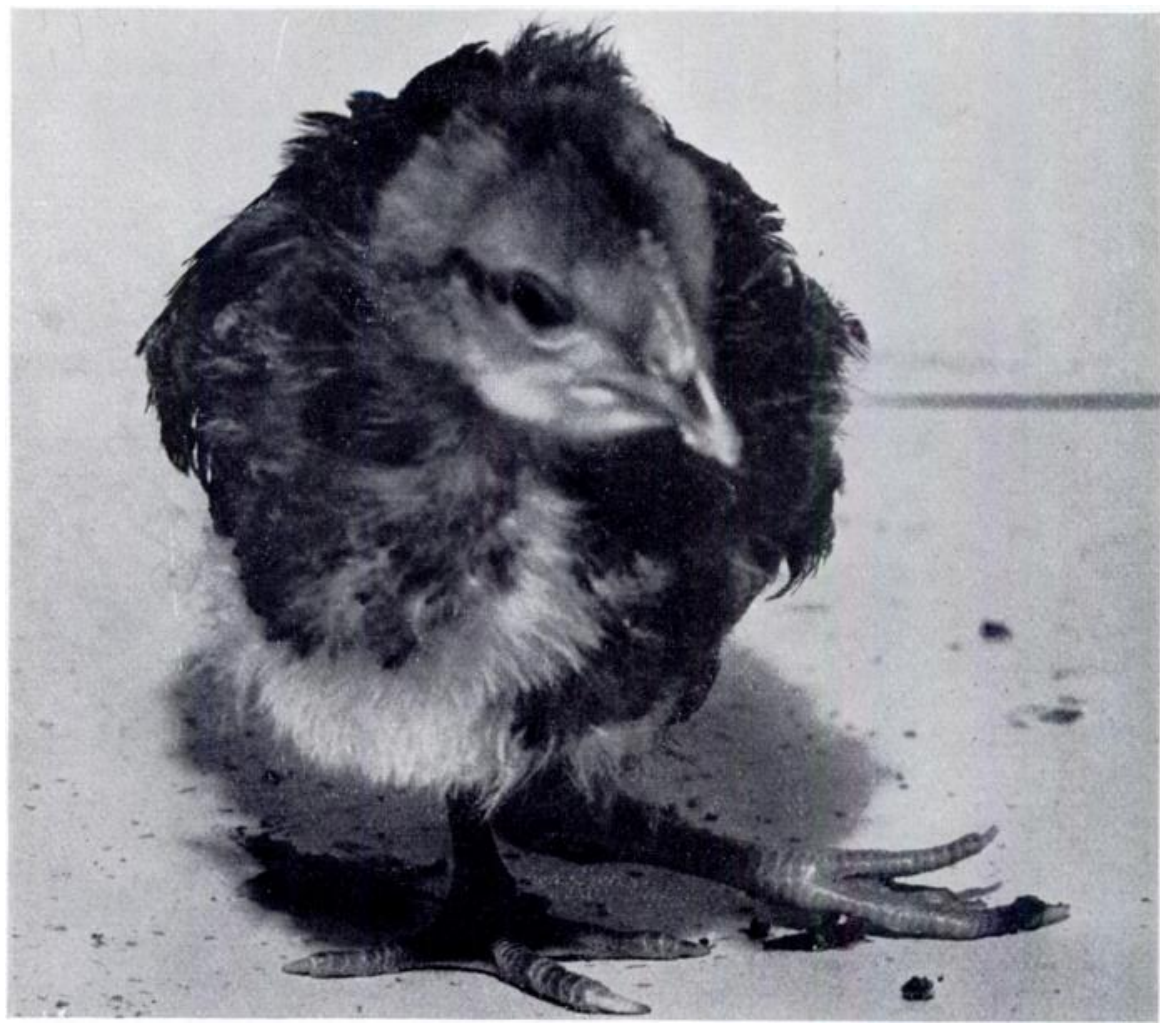

FIG. 17

Congenital dislocation of the left hip in a four-weeks-old chick (egg treated with insulin on the sixth day of incubation). Note the lateral rotation of the left limb due to the dislocation being anterior.

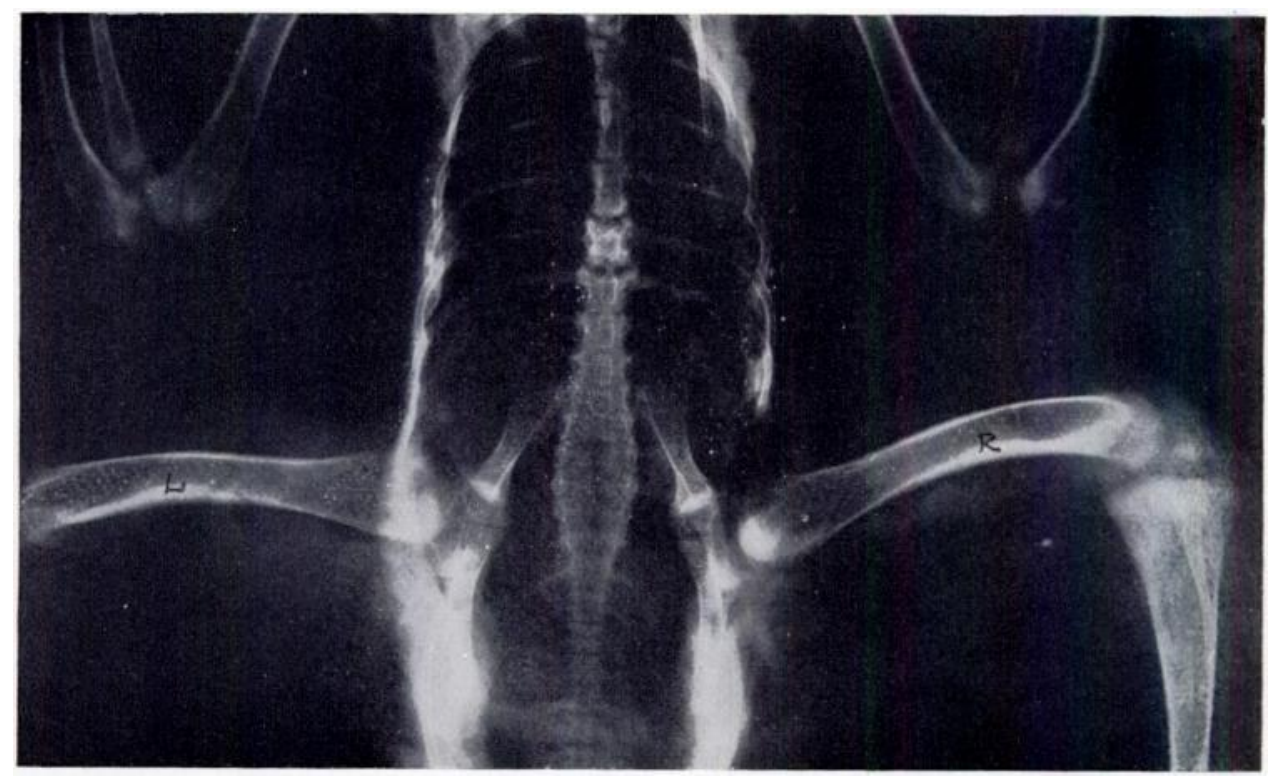

FIG. 18

Radiograph of the chick shown in Figure 17 (posterior-anterior view).

vol. $34 \mathrm{~B}$, No. 4, NOVEMBER 1952 


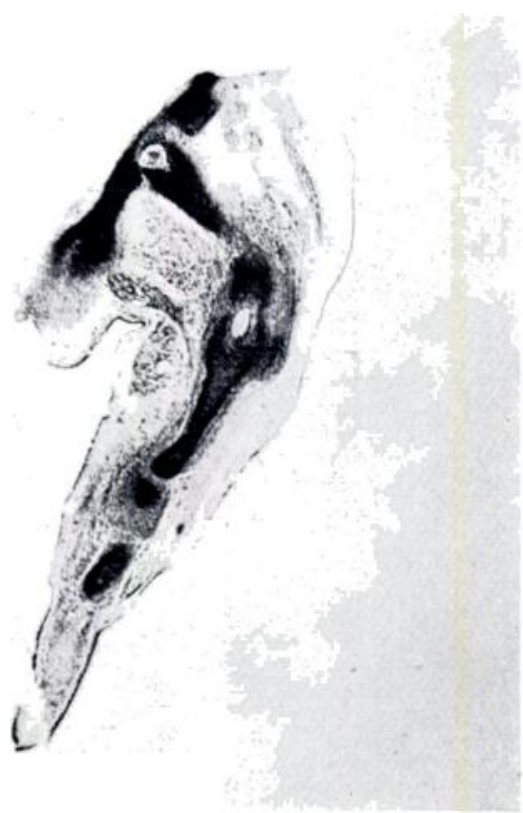

FIG. 19

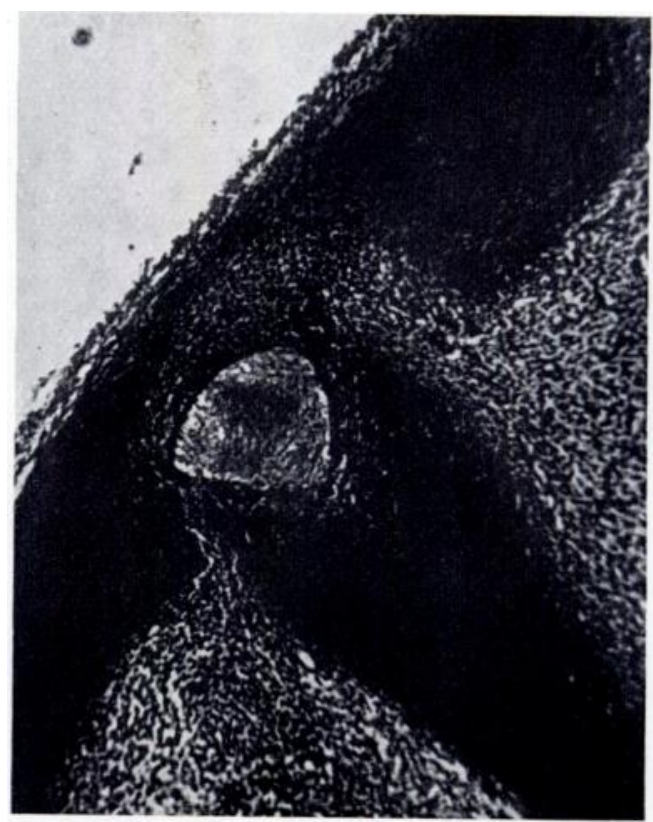

Fig. 20

Figure 19-Sagittal section $(\times 18)$ of the left hind limb of a seven-days-old insulin-treated embryo showing areas of degeneration in the upper ends of the femur and tibia. These may result in the alteration of the hereditary forms of epiphyses which may be followed by dislocations, as suggested by Harris (1933). Similar changes have been noticed in the acetabulum. Figure 20 -Photomicrograph $(\times 100)$ to show the degenerative changes in the upper end of the femur.

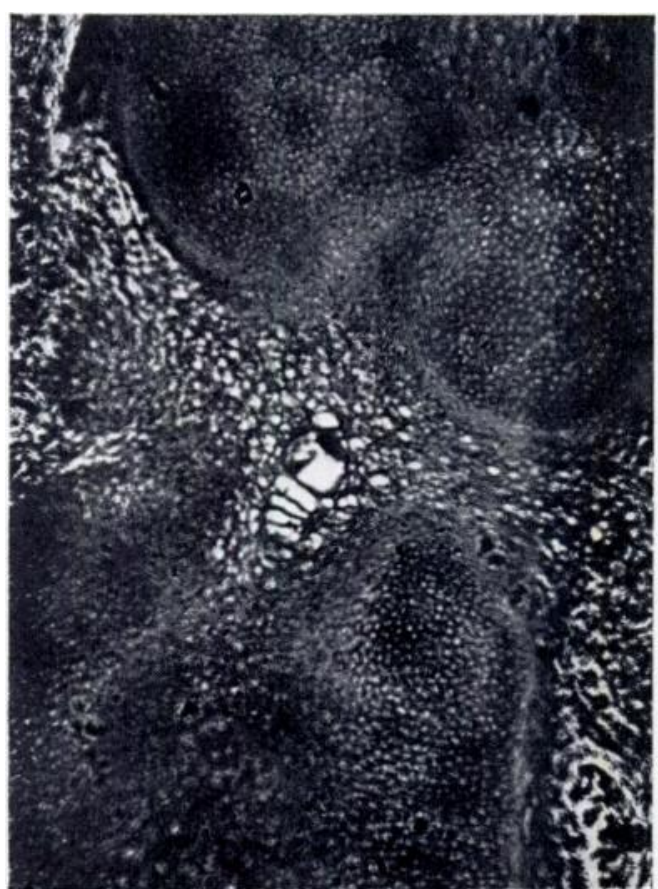

FIG. 21

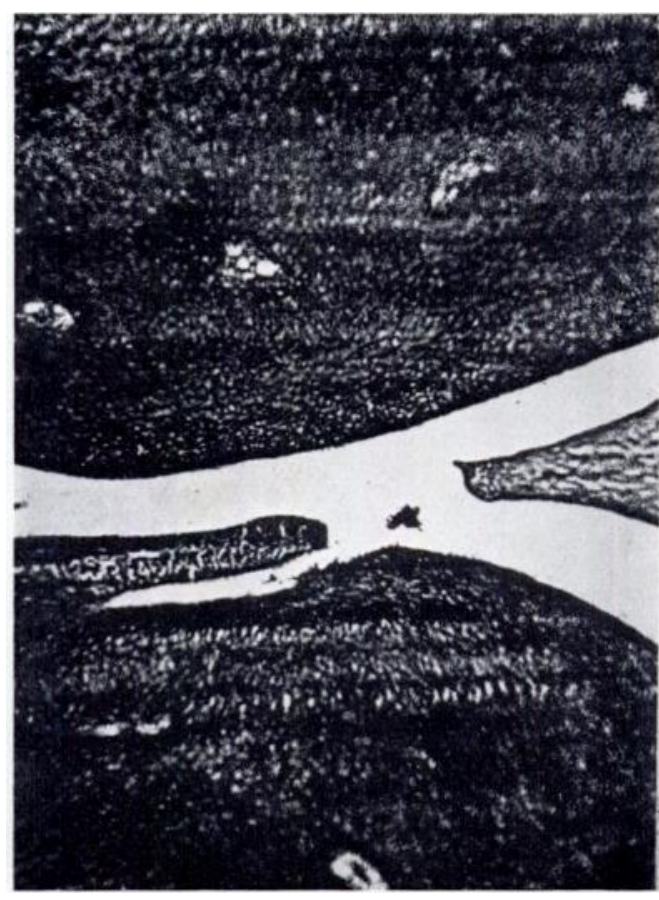

FIG. 22

Figure 21-Photomicrograph $(\times 100)$ of a sagittal section through the knee joint of an insulin-treated twelve-days-old embryo showing degenerative changes in the articular ends of the femur and tibia. The joint space, which should be clear and well defined at this stage, is filled with degenerated cartilage cells. Figure 22-Photomicrograph $(\times 100)$ of a sagittal section through a normal knee joint of a twelve-days-old embryo. 


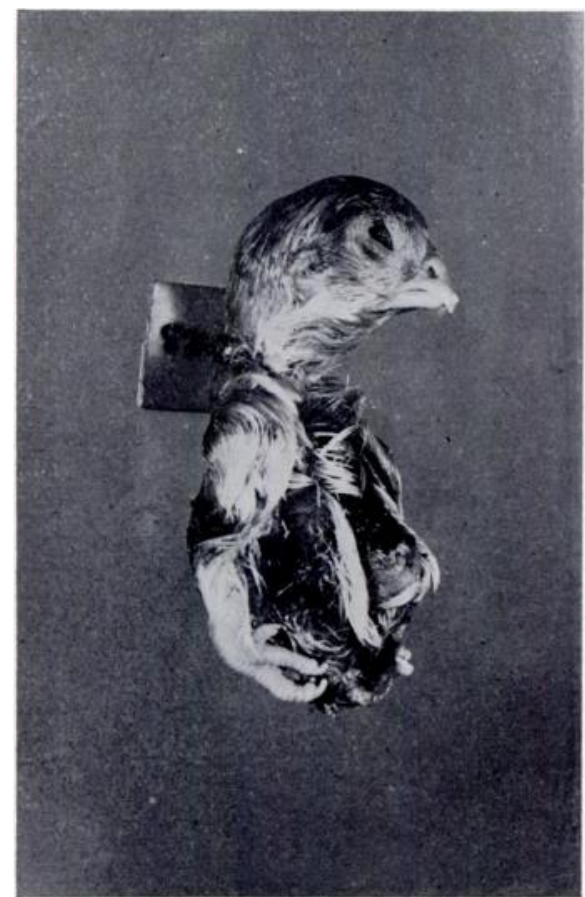

FIG. 23

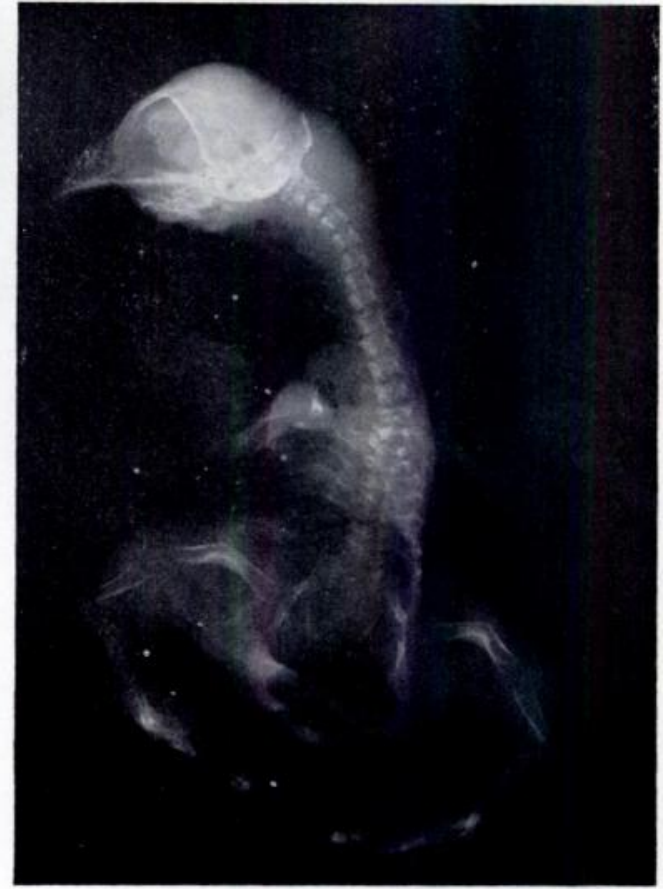

FIG. 24

Figure 23-Twenty-days-old embryo showing insulin-induced " micromelia " due to a generalised developmental disturbance of bone resembling osteogenesis imperfecta. Compare with Figure 3 . which is on the same scale. Note the "parrot " beak. Figure 24-Radiograph of a twenty-dav's-old chick embryo treated with 5 units of insulin on the fifth day of incubation, showing generalised developmental disturbance of bone resembling the pre-natal type of osteogenesis imperfecta, with defective ossification, typical deformities and pathological fractures.

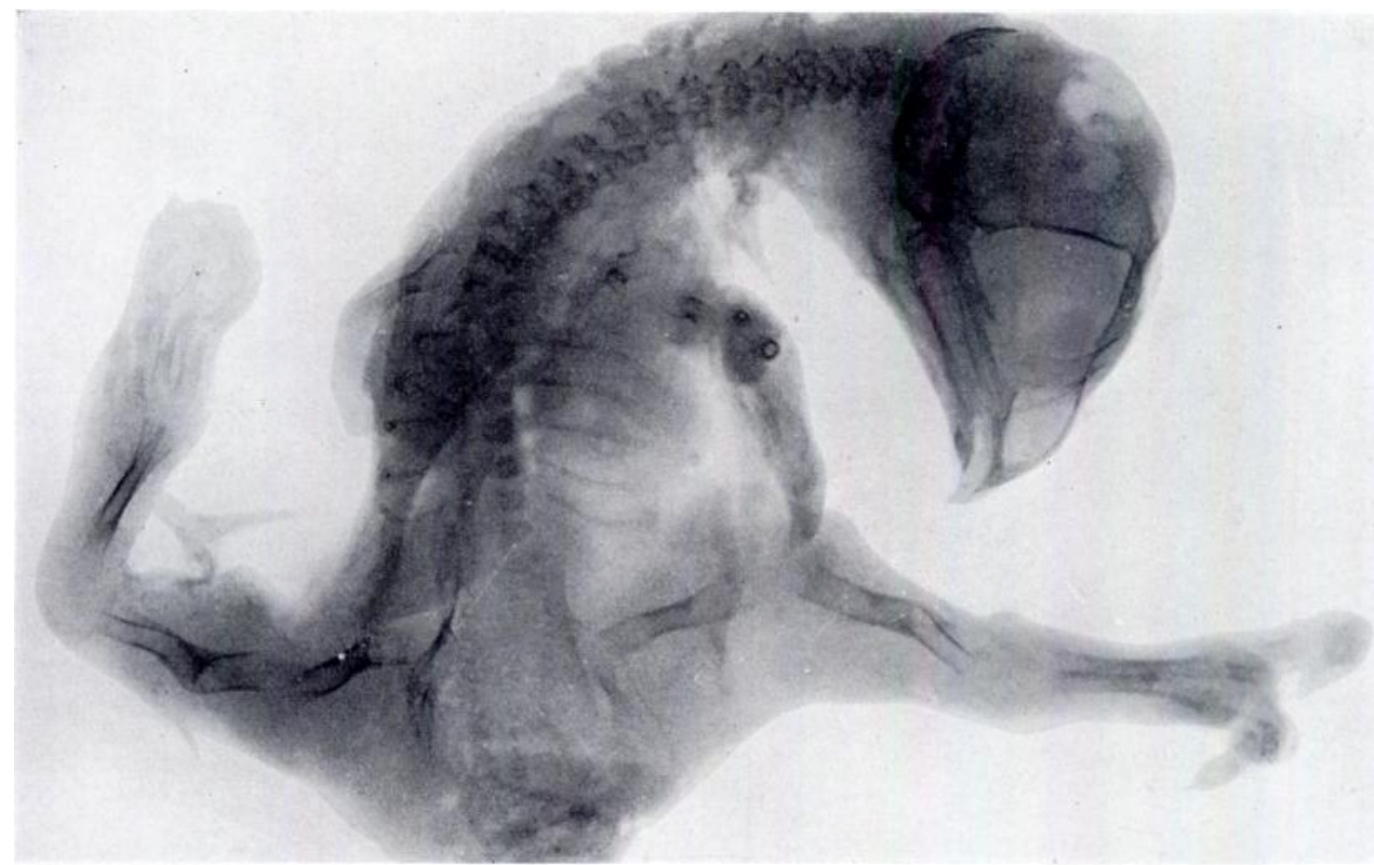

FIG. 25

Radiograph of a twenty-days-old chick embryo with insulin-induced osteogenesis imperfecta (pre-natal type). The appearance of the skull is due to an artefact.

vol. $34 \mathrm{~B}$, No. 4, NOVEMBer 1952 


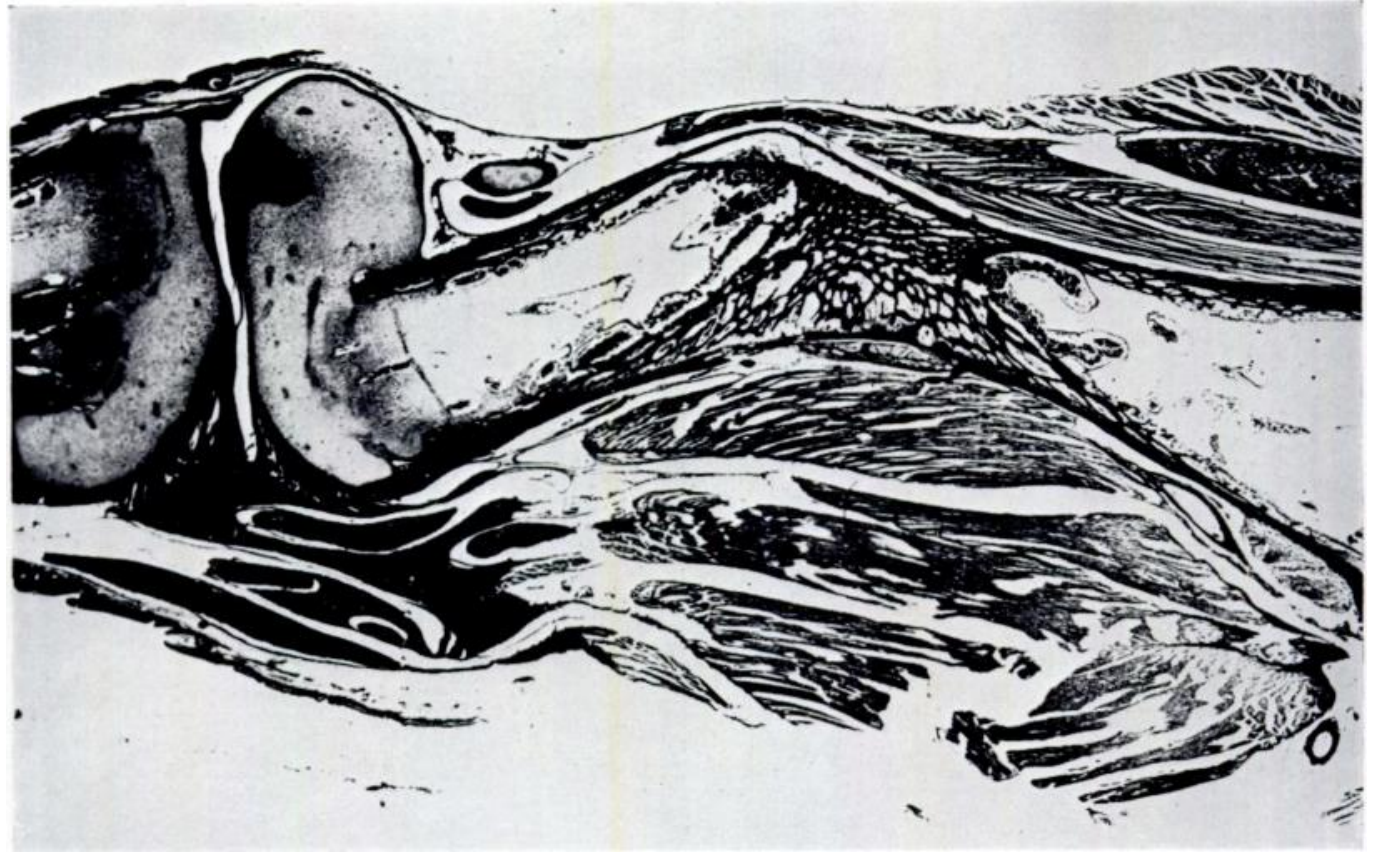

Fig. 26

Sagittal section $(\times 8)$ of the tibia of a twenty-days-old chick embryo treated with 5 units of insulin on the fifth day, showing osteogenesis imperfecta (pre-natal type) with pathological fracture and deformity of the tibia.

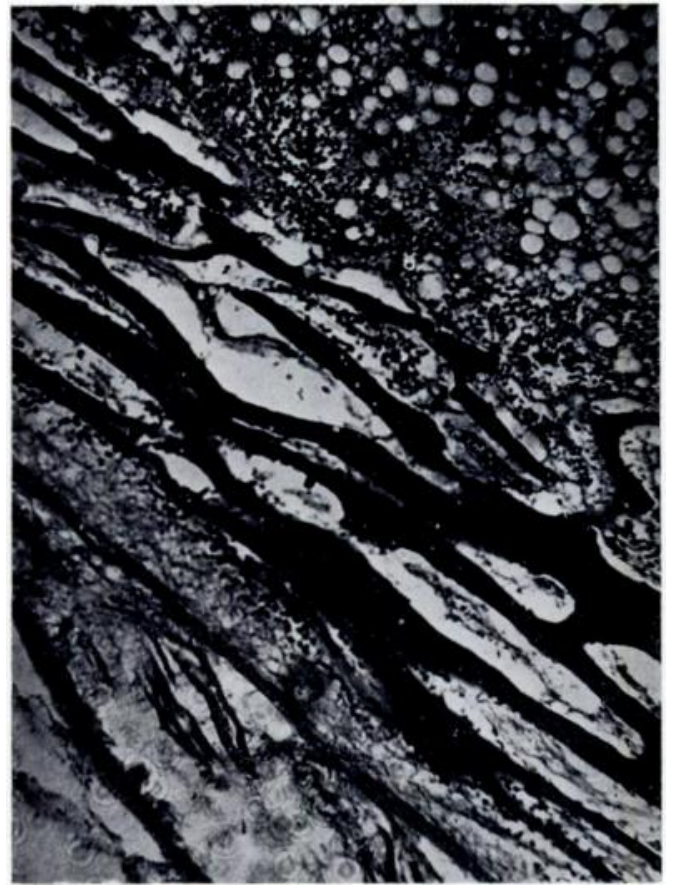

FIG. 27

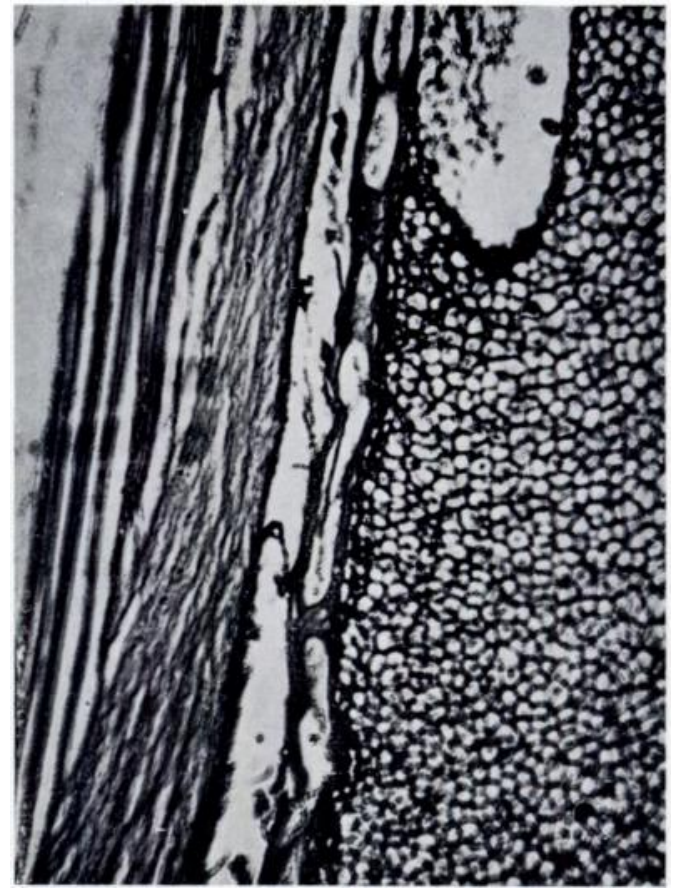

FIG. 28

Figure 27-Photomicrograph $(\times 100)$ of a longitudinal section of the tibia in a twenty-days-old normal chick embryo to show the amount of subperiosteal bone formed and the appearance of the marrow cavity. Figure 28-Photomicrograph $(\times 100)$ of a comparable section taken from the tibia of insulin-treated embryo of the same age. Note the lack of subperiosteal ossification and the thickening of the periosteum, as seen in human osteogenesis imperfecta. 


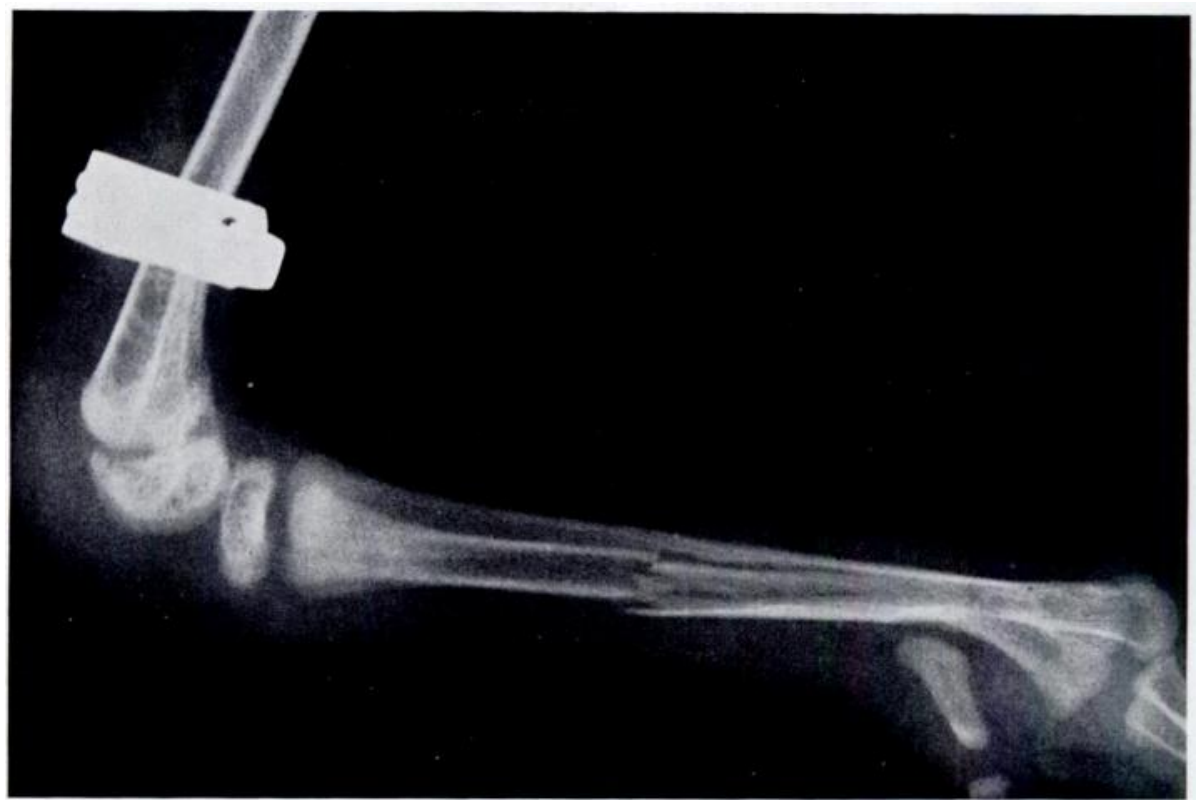

FIG. 29

Radiograph of a pathological fracture of the left first metatarsal in a three and a half-months-old chicken with insulin-induced osteogenesis imperfecta (post-natal type). Note that it is typically. transverse and "subperiosteal." The fracture occurred spontaneously.

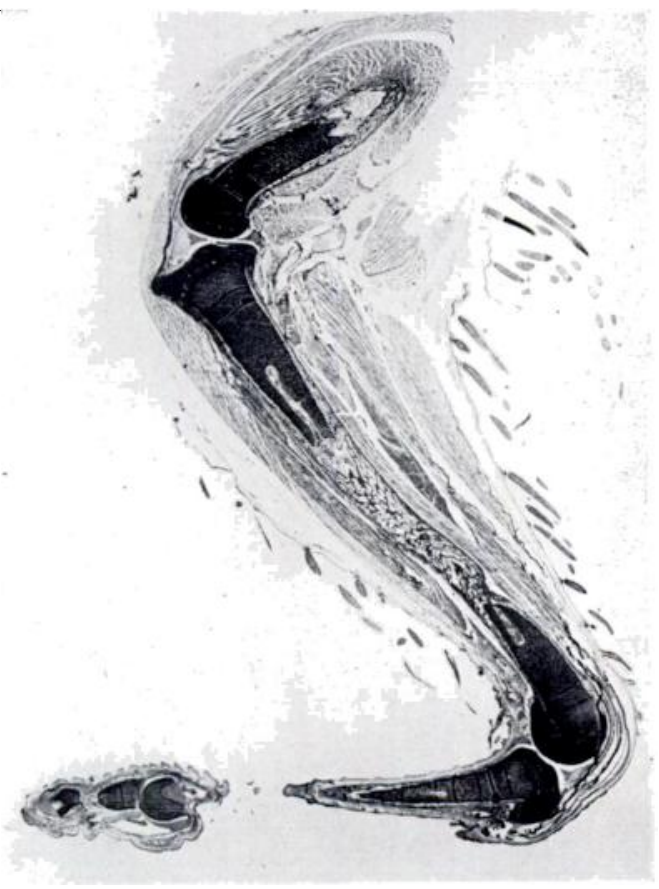

FIG. 30

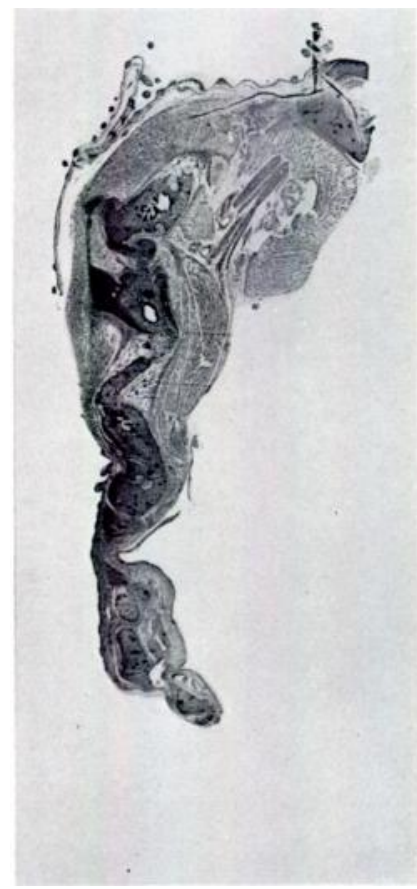

Fig. 31

Figure 30-Sagittal section $(\times 6)$ of a normal twelve-days-old embryo stained with toluidine blue. The cartilaginous core of the tibia has been stained deeply by the selective stain. Figure 31-Sagittal section of the tibia $(\times 6)$ of a twelve-days old embryo treated with 5 units of insulin on the fifth day of incubation. Note the severe degree of degeneration in the cartilaginous core and the deformity of the tibia. The stunting in the growth of the tibia is obvious from comparison with the normal tibia (on the same scale).

vol. $34 \mathrm{~B}$, No. 4, NovenBer 1952 


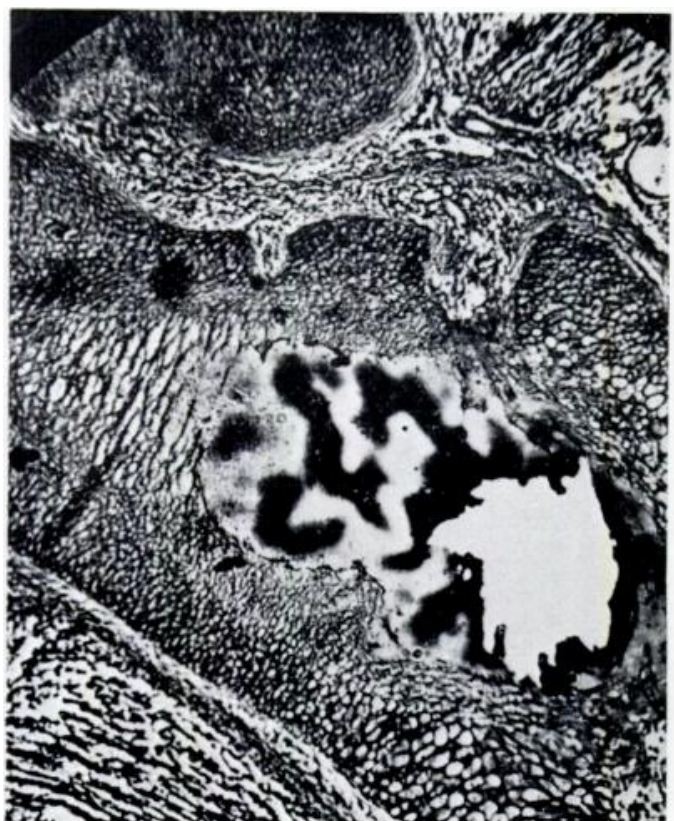

FIG. 32

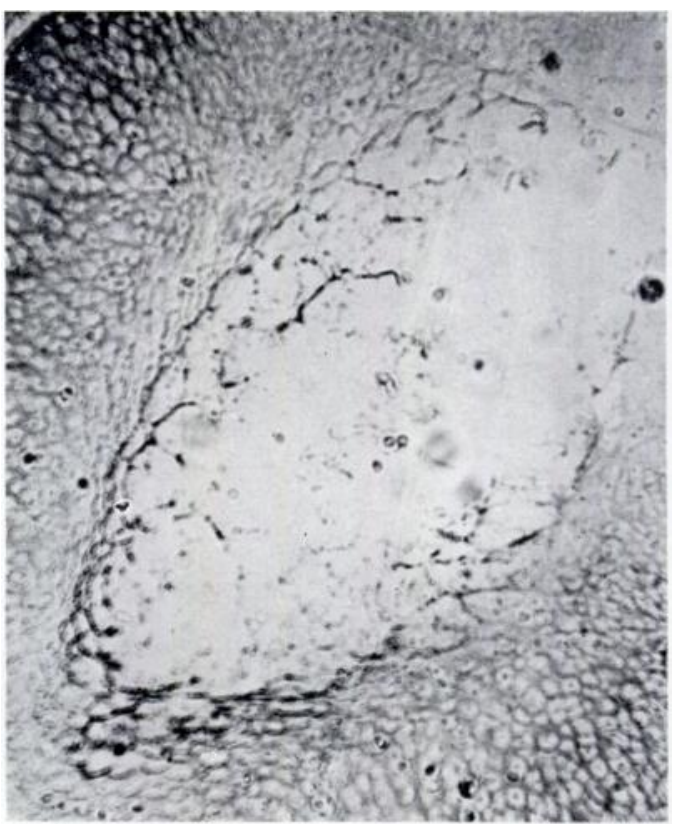

FIG. 33

Figure 32-Photomicrograph $(\times 100)$ of a section from the cartilaginous lower epiphysis of the femur of the insulin-treated embryo shown in Figure 31. Note the severe degree of mucoid degeneration with a hole in the degenerated area. Figure 33-Photomicrograph $(\times 100)$ of a section from the cartilaginous shaft of the tibia of an insulin-treated ( 6 units on fifth day) twelve-days-old embryo. Note the severe mucoid degeneration with a big hole in the centre of the degenerated area.

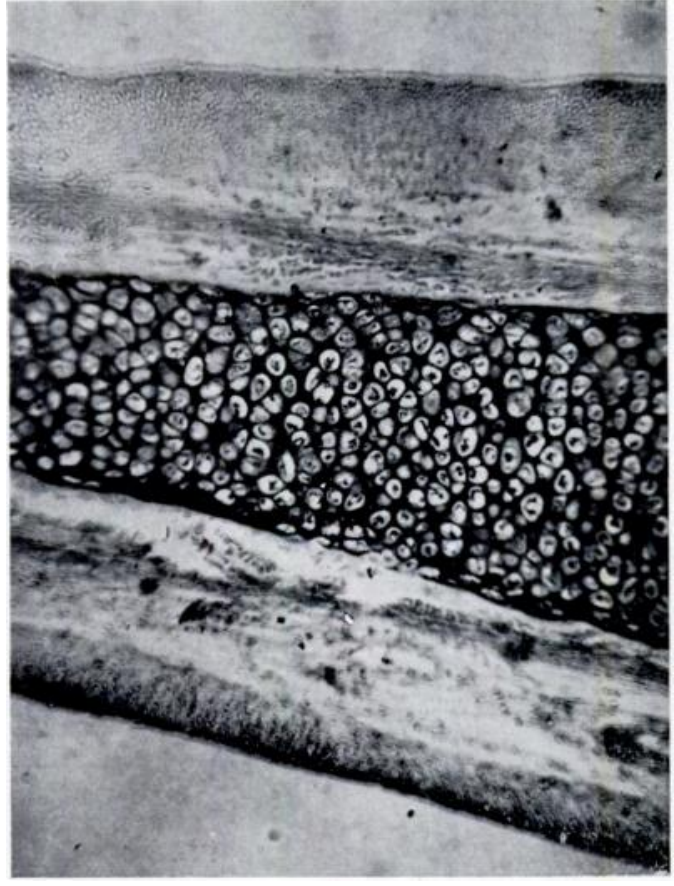

FIG. 34

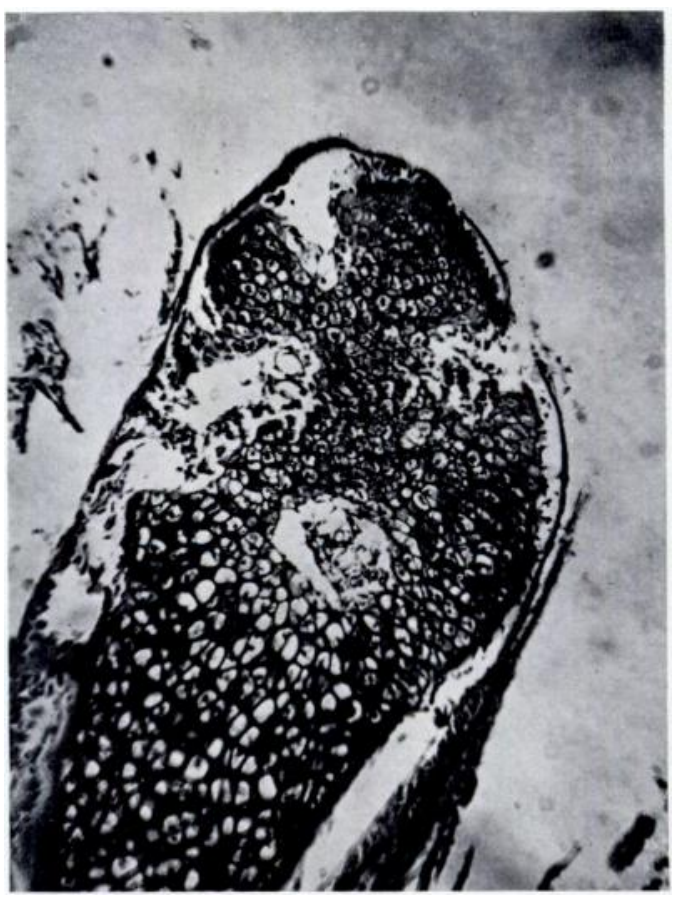

FIG. 35

Figure 34-Photomicrograph $(\times 60)$ of a section from the cartilaginous core of the tibia of a twelve-days-old normal embryo stained with toluidine blue. The cartilage cells have been stained deeply and appear normal. Figure 35-Photomicrograph $(\times 60)$ of a similar section from a twelve-days-old embryo treated with 2 units of insulin on the fourth day. Note the moth-eaten appearance. The degeneration in this section is not as severe as that seen in Figures 32 and 33 ; the dose of insulin in this case was only 2 units. 


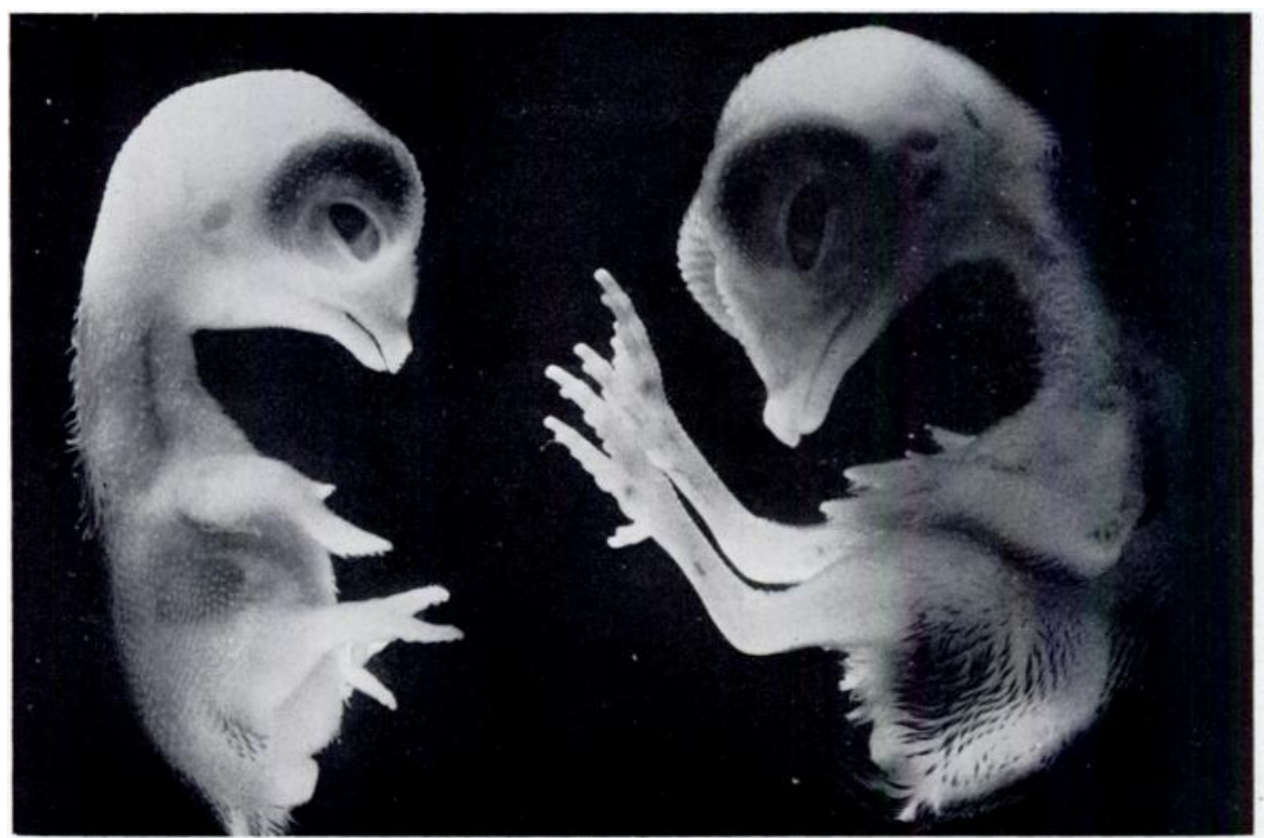

FIG. 36

Ten-days-old embryo with achondroplasia induced by 4 units of insulin on the fifth day, with a normal ten-days-old embryo for comparison. The short limbs of the achondroplasic embryo contrast typically with the nearly normal trunk to which they belong.

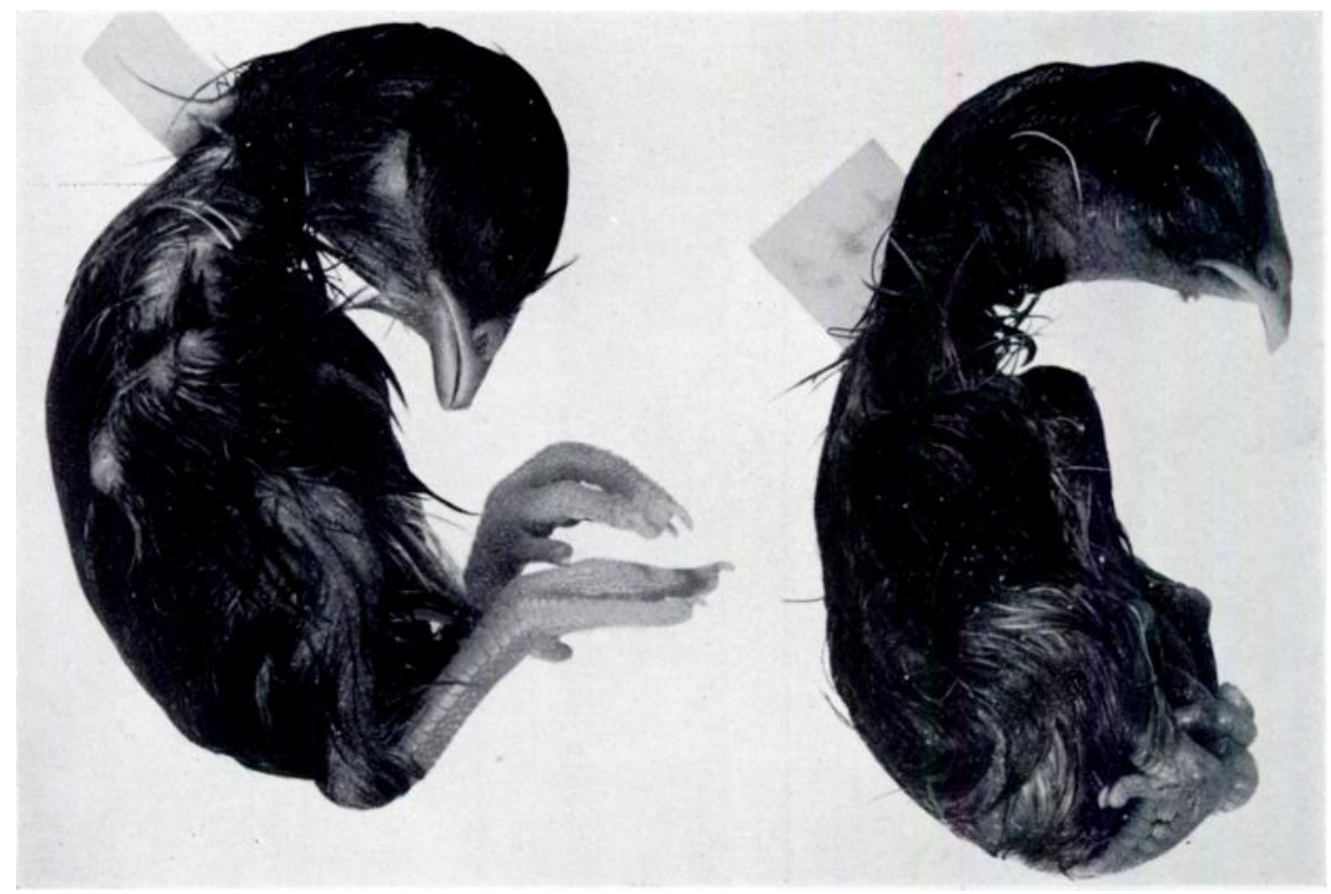

FIG. 37

Twenty-days-old chick embryo (right) showing achondroplasia induced by $\mathbf{2 . 5}$ milligrams of thallium nitrate injected into the yolk on the fifth day of incubation. Note the short lower beak and the typically short limbs whose proximal parts are disproportionately retarded in growth. Due to the retardation in the growth of the base of the skull, which is developed from cartilage, and the normal growth of the vault, developed from membrane, the embrvo appears to be dolico-cephalic and the upper beak seems to overgrow the lower. Normal twenty-days-old embryo for comparison.

vol. $34 \mathrm{~B}$, No. 4 , NOVEMBer 1952 


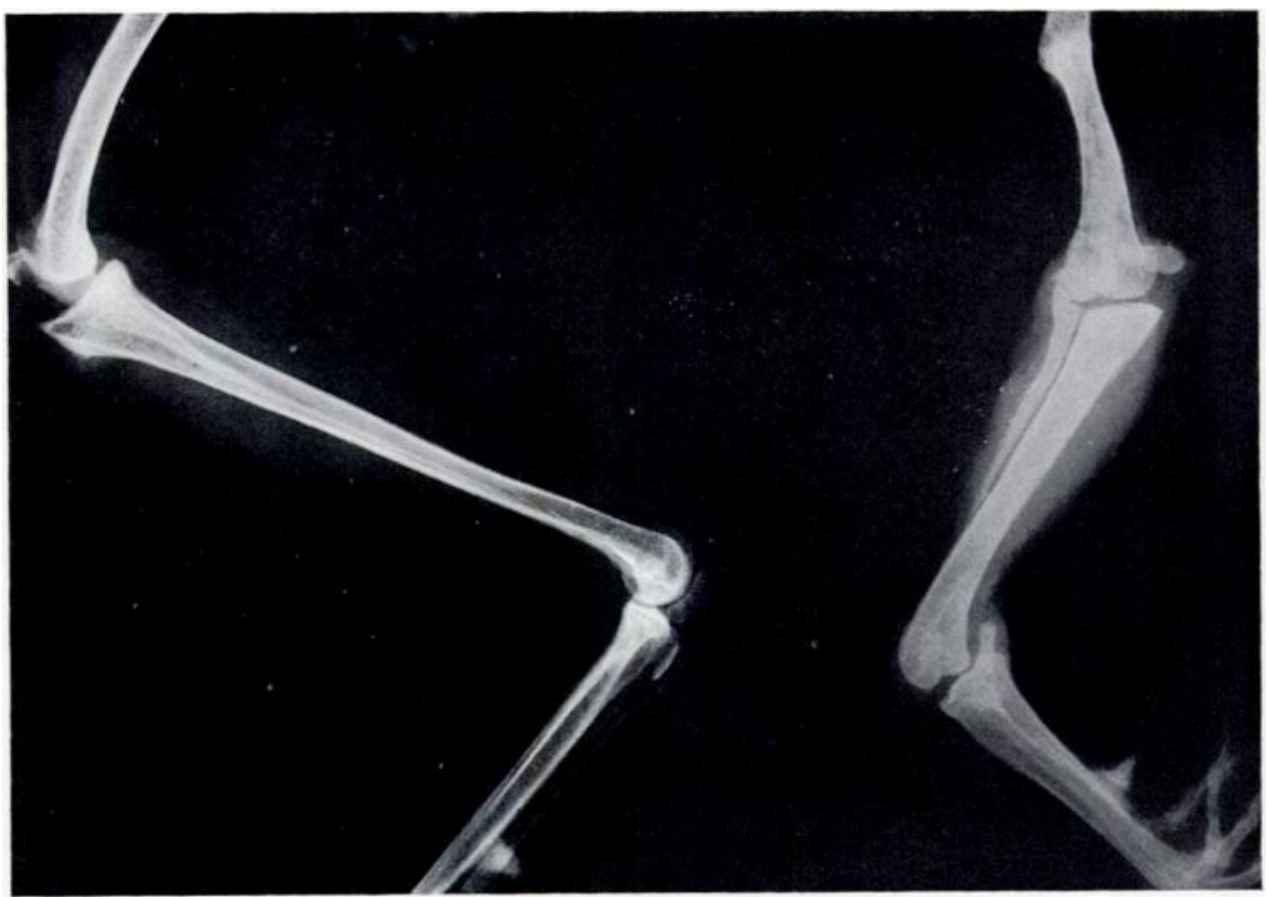

FIG. 38

Radiograph of a limb from a nine-months-old chicken showing insulin-induced chondro-osteodystrophy with appropriate control for comparison. The short, deformed bones of the limb of the insulin-treated chicken contrast typically with the radiograph of the control.

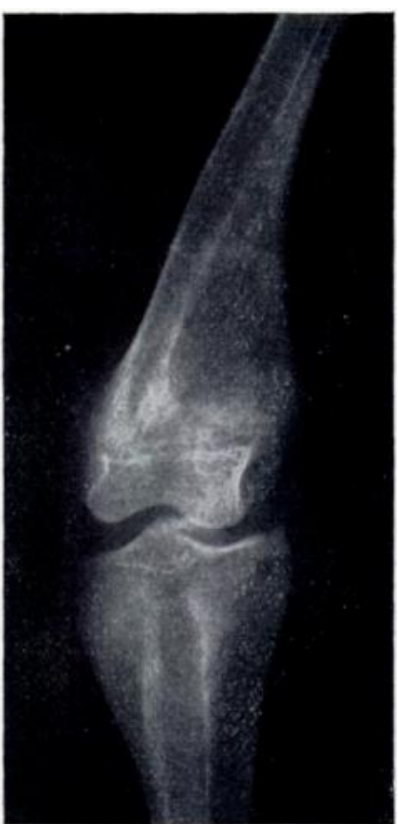

FIG. 39

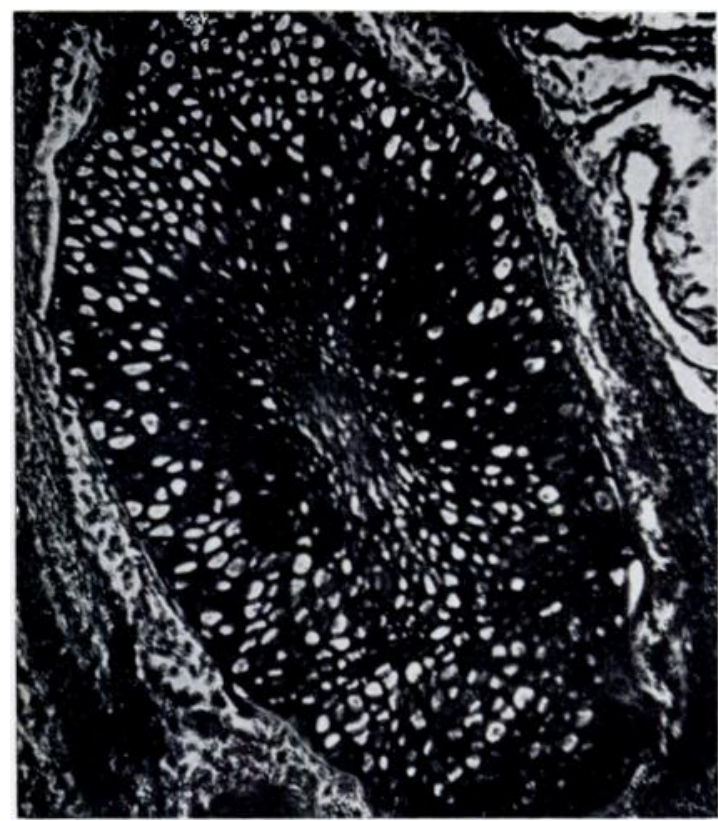

FIG. 40

Figure 39-Radiograph of chicken with insulin-induced dyschondroplasia. The lower end of the femur presents a cystic appearance. Histological appearance of a similar mass of cartilage is shown in Figure 40. Figure 40-Photomicrograph $(\times 100)$ of a sagittal section through a mass of unossified cartilage near the lower metaphysis of the femur from a chick with insulin-induced dyschondroplasia, showing a central area of degeneration with a ring of calcified cartilage surrounding it. 
Associated abnormalities-Abnormalities associated with skeletal deformities included the following. Beak deformities-A highly arched upper beak was often associated with limb deformities (Fig. 23) and much less commonly a short upper beak and crossing of the beaks were observed. Eye abnormalities-Anomalies of the eyes such as anophthalmos (Fig. 5), microphthalmos and buphthalmos have been associated with skeletal abnormalities. Genital glands-The gonads appear to be relatively smaller in the insulin-treated chickens than those of the controls of corresponding ages. Some among thermer group show marked atrophy of the germinal cells, though the interstitial cells seem to escape.

\section{PREVENTION OF INSULIN-INDUGED ABNORMALITIES}

I have injected solutions of nicotinamide and riboflavin into the yolk after making an injection of insulin, on the hypothesis that nicotinamide and riboflavin, which are known to play an important part in carbohydrate metabolism, would perhaps counteract the effects of insulin hypoglycaemia by accelerating the synthesis of the saccharides in the yolk-sac and promoting their utilisation by the embryonic tissues. I was indeed gratified to find that these substances prevented to a remarkable extent the induction of deformities by insulin. It is proposed to consider this aspect of the subject in detail in a later communication.

\section{DISCUSSION}

The question naturally arises whether the various deformities observed are due to the mechanical trauma caused by the injection or to specific action of insulin. Saline in quantities very much larger than the volumes of insulin solution, and A.C.T.H. (up to 4 milligrams per egg), have been injected, by the same technique, into hundreds of control eggs without any resulting abnormalities. Injections of substances that are known to influence ossification, such as parathormone (up to 5 units), calciferol (up to 2,000 i.u.), and radioactive phosphorus (up to 20 microcuries), have been made, also without affecting the normal development of the embryos. Insulin inactivated by the methyl-alcohol-hydrochloric method of Charles and Scott (1931) has been injected and no deformities have appeared whereas, when inactivated insulin was reactivated by alkali and then injected, the deformities have occurred. Ancel and Lallemand (1942) who had injected more than ninety substances into hens' eggs succeeded in inducing "micromelia" and beak deformities in the chick embryos only with twosulphonamide and eserine sulphate. In view of the above experimental evidence I am satisfied that the possible mechanical trauma of injection is not a factor in causing the various deformities. In point of fact, there is adequate experimental evidence to suggest that insulin induces the abnormalities by upsetting the carbohydrate metabolism of the embryo.

Insulin, if injected during the first week of incubation, produces a definite hypoglycaemia which persists till about the twelfth day of incubation in brown leghorn and light Sussex chick embryos with which I have conducted my experiments (blood sugar estimated by Hagedorn-Jansen method). Zwilling (1948) has made similar observations, experimenting with white leghorn chick embryos and employing a different technique (Folin-Malmros) for estimating the blood sugar, after injecting different doses of insulin into the yolk. He was also able to demonstrate a close association between insulin-induced " micromelia " and the hypoglycaemia caused by the hormone. Zwilling states: "Without exception all insulintreated embryos regain normal blood sugar levels by the fourteenth day of incubation. Apparently some mechanism of sugar control which becomes effective some time between the twelfth and fourteenth day of incubation overcomes the hypoglycaemic effects of insulin." I believe the explanation for this may very well lie in the experimental observations made by Idzumi (1924), Murray (1926) and Potvin and Aron (1927), indicating that the embryonic

vol. 34 B, No. 4, NOVEMBER 1952 
liver in the chick begins to store glycogen in appreciable quantities about the eleventh day of incubation and it is only thereafter that the carbohydrate metabolism in the chick embryo is controlled by the interaction between the appropriate endocrine glands, which also begin to secrete active hormones about the same time. Presumably insulin could induce the various abnormalities before this control is established in the embryo.

Zwilling (1951) has made further experimental observations which lend additional support to the view that insulin-induced abnormalities result from a derangement of the carbohydrate metabolism. He states: "We have demonstrated that the yolk-sac membrane contains a considerably increased amount of glycogen for several days after insulin is injected into the yolk-sac of five-day embryos. This reaction accounts for the hypoglycaemia in the embryonic circulation. The hypoglycaemia observed in the younger embryos, after injection at thirty hours, is presumably due to the same type of reaction of the yolk-sac membrane ... The pronounced association of hypoglycaemia and rumplessness at four days may indicate that both the embryonic and yolk-sac tissues respond to insulin in the susceptible eggs; the carbohydrate metabolism of both may be altered ... In view of the sensitivity of embryonic tissue to carbohydrate lack (Spratt 1948), it is likely that these tail anomalies (' rumplessness ') may be causally related to the lowered blood sugar."

My own histochemical investigations, employing the techniques of Hotchkiss and Lison, reveal that at least two of the major carbohydrate components, glycogen and acid mucopolysaccharides (chondroitin-sulphuric acid complexes), are involved in the insulininduced distrubances to the carbohydrate metabolism of the chick embryo. It is therefore conceivable that insulin may deprive the actively proliferating mesenchyme-which is rich in glycogen and mucopolysaccharides, according to Barfurth (1885)-precartilage or cartilage of glycogen and mucopolysaccharides, depending on the time ("critical period ") at which it is injected as well as its dose, and thus may give rise to a variety of single and multiple deformities in the cartilaginous skeleton.

Now let us examine how a derangement of the carbohydrate metabolism in the embryo can affect the ossification in the cartilaginous skeleton. Since the demonstration of glycogen (zoamyline) in cartilage by Rouget in 1859, a number of histochemical observations of this material have been reported. With the passage of time there has grown a feeling that the presence of glycogen might have some bearing on the process of calcification. In 1885 Marchand called attention to the increase in size of the cartilage cells at the growing ends of the kones and ascribed this "hypertrophy" to an accumulation of glycogen in the cells. Hoffman and his associates (1928) have demonstrated that a "striking relationship exists between the disappearance of glycogen in cartilage and its ossification." According to Harris $(1932,1933)$, the " hypertrophic cartilage cells provide both the phosphatase enzyme described by Robison (1923) and glycogen which, on hydrolysis, yields hexose-phosphoric esters." Due to the interaction between phosphatase, hexose-phosphoric esters and calcium of the circulating body fluids, an insoluble phosphate of calcium is deposited into the cartilage matrix. (It may be recalled that it was in the course of my experiments to verify this hypothesis that I accidentally observed the teratogenic properties of insulin.)

More recently, the presence of glycogen in hypertrophic cartilage cells has assumed further importance as a result of the demonstration of phosphorylase activity in the epiphysial cartilage by Gutman and Gutman (1941). In 1949 Gutman and Yu put forward their concept of the role of enzymes in calcification in cartilage as follows: "Calcification in cartilage evidently is a much more complex process than mere precipitation or the simple scheme proposed by Robison. It seems clear that enzymes other than phosphatase are involved. From the combined chemical and histochemical evidence, phosphorylate glycogenolysis would appear to be an essential part of the process in its preparatory phases, and probably corresponds at least in part to what Robison called the second mechnism ... Our experiments offer an explanation for the accumulation and disappearance of glycogen at the site of 
calcification in cartilage and provide for a potential source of phosphoric ester substance for phosphatase ..." A schematic representation of their concept of the role of phosphorylate glycogenolysis in endochondral ossification is as follows:

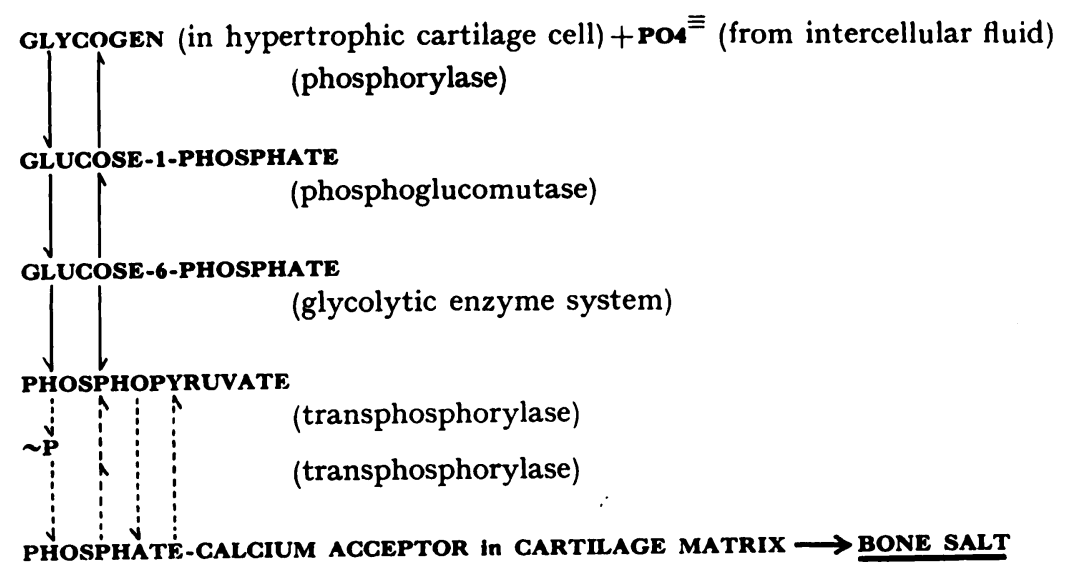

Follis (1949a and b) presented even more direct experimental evidence to support this concept of the relation between phophorylative glycogenolysis and ossification in cartilage. By employing special histochemical methods he showed that in normal endochondral ossification there is an inverse relationship between the presence of glycogen and the deposition of lime salts in the zone of provisional calcification. He also observed in rats (Follis and Berthrong 1949) that in markedly rachitic cartilage glycogen is present only in the more recently matured hypertrophic cartilage cells. When healing of rickets was effected by intraperitoneal injection of phosphate, deposition of bone salts was found to occur only in the matrix adjacent to the glycogen-containing hypertrophic cartilage cells and not in the area devoid of glycogen - this apparently accounting for the well-known "line" test for healing rickets. Marks and Shorr (1950) have shown that ptyalin-treated cartilage from which glycogen was removed by enzymatic digestion did not calcify in vitro in calcifying solutions containing phosphorus as inorganic phosphate; addition of glucose-1-phosphate to such solutions, however, restored the calcifying capacity of the ptyalin treated cartilage.

So far, we have confined our attention to the part played by the large glycogen stores of the hypertrophic cartilage cell in the processes of normal calcification in cartilage. According to Rubin and Howard (1950), this is not the whole story. On the basis of their histochemical observations, employing Lison's technique with toluidine blue stain and Hotchkiss histochemical reaction, on a number of different calcifying and calcified structures, both normal and pathological, they have concluded that acid mucopolysaccharides (chondroitensulphuric acid complexes) in the cartilage matrix also play a specific role in the calcifying mechanism by acting like " sulphonated cation exchange resins which absorb calcium, among other cations."

On the strength of all the above-mentioned experimental evidence demonstrating the important role of glycogen of the hypertrophic cartilage cell and the mucopolysaccharides of the cartilage matrix in normal endochondral ossification, I believe it is reasonable to attribute the defective ossification in the cartilaginous skeleton of the insulin-treated embryos to an abnormal carbohydrate metabolism. Thus the possible mechanism involved in the teratogenic action of insulin may be summed up as follows. Insulin-induced hypoglycaemia may deprive the mesenchyme, pre-cartilage, and cartilage of glycogen and mucopolysaccharides, depending on the time of injection and its dose, and thus give rise not only to a variety of single and multiple deformities in the cartilaginous skeleton but also to a defective endochondral

Vol. 34 B, No. 4, NOVEMBER 1952 
ossification which may result in a generalised developmental disturbance of bone resembling osteogenesis imperfecta in man.

\section{SIGNIFICANCE OF THE EXPERIMENTAL OBSERVATIONS IN ORTHOPAEDIG SURGERY}

Now let us examine the significance of some of the experimental findings recorded in the previous sections. The question naturally arises: do these throw any light on the causation of congenital defects in man ? It seems to me that the best way to answer this question is to discuss, first, the more important theories that have been put forward on the etiology of congenital malformations in the light of the various observations recorded in the preceding pages, and then to consider the practical application of some of my own experimental results in conjunction with those of others in order to formulate a possible hypothesis.

GURRENT THEORIES ON THE ETIOLOGY OF CONGENITAL MALFORMATIONS

Genetic theory-It has been well established that the basic laws of heredity apply not only to plants and lower animals but also to mammals, including man, and that certain pathological traits are inherited in the same manner as normal ones. However, the details of the mechanism of operation of the genetic factors are imperfectly known and it is seldom that the physician can speak to parents with any degree of certainty about the probable condition of their unborn child even when an accurate family history is available to him. In some types of congenital detormities-for example, polydactyly and symphalangism-the hereditary incidence is high whereas in others it is low. In some varieties, such as fragilitas ossium, we notice a definite familial tendency whereas others occur only sporadically. From the scientific point of view heredity is a strong argument in favour of the germplasm theory. From the clinical point of view, the aspect of eugenics is important in so far as the likelihood of transmission from the parent to the prospective children is concerned.

As pointed out at the beginning of this essay, genetic factors have, until recently, been the only ones to be studied in the field of mammalian teratology; so much so that it has often been stated that all congenital malformations in man and other mammals are determined genetically and are, therefore, inheritable. While I do not wish to minimise the importance of genetic factors in the causation of congenital defects, " clinical observation, as well as experimental work; have now shown environmental factors must be considered as teratogenic agents" (Warkany 1947). Eminent geneticists like Goldschmidt and Landauer hold similar views. With regard to the phenocopy phenomenon induced in drosophila by applying high temperatures at different times during development, Goldschmidt (1935) stated: "The essential point is that the normal integration of all reaction rates in the embryo is subject to interference. Such interference may be brought about by external agencies at the will of the experimentalist or by internal changes in the genes which may be catalysts or producers of inhibitors. If gene changes shift the rates of reactions during embryonic development relatively to one another, so also can external agencies." Landauer (1947) was impressed by the resemblances between insulin-induced " rumplessness " and the two types of hereditary "rumplessness," and between the micromelia and beak abnormalities of insulintreated chick embryos and the hereditary micromelia seen in the "short upper beak" stock. He stated: "It may be assumed that either mutant genes or experimental procedures such as the injection of insulin into chicken eggs may interfere with the normal functioning of developmentally important physiological events, perhaps the elaboration of particular substances."

Needham (1942) has referred to a number of experimental observations by different investigators to prove his statement that genes could induce various metabolic changes. For example, Watchorn (1938) demonstrated that the autosomal recessive gene in the mouse grey-lethal gave rise to low blood phosphate, low liver glycogen and hypoglycaemia, though the muscle glycogen was known to be normal. Grüneberg $(1935,1936,1938)$ has also observed in the 


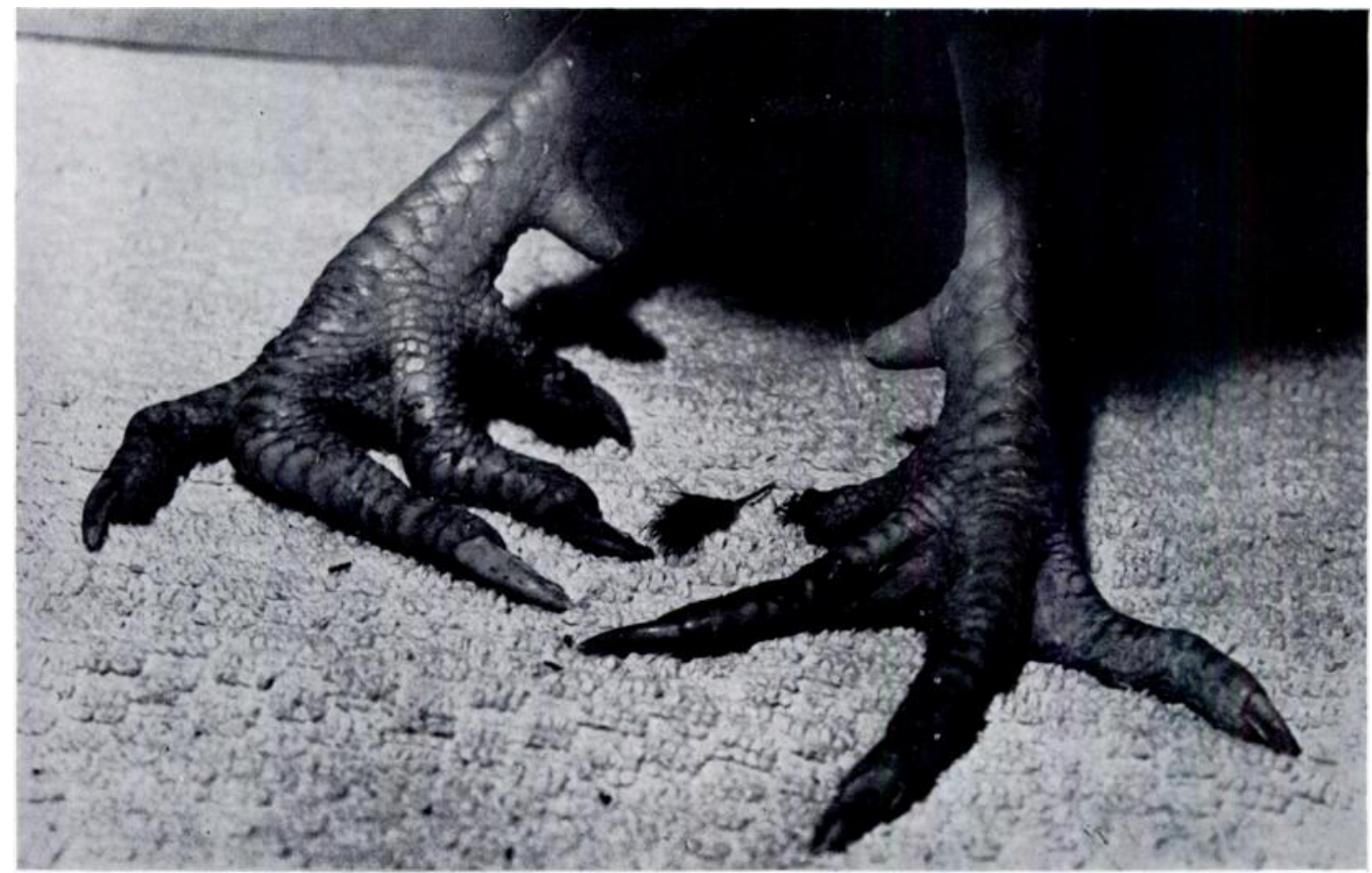

FIG. 41

Adduction deformity of the toes of the right foot induced by insulin. The deformity was transmitted to the offspring (Fig. 42) after mating with a normal hen. The egg was not treated with insulin.

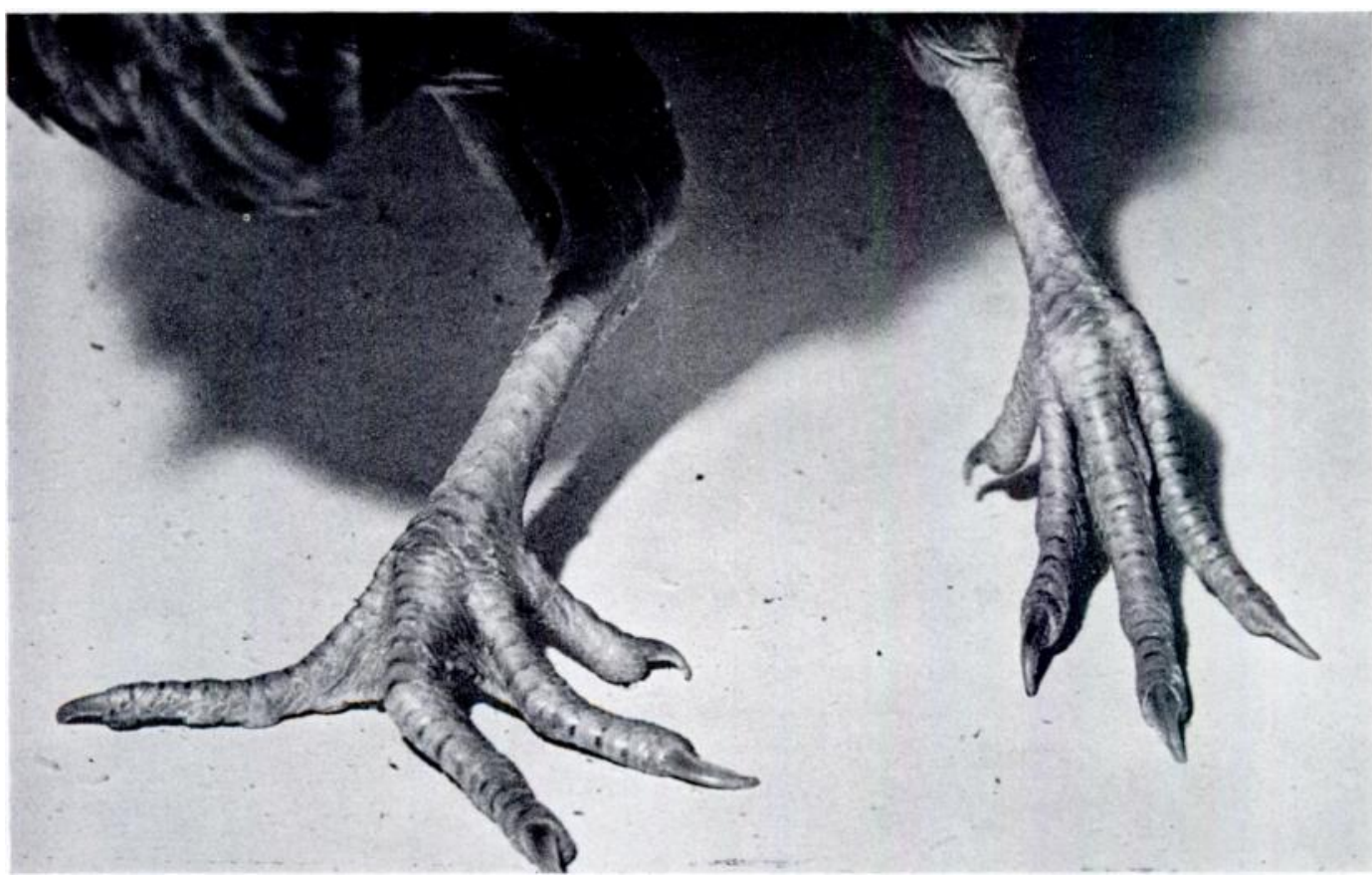

FIG. 42

Adduction deformity of the toes of the right foot in a ten-weeks-old chicken inherited from its male parent shown in Figure 41.

Vol. 34 B, No. 4 , NOVEMBER 1952 


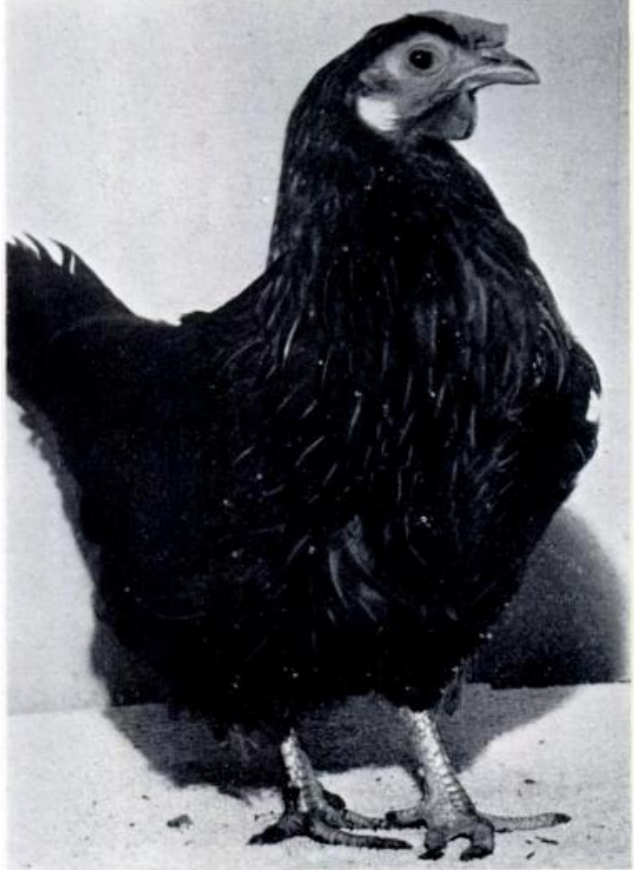

FIG. 43

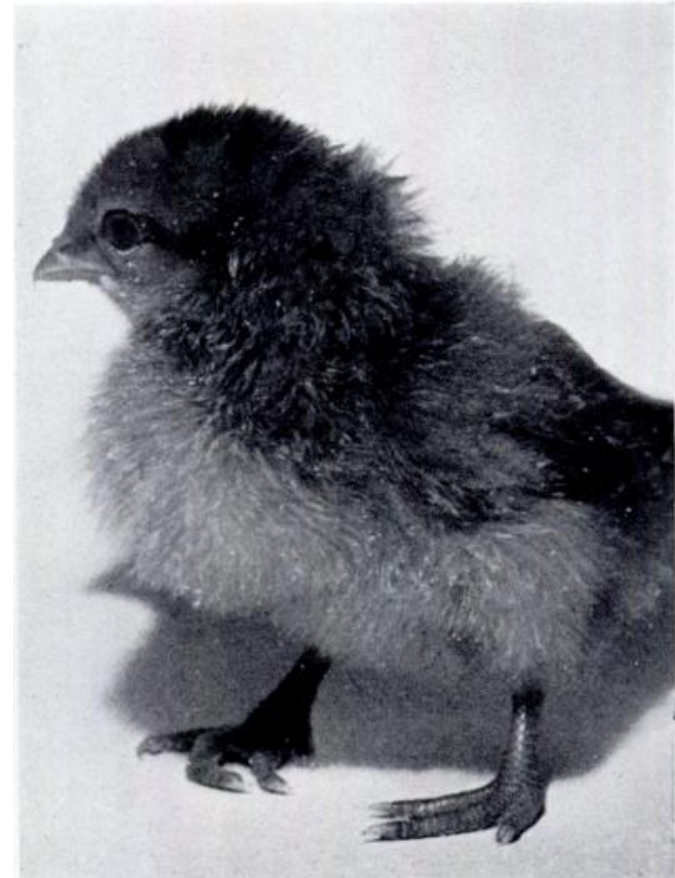

FIG. 44

Figure 43-The mother of the chicks shown in Figures 44 and 45. She has club feet induced by insulin. She was mated with a normal cock and the eggs were not treated with insulin.

Figure 44-Bilateral club feet in a five-days-old chick inherited from its mother with club feet induced by insulin.

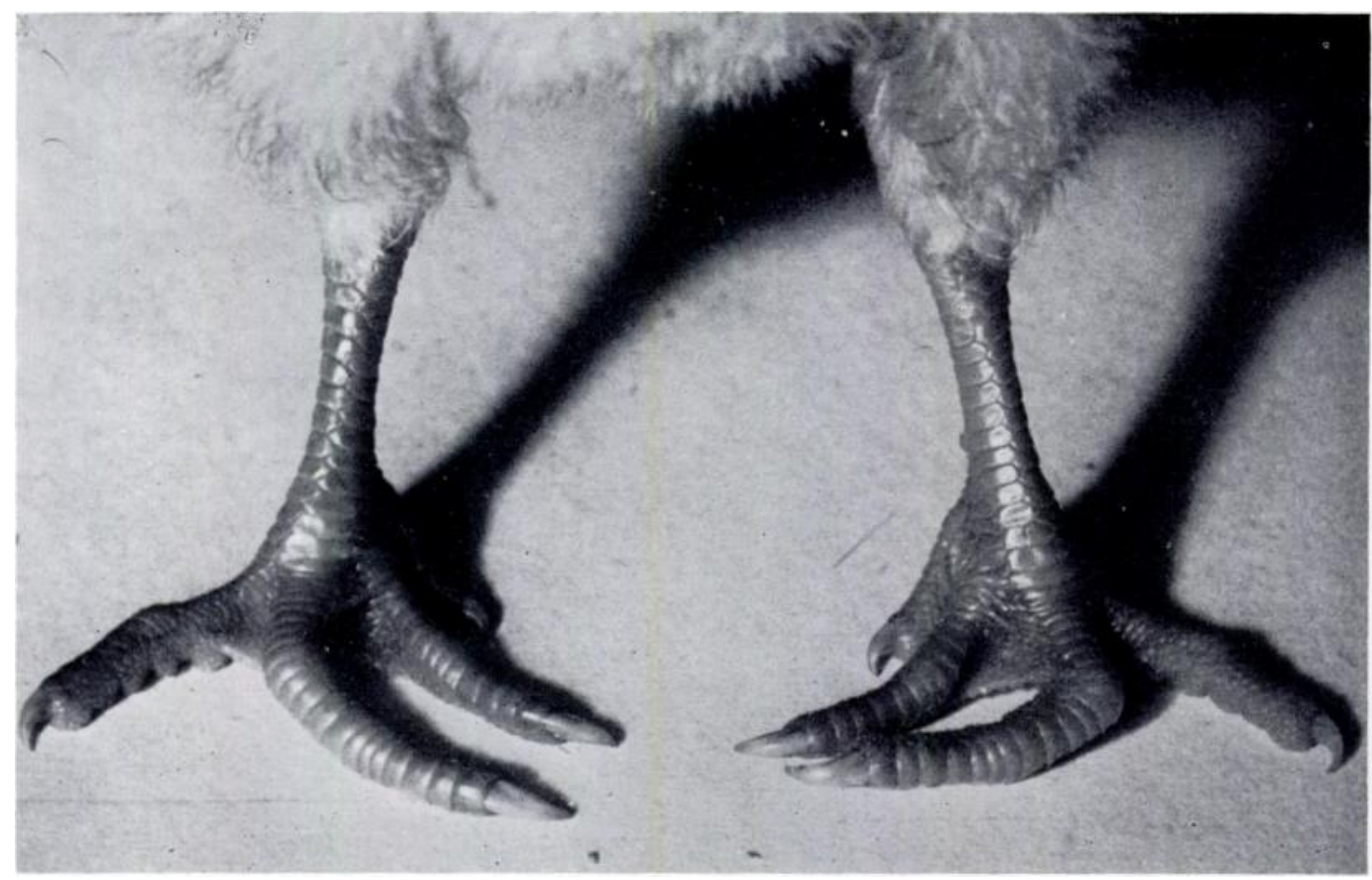

FIG. 45

Three-weeks-old chick showing bilateral club feet inherited from the same hen shown in Figure 43. (This is the third in the series to inherit the deformity; other offspring appeared normal.) 


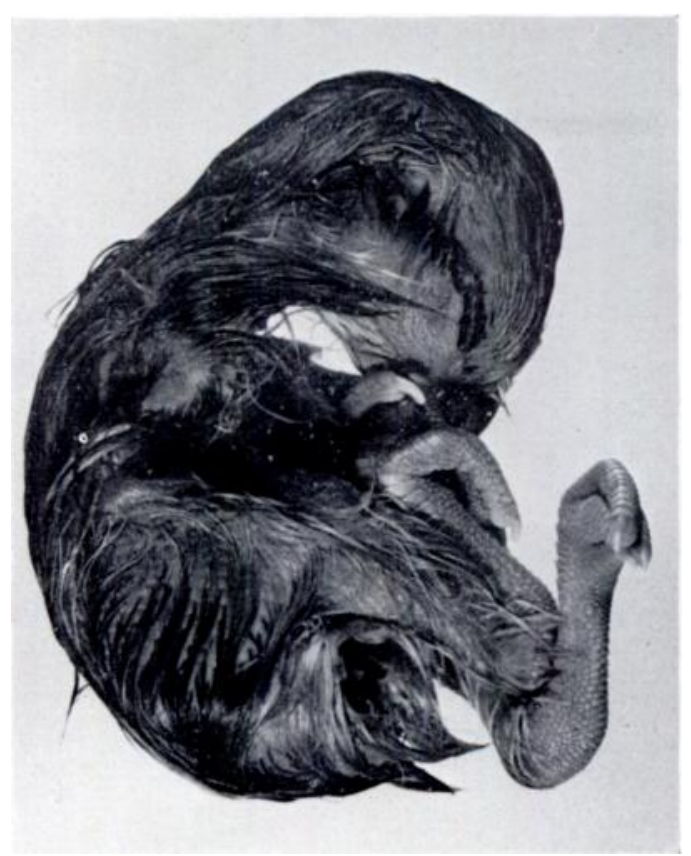

FIG. 46

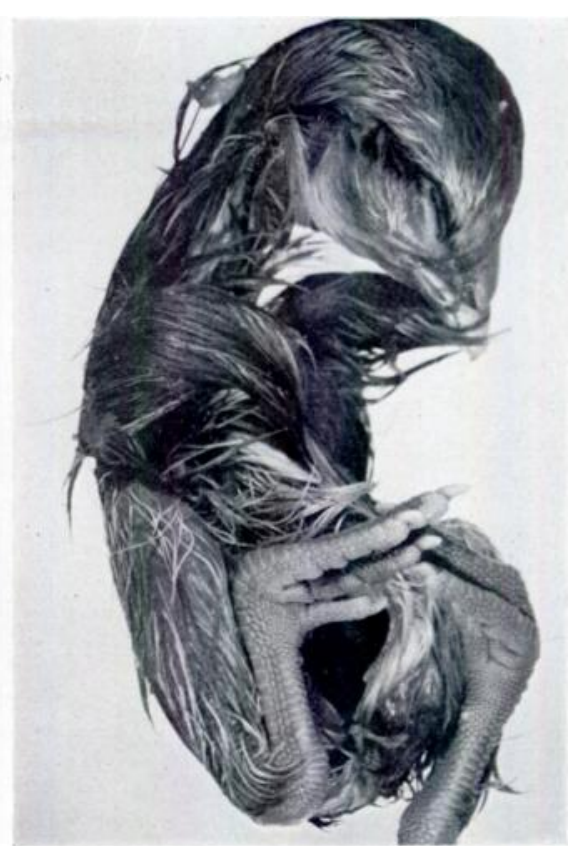

FIG. 47

Figure 46-Twenty-days-old embryo (dead in shell) with osteogenesis imperfecta (pre-natal type) inherited from both parents with similar abnormalities induced by insulin. There was a pathological fracture of the right femur. Figure 47-Another twenty-days-old embryo (dead in shell) showing osteogenesis imperfecta (pre-natal type) inherited from both parents with similar abnormalities induced by insulin. Figure $\mathbf{4 8}$ shows the radiograph of the skeleton of this embryo.

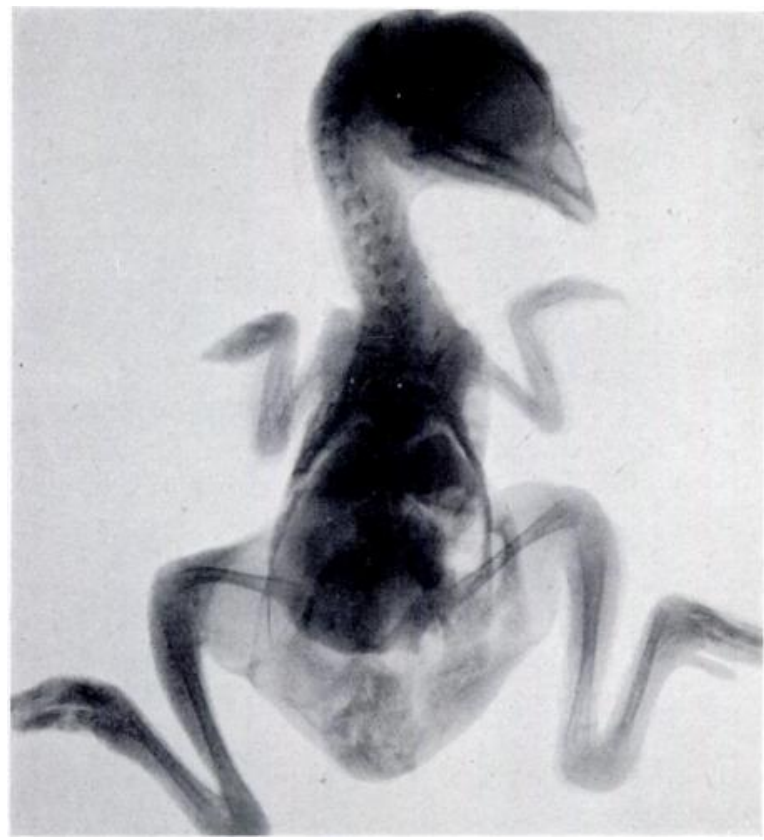

Fig. 48

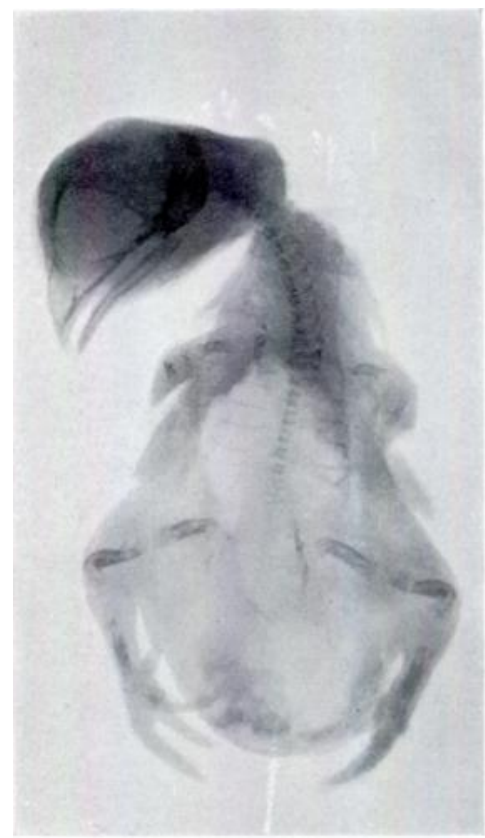

FIG. 49

Figure 48-Radiograph of a twenty-days-old chick embryo with pre-natal type of osteogenesis imperfecta inherited from both parents with similar abnormalities induced by insulin. Note the thin cortices of the long bones and the deformities, which are, however, less marked than those seen in the original condition induced by insulin, shown in Figure 49. Figure 49-Radiograph of a twent $\mathrm{y}$ days-old embryo treated with 5 units of insulin on the fifth day, showing a severe degree of osteogenesis imperfecta, for comparison with the inherited abnormality.

vol. $34 \mathrm{~B}$, No. 4, NOVEMBER 1952 
same mouse that there is incomplete calcification, resulting in severe skeletal abnormalities. The animals fail to grow normally and also die at weaning if a supply of a special type of food is not given during this period. I believe that all the above-mentioned observations made by various geneticists and others are significant in the light of the results obtained from experimental teratogenesis with insulin, especially in view of the fact that common factors such as hypoglycaemia, low liver glycogen, and incomplete calcification seem to play an important part in the causation of congenital skeletal abnormalities induced by abnormal genes as well as environmental teratogenic factors such as insulin. I must admit that, at present, it is only a hypothesis which needs to be confirmed by further experimental and clinical research. Nevertheless, if it were confirmed, considerable light would be thrown on the mechanism of causation of the most important group of congenital defects-hereditary anomalies-and, what is even more valuable, we might be able to prevent them.

I wish to quote the following three sets of examples given by Warkany (1947) in his chapter on "Etiology of Congenital Malformations" in Advances in Pediatrics which seem to lend further support to this hypothesis:-(a) Cleft palates of different etiology: (i) Mouse derived from strain in which hare-lip and cleft palate were hereditary. (ii) Rat whose mother had deficiency of riboflavin. (iii) Rat whose mother had been exposed to roentgen rays on fifteenth day of gestation. (b) Syndactylism of different etiology: (i) Mouse derived from strain with hereditary congenital defects. (ii) Rat whose mother had deficiency of riboflavin. (iii) Rat whose mother had been exposed to roentgen rays on thirteenth day of gestation. (c) Microcephaly of different etiology in humans: (i) Microcephaly genetically determined (the subject illustrated by Warkany was a boy who had two siblings with microcephaly, and a paternal grand uncle who was mentally deficient). (ii) Microcephaly in a child with toxoplasmosis. (iii) Microcephaly in a child whose mother was irradiated with roentgen rays during the second and third months of pregnancy.

"Mechanical pressure" theory-This is the oldest theory and the notion that the congenital deformities may be caused by pressure in utero dates back, according to many authors, to Hippocrates. One of the foremost among the contemporary protagonists of this theory is Denis Browne. I propose to deal with his views in some detail because Browne has attempted to explain a variety of orthopaedic deformities by this theory. He states: "To prove the question one way or another by direct observation is at present impossible, and it appears likely ever to remain so. In consequence I am reduced to a method that might possibly be used more in medicine than it is, the method of comparing what abstract argument shows to be the consequence of the granting of the hypothesis under test with what is found in real life" (Browne 1936). Browne assumes first of all that a " normal" newborn baby shows "obvious stigmata of mechanical compression," and then proceeds to classify the possible disorders that may befall the foetus as a result of increased mechanical pressure under the following categories:

1) Effects of normal mechanical pressure upon a foetus in normal position-These include: bending of the back; calcaneus position of the feet from pressure of uterine wall upon the soles; and dimples over the bony points in contact with the uterine wall.

2) Effect of normal pressure and development of the foetus plus abnormal position-The commonest deformities such as congenital talipes equino-varus, malposition of the toes, "postural " torticollis, and displaced ears are included in this group.

3) Normal mechanical and hydraulic pressure plus defective development-It is important to note that Browne says, in contrast to Jansen: "The defective development has, of course, nothing to do with mechanical influence of any kind." Jansen stated in 1912: "Thus it may be considered probable that direct amnion-pressure has the power of destroying deep-lying parts in a perfectly normal embryo - either with or without injury to the skin." Browne includes congenital dislocation of the hip, " congenital" fracture of tibia, and congenital club hands in this group. In the case of the congenital dislocation of the hip, he thinks that 
there are two factors in the causation of this deformity. The first is the " abnormally shallow acetabulum " which makes the dislocation easy, though the origin of the abnormally shallow acetabulum has not been explained. The second factor is a thrust on the knee from the uterine wall against which it lies, acting along the line of the femur to drive its head above the acetabulum and backwards. Turning to " congenital " fracture of the tibia, he remarks: "Here there is almost always a faulty formation of the bones of the leg, usually an absence of the fibula." (Again, he has not explained why there is a faulty formation of the bones of the leg to begin with.) "The invariable scar over the apex of the angle in the tibia is a typical pressure dimple. As to the angle itself, if it is not an effect of the bending of the presumably weaker leg over the other, it is curious that the invariable equinus position of the foot should correspond to the force necessary, and that the point of bending should correspond to the spot just above the heel, where the other skin would catch to form a fulcrum " (Browne 1936). It is pertinent to point out here that if 5 units of insulin were injected into hens' eggs on the fifth day of incubation, 85 per cent of the surviving embryos would show similar deformities of the tibia (Fig. 16), without any evidence of mechanical pressure. As already mentioned Warkany and his associates (1943) observed similar tibial deformities in a high percentage of the offspring of rats reared and bred on a diet deficient in riboflavin. When I visited Cincinnati recently I had an opportunity to examine many of these specimens and I could not find any evidence of mechanical pressure which could have given rise to these defects. On the other hand, there was adequate pathological evidence in the tibia itself to account for the deformity, as in the insulin-induced abnormality in the tibia. One cannot deny that mechanical pressure of any sort, and for that matter, even normal movements of the embryo or foetus, as the case may be, may aggravate the original deformity due to obvious pathological changes as seen in the cartilaginous tibia (Fig. 31). I believe that emphasis should be placed on what Browne calls " a faulty formation of the bones of the leg," whatever its origin may be, rather than on his hypothetical " mechanical and hydraulic pressure." For example, the more common anterior angulation of such a tibia showing pathological changes in the cartilaginous core may very well be due to an unopposed action of the calf muscles, there being no necessity to postulate mechanical and hydraulic pressure.

4) Normal hydraulic pressure and normal position aith increased mechanical pressure-Browne thinks that this will cause the spine to be "shortened by the acute scoliotic bends" and the muscles of the legs to become atrophied and fibrosed from interference with the circulation.

5) Effects of normal hydraulic pressure plus increased mechanical pressure plus abnormal position-In this group he includes "club feet of the usual type with muscle and joint degeneration, atypical talipes with muscle and joint degeneration, displaced finger showing arthrogryposis (confined to the fingers alone), spina bifida with talipes and degeneration of the muscles and joints of the legs." Browne (1936) gives the following explanation for the formation of spina bifida: "This most complicated and intractable deformity appears to me quite easily explicable under this heading. Let us imagine again what would happen if right at the start of foetal life the relation between the expanding foetus and its surroundings was disturbed, so that the bending of the back was exaggerated from its very beginning. At this time when the foetus (embryo) is barely 2 millimetres long, the edges of the neural groove are joining to form the neural tube. Any extra bending would make the sides of this groove gape at the point of the maximum curve, that is, the lumbar region. Accordingly faulty fusion would be likely, with the formation of a spina bifida at this point." Browne has not, however, indicated the nature of the disturbance which is supposed to exaggerate the bending of the back, "when the foetus is barely 2 millimetres long."

6) Effects of increased hydraulic pressure-Browne postulates increased hydraulic pressure for the causation of arthrogryposis. According to him the hydraulic pressure could be increased in two ways: first by the amount of fluid being too large, and secondly by the container being too small. He explains: "With such an increase one would expect that the waves of

vor.. $34 \mathrm{~B}$, No. 4, NOVEMBER 1952 
blood sent into the foetal circulation from its own heart and the maternal one would be very readily diminished by the elastic pressure. Consequently only the muscles and viscera close to the impulse would get a full supply, and the limbs would be in a condition of reduced arterial supply combined with venous stasis. The degeneration of muscle and stiffening of the joints already described would occur just as before, but the nerves would be less liable to harm than they are in mechanical pressure." It is difficult to understand how the increased hydraulic pressure which should be transmitted equally in all directions, according to Pascal's law governing fluid pressure, can be postulated to obliterate, even partly, deeply placed arteries of the limbs without at the same time causing serious damage to the brain by pressure on the fontanelles and the thin membranous vault of the skull. Moreover, there is evidence to show that the pathology in the amnion (hydramnios, oligamnios, and amniotic bands) may be caused by the same noxious agent - for example, 3-acetyl-pyridine-which gives rise to degeneration in the affected muscles. It is interesting to note that the incidence of hydramnios in diabetic mothers is high (27 per cent) according to Oakley and Peel (1949), whereas arthrogryposis does not occur any more frequently among the children born to diabetic mothers than among other children. On the other hand, it is conceivable that those factors which are responsible for the high incidence of other congenital malformations in children born to diabetic mothers may very well give rise to hydramnios in a high percentage of cases. I have observed that cortisone, when injected into the yolks of hens' eggs, induces not only certain congenital abnormalities, such as ventral hernia, in the chick embryos but also produces oligamnios and amniotic bands. Dareste (1882) claimed to have induced hydramnios, oligamnios and amniotic bands together with developmental deformities in the embryo in the course of his numerous experiments in teratogenesis (Ballantyne 1904).

Many observers have raised objections against the mechanical pressure theory on the ground that the uterus is not a rigid chamber but one which accommodates itself, under the influence of the appropriate endocrines during pregnancy, to its contents; and twins are seldom affected. Further, the foetus is known to be constantly changing its position and moving its limbs so that continuous pressure on any particular part is hardly possible. Middleton (1934) who strongly opposed the pressure theory stated: "It is well that there should be a clear understanding of what uterine pressure can and cannot do in the way of producing deformities of the extremities. The so-called packing of the foetus in the later months of pregnancy consists in the mutual accommodation of parts physiologically unresistant, and appears to produce distortions of the limbs such as the normal slight flexion contracture of the hips and the common talipes calcaneo-valgus . . Real and persistent deformities such as tibial kyphosis, talipes equino-varus and very many more cannot be caused by intra-uterine packing, and the mistaken impression that they can be is largely due to the fact that the position of the foetus in utero adapts itself to any deformity which may be presented."

The " bleb" theory-This theory has been offered to explain the developmental mechanism of deformities such as club foot, congenital dislocation of the hip, Sprengel's shoulder, cleft palate, spina bifida; and also syndromes like Laurence-Moon-Biedl syndrome, chondro-osteodystrophy (Morquio-Brailsford type), pleonosteosis familiaris (Léri), Turner's syndrome, cranio-carpo-tarsal dystrophy, oxycephaly, acrocephalosyndactyly, dysostosis craniofacialis (Crouzon) and others (Engel 1940, 1943).

Origin of the "bleb"--Reference has already been made to Bagg's experiments on mice employing $\mathrm{x}$-radiation as a teratogenic agent as a result of which malformations such as club foot, syndactylism, polydactylism and congenital amputations were produced. According to Bagg the earliest foot defect was associated with the formation of a blister-like bleb, which raised the epithelium of the foot, usually in a localised area. This bleb was generally observed during the twelfth to fifteenth day of prenatal life and was followed by the escape of blood into the bleb and the formation of a localised blood clot. 
Bonnevie (1934) investigated the bleb structures in the mice that were bred from six extracted abnormals which were sent to her in Norway by Bagg's associate, Little, in 1930 for further breeding experiments. According to Bonnevie the bleb fluid is really cerebrospinal fluid which is expelled through the foramen anterius, a pear-shaped foramen existing for a short time in the anterior part of the roof of the fourth ventricle of the embryo. She believed that the expulsion of the cerebrospinal fluid through this opening was a normal occurrence. In this case, however the quantity of the expelled fluid was abnormally high either from excessive production or deficient absorption or to a primary dysunion in the mid-dorsal line. The subcutaneous blebs so formed began to spread to the body surafce and on their paths exerted a "deleterious influence by pressure, and provoked an inflammatory reaction" (Bonnevie 1934). They were "driven by physical forces towards areas of least resistance and were arrested and retained by preformed cavities and pockets, like the orbits and limb buds." Bonnevie thought that the displacement of the blebs along the embryonic surface was probably governed by mechanical forces and above all by the elasticity of the epidermis forming the bleb roof.

Divergent views on the origin of the "blebs"- Unlike Bonnevie, Bagg (1929) attributed the formation of the blebs to " a localised arrest of development . . . associated with a perivascular lymph stasis." Keith (1940) disagreed with this view and said: "A localised arrest of development need not give rise to effusion of lymph and blood; only a localised necrosis of foetal tissue could occasion such a train of events, and the most probable cause of necrosis is a localised failure of circulation of blood. Nowhere has Bagg recorded the state of the placenta in these dysplastic embryos, although placental lesions, were they present, would not likely escape his vigilant eye." Plagens (1933) has presented experimental evidence to show that the bleb flu'd takes origin from the blood stream, as will be seen later. Blister-like blebs have not infrequently been associated with the necrotic changes induced by insulin in chick embryos.

Engel $(1940,1943)$ attempted to harmonise, rather unconvincingly, the above experimental findings and the clinical experience, and to give "a morphogenetic explanation" for the various deformities and syndromes enumerated. On the basis of Bonnevie's observations in mice, he suggested vaguely that the localisation of the blebs may depend upon "some modifying factors or genes" and "by regular combinations of genes some deformities will manifest themselves as syndromes."

Objections to the "bleb" theory-The "bleb" theory was vehemently opposed by Plagens (1933) who experimented with the same mouse strain as Bonnevie. In contrast to Bonnevie's observations, Plagens found that there was no regular movement of the blebs along the surface of the developing embryo and that the blebs were transitory and they never formed haematomas. He observed that the number of blood cells increased considerably in the abnormal embryos, more so in individuals possessing larger and more numerous blebs. He attributed this change to an escape of the liquid part of the blood from the circulation and its accumulation in the blister-like structures which, therefore, could not have been formed by expelled cerebrospinal fluid as was suggested by Bonnevie. As mentioned above, Plagens presented experimental evidence to prove that the bleb fluid had its origin from the blood stream. On the basis of his experimental observations, Plagens concluded that the blebs, after all, played only a minor role in the production of the gross disturbance in the limb and the primary cause of the abnormalities in this mouse strain lay in the "thrombi which usually appeared two or three days later than the blebs and haematomas." He pointed out that in the photomicrographs published in Bonnevie's paper there are many examples of haematomas and thrombi. Plagens did not, however, give any clue with regard to the active agent responsible for the formation of the thrombi. It is not inconceivable that abnormal genes may induce these changes in the blood stream at critical periods during the development of the pathological descendants, thus giving rise to the primary dysplastic lesions as well as secondary "blebs," in the same

vol. $34 \mathrm{~B}$, No. 4, November 1952

$\mathbf{K}$ 
way as the autosomal recessive gene in the mouse grey-lethal has been shown by Watchorn (1938) to give rise to low blood phosphate, low liver glycogen and hypoglycaemia.

Streeter's foetal dysplasia theory-By 1930 Streeter had at his disposal sixteen cases of a condition which he designated "foetal deficiencies in foetal tissues" but which Keith preferred to call "Streeter's foetal dysplasia" Streeter (1930) believed that the dysplasia was the cause of many malformations. He ascribed the lesions, which became manifest in the foetus as it developed, to a fault inherent in the chromosomes of the fertilised ovum. Keith (1940), however, considered it more reasonable to regard the fault as lying in a temporary-or permanent-breakdown in the circulatory system in the foetus. The lesions in Streeter's foetal dysplasia may give rise to circular necrotic grooves filled with exudative tissue in which there is embedded a constricting ring or anklet of fibrous tissue or in some cases lead on to intra-uterine necrosis of the limb or digit affected and congenital amputation.

Circulatory failure theory (Keith)-According to Keith (1940), at the end of the second month of foetal life, which appears to be the period at which foetal dysplasia of the limbs usually begins, the placenta is undergoing a rapid expansion and is therefore in its most vulnerable phase of growth. Nevertheless, the results which follow circulatory failure in an early human foetus seem to differ in certain respects from those seen in adult tissues. First of all it must be remembered that it is not until the end of the second month that a cardiac circulation is fully established, though the human heart begins to beat about the twenty-fourth day of intra-uterine life, and until then the tissues are dependent on lymph seepage and not on blood supply as in adult tissues. Keith thinks that foetal tissues have a higher degree of vitality and individual response than mature tissues. Some foetal tissues, such as the fibroblasts of the skin and deep fascia, respond in a particularly vigorous manner when cut off from their blood supply.

Keith believed that the congenital dysplastic lesions such as defects of the scalp, meningoceles, spina bifida and the various degrees of anencephaly were caused by local necrosis from a circulatory failure which might be placental in origin. The failure was supposed to occur along marginal areas where capillary formation is in progress. According to Keith the lesions become manifest at two stages of development: towards the end of the first month; and at the end of the second month. These may be considered critical periods for the placental circulation. Though this theory seems attractive, we are still in the dark with regard to the cause of the localised anaemia, as the following statement of Keith's (1940) will show: "The active agent which brings about this localised anaemia and necrosis in dysplasia foetalis still awaits discovery."

Theory of muscular derangement in the mechanism of congenital deformity (Middleton) - Though congenital myodystrophy was first described by Otto in 1841 and many examples of the condition may be found scattered through the world literature since that date, it was Middleton (1934) who drew an analogy between this condition and the muscular dystrophies of postnatal life. Middleton thought that the muscular derangement was primary in the mechanism of the congenital deformity and that the errors of the bone were in the nature of structural adaptations to the primary error of the muscle. According to him the pathology of the muscular derangement might be of three types: 1) arrest of development at the myoblastic stage; 2) fallure of elongation of the muscles after normal development; and 3) intra-uterine degeneration with progressive conversion into scar tissue as in myodystrophia foetalis deformans (arthrogryposis multiplex congenita). Middleton attributed the congenital angulation of the tibia which he named " congenital tibial kyphosis," to a failure of the later stages of development of the calf muscles during intra-uterine life.

Browne (1936) raised the following objections to Middleton's theory: "The suggestion that this condition (myodystrophy) is a primary spontaneous one has two obvious weaknesses. First, it assumes a totally new pathological condition. Second, it does not explain the 
associated conditions: the stiffening of joints, the deformities of the feet, and the presence of the pressure dimples when the legs alone are affected, and their absence in many cases when the arms suffer too." I believe these objections have little substance. In a careful and fascinating study of the condition of the muscles involved, Middleton presented irrefutable evidence of myodystrophy in the affected muscles. The histological sections showed fibro-fatty material containing, at scattered intervals, some remnants of muscle fibres displaying degenerative changes. I have observed that 3-acetyl-pyridine (nicotinamide "antagonist"), when injected into the egg yolk in the same way as insulin, induces myodystrophy resembling the type described by Middleton. It is interesting to note that Middleton observed, in a boy of seven, congenital scoliosis caused by myodystrophy similar to the scoliosis caused by 3 -acetyl-pyridine.

The atavistic theory (Bardeleben)-Bardeleben (1874) tried to explain the etiology of congenital deformities solely on the basis of atavistic throwbacks. This theory goes back to remote phylogenetic era. Oligodactyly was thought to represent an atavistic form-namely a reduction of the digits as seen in the horse. However, the idea of atavistic reduction or increase of digits was strongly refuted by Prentiss (1910) who drew attention to the fact that all mammalian ancestors were polydactylous. Prentiss has also shown that in polydactyly the extra digits do not develop from the digital rudiments and that the abnormal occurrence of six or seven digits on the usually five-toed extremities is not a reversion to type. The supernumerary toes or fingers are duplications of normal digits caused either by primary germ variation or " extrinsic influences."

The archipterygial theory (Gegenbauer) - This theory follows more or less the same trend of thought as the atavistic theory. Gegenbauer (1864) believed that it was the suppression of "primitive rays" which was responsible for the deformities. From the phylogenetic point of view the same objection can be raised-namely, that the wing of the bird which Gegenbauer mentions in support of his theory does not represent a recession but rather a progression from the common amphibian stock which marks the cross-roads between birds and mammals.

The theory based on the concept of organisers - We are indebted to the German zoologist, Spemann (1938) for the concept of organisers. In his Silliman lecture delivered at the Yale University he has given an unparalleled account of the principal processes in development (though confined to the development of the amphibia), based on the concept of organisers. According to Spemann, Corner, and others this concept of "The hierarchy of organisers in animal development" casts a flood of light upon the problem of developmental defects induced by heredity or environment. It is outside the scope of this paper to enter into a detailed discussion on the role of organisers in the normal and abnormal development of the embryo, but this is what one of the foremost contemporary embryologists has to say about the whole concept: " Thus either a bad egg in a good environment or a good egg in a bad environment can become abnormal in the same way. This is a remarkable thing in that exactly, or almost exactly, similar injuries, often of a highly specific sort, and dependent upon very special maladjustments at very particular times in the embryonic life, can result from such dissimilar causes. How this can be is to a certain extent explained by the theory of organisers ... Indeed the action of the genes is believed to be effected by the production of catalysts, substances which speed up chemical reactions, or of inhibitory substances, and thus there may be little difference as far as the effects on an organiser centre are concerned, between the action of a deleterious gene and of a toxic solution applied by the experimenter. It should be remembered also that the injury to the reactant tissue (that which responds to the organiser) will cause failure of embryonic growth just as much as if the organiser is disturbed, so that the harmful agencies have two targets, upon either of which they may act in one case or another" (Corner 1944). It must be made clear that practically none of the experiments on organisers have so far been conducted on mammals. However, Corner states:

vol. $34 \mathrm{~B}$, No. 4, NOVEMBer 1952 
"We may provisionally accept the thought that in all vertebrates, including man, the development of the animal body from the egg is guided by the action of a succession of organiser centres, getting more and more specialised and more local as they succeed one another, until the whole complex system of tissues and organs has differentiated itself out of what was once an egg of very general potency" (Corner 1944).

\section{PRACTICAL APPLICATION OF SOME OF THE OBSERVATIONS MADE ON} EXPERIMENTALLY INDUCED DEFORMITIES

The various theories on the causation of congenital defects which have been discussed in the preceding pages are rather difficult to co-ordinate. In the long chain of cause and effect each theory applies to a different level. Some, such as the atavistic theory, are rooted into the remote and obscure past; others, like the doctrine of the intrinsic germ variation, are based on the ontogenesis of the embryo itself. Still others are concerned with more immediate and recent events, such as theories that refer to mechanical, vascular, serological, metabolic and biochemical factors operative within the life span of the embryo. The later the epoch to which the theory refers, the more plausible it must appear. However, the fact remains that congenital deformities vary between themselves as follows: first of all, in type, degree and time of appearance during embryonic development; secondly, in the way in which they become associated with one another in the case of multiple deformities; and lastly, but certainly not the least in importance, in their tendency to hereditary transmission. It is therefore understandable that no single theory can easily explain all types of malformations. It is just as difficult to accept any single theory without reservation as it is to reject it unconditionally.

Discussing the merits of an etiological classification of congenital defects, Steindler (1950) says: "In spite of all information collected from experimental and genetic studies, our present meagre knowledge of the causes of congenital deformities does not warrant etiological classification. We must still depend on grouping deformities purely on morphological lines. Such morphological divisions as club hands, syndactyly and congenital dislocation of the hip contain little information regarding differences in etiological factors or in the time of incipiency of the deformity. Still, as we recognise certain morphological variants, subdivisions of these groups begin to appear, based on developmental points. The congenital dislocation of the hip is an example. We accept it no longer as a morphological unit. A distinction is now recognised between a prenatal and postnatal type which is a step forward in comprehending the nature of the deformity. A similar situation exists in congenital club foot. However, such etiological subdivision is still the exception."

I believe that there are practical difficulties in classifying congenital malformations on a purely anatomical and morphological basis, apart from its being irrational. Microphthalmia, malformed ears, cleft palate and hare-lip are common congenital defects, but unfortunately the names give no indication of the groupings of associated deformities or transitional forms between them. Congenital cataract, cardiac septal defects, patent ductus arteriosus, deafmutism, dental defects, microcephaly and mental retardation which result from maternal rubella during the early months of pregnancy obviously cannot be grouped together on a morphological and anatomical basis, though the etiological factor is the same. Etiological classification, surprisingly advanced in 1836, mainly due to Saint-Hilaire, was given further impetus by the experimental, embryological, clinical and epidemiological studies of various workers during the past few decades. A concept of its nature has already begun to take form, though at present its extent in detail and design remains still ill-defined, and only future research, carefully planned and wisely co-ordinated between laboratory workers and clinicians, can throw more light on this admittedly complex problem. Nevertheless it is hoped that the following classification will be of some use in grouping different anatomical and morphological malformations arising from the same or similar causes, in spite of its imperfections. 


\section{Genetic factors}

\section{Etiology of Congenital Malformations}

\section{Environmental teratogenic factors}

Faulty maternal diet during gestation-deficiency of calcium, phosphorus, iodine, iron, and vitamins A, B-complex, C, D (Murphy 1947).

Maternal pelvic irradiation-x-rays, radium.

Maternal intercurrent infectious diseases-rubella, measles, chicken-pox, mumps 'Fox et al. 1948).

Maternal metabolic disorders-diabetes mellitus; hypoglycaemia due to various causes including hyperinsulinism.

Abnormalities of maternal hormonal mechanism.

Diseases and mechanical disorders of the uterus (Ingalls and Gordon 1947).

Lesions of the placenta-vascular aberrations; diseases and disorders; placenta praevia.

Toxaemia of pregnancy (Ingalls and Gordon 1947).

Tubal gestation (Mall 1917).

Intra-uterine asphyxia or anoxia (Ingalls et al. 1950).

Iso-immunisation (Rh., A.B.O.).

Toxoplasmosis: ? malaria.

Drugs and metallic poisons administered during pregnancy, inadequate to cause abortion but perhaps sufficient to cause malformations (Brailsford 1948).

Mechanical factors (may aggravate the original dysplastic lesions).

Other environmental factors of unknown origin.

As mentioned before, the role of some of the environmental factors enumerated above is still sub judice. On the other hand, it is very likely that more will be added to the list in the near future, as Gregg (1945) has predicted: "I regard rubella and its sequelae as the title of but one chapter in the full story of congenital defects; many more chapters have yet to be written."

To sum up the hypothesis: the development of an embryo, which is presumably guided by a succession of organising processes, may be interfered with during critical periods by genetic or environmental teratogenic factors. Such disturbances caused to the organiser system may, in their turn, produce metabolic, biochemical, and other changes through the intervention of hormones and enzyme systems and thus interfere with the normal development of the embryo. The resulting abnormalities in development would not occur in a random assortment, but tend to fall into certain categories corresponding to the critical stages of development of susceptible tissues and the quality and intensity of the noxious agent. Developmental malformations may result not only from arrest of growth and differentiation of the embryo as a whole, or some of its parts, as was pointed out by Stockard (1920), but also from degeneration in tissues which had developed normally up to a certain stage, as has been clearly demonstrated in the case of insulin-induced deformities (Fig. 35) and rubellainduced lenticular lesions.

Now let us see how this general hypothesis may be applied to congenital orthopaedic deformities. It will be of interest to the orthopaedic surgeon to know that it is possible to demarcate in the life of the human embryo certain critical periods which are "peculiarly associated with catastrophic changes in the development of the skeleton" (Harris 1933). The fourth and fifth weeks of intra-uterine life are definitely associated with the development of the cartilage skeleton. The seventh and ninth weeks present widespread calcification of the cartilage of the long bones as the main feature. The last two months of foetal life are marked by the rapid growth in the length of the bones, as distinct from the increase in the size of the epiphyses. The orderly progression from the mesenchymatous condensation to cartilage, and then through calcified cartilage to bone may be disturbed by genetic or environmental teratogenic factors, as explained above, and thus may result a variety of single and multiple skeletal deformities.

In the first place, a suppression of proliferation of cells in the mesenchyme which is

VOl. $34 \mathrm{~B}$, No. 4 , NOVEMBER 1952 
destined to form a limb will result in phocomelia (total absence of a limb) or ectromelia (absence of a part of a limb). Secondly, a suppression of mitosis in the cartilage during the fifth week of intra-uterine life may lead to a complete failure of development of the cartilage, resulting in agenesis of any of the long bones such as the radius or the fibula; or agenesis of the sacrum and coccyx. Thirdly, inhibition of the active process of mitosis in the cartilage at one end of the bone will lead to a partial aplasia of the long bone such as the femur of the fibula. Lastly, varying degrees of interference with the nutrition or metabolic processes of the proliferating cells of the mesenchyme, pre-cartilage or cartilage, or any disturbance to endochondral ossification may lead to a variety of abnormalities, in a manner broadly analogous to the deformities induced experimentally with insulin and other teratogenic agents.

Discussing the etiology of congenital malformations, Warkany (1947) writes: "There can be no doubt that we are witnessing a renaissance of the science of teratology. The role of congenital malformations in human morbidity and mortality is finding increasing recognition and some fundamental clinical and experimental contributions to mammalian teratology have been made in recent years . . . It is to be expected, therefore, that in the coming decades the subject will attract a great deal of attention." Though some of the insulin-induced deformities resemble human developmental abnormalities, we must await the results of further fundamental investigations, some of which are in progress at the present time, before drawing our conclusions. However, I submit that our aim should be to explain the mechanism of causation of human congenital abnormalities also on the basis of well understood metabolic, biochemical and histological changes, whether they are induced by abnormal genes or environmental teratogenic factors, rather than by flimsy subcutaneous blebs or doubtful intra-uterine or amniotic pressure.

To further this aim, we should encourage thorough examination of aborted foetuses and stillborn infants, more or less on the lines we have followed for the experimentally induced abnormalities. It is only by such investigations that we can confirm Mall's observation that 50 per cent of all aborted human foetuses show an astounding variety of developmental malformations and, more important still, we can apply the valuable knowledge gained from animal experiments to a better understanding of the etiology and pathology of human congenital anomalies. As mentioned at the outset, the greatest practical difficulty with early human embryos and foetuses is that they show post-mortem degenerative changes before accurate histological methods can be applied. This naturally emphasises the necessity of conducting all pathological examinations of these specimens with the least possible delay after abortion, natural or therapeutic. It is interesting to note that Hertig (1948) had a valuable opportunity to examine twenty-six implanted ova from surgically removed uteri, within six weeks of fertilisation of the ova. He concluded that over 40 per cent of the embryos were abnormal. A routine examination of all uteri surgically removed may enable one to obtain much valuable information.

I had an opportunity to examine the radiographs of the skeleton of a stillborn infant through the courtesy of Dr E. G. Hall, of Alder Hey Hospital, who had conducted a thorough post-mortem examination on this interesting case. The radiographs and histological sections of the long bones presented features of both osteogenesis imperfecta and dyschondroplasia. I have observed similar radiological and histological appearances in the bones of chick embryos with insulin-induced skeletal abnormalities. Harris (1933), who had an opportunity to conduct necropsies on infants with generalised developmental diseases of bone such as achondroplasia, chondro-osteo-dystrophy and epiphysial dysplasia, observed that mucoid degeneration of cartilage in place of normal calcification was the fundamental change in all these conditions. He has also come to the conclusion that the failure to maintain the hereditary form of the epiphysis as a result of mucoid degeneration is probably the prime factor in a congenital dislocation. My experimental findings with regard to the analogous abnormalities induced in chicks by insulin resemble these observations in the human. 
The multiplicity and variety of skeletal abnormalities induced by a single teratogenic agent such as insulin, depending on the time of its injection into the yolk and its dose, need not perplex us. As shown already, the basic factor in the pathogenesis of the various anomalies is a derangement of the vital carbohydrate metabolism in embryonic tissues such as the mesenchyme, cartilage and bone, and insulin has been found to be an eminently suitable agent with which the carbohydrate metabolism of the developing chick embryo may be deliberately upset during the first week of incubation, before it is controlled by the interaction of the various hormones and before the liver starts to store glycogen in appreciable quantities. "It is significant, therefore, that bone appears as the outstandingly susceptible tissue in these examples of experimentally induced abnormalities, and that such physiological factors as blood sugar, hormones and vitamins appear to control the normal development of the tissue " (Editorial: British Medical Journal, August 12, 1950, p. 405). It is possible that there may be other teratogenic agents capable of inducing congenital malformations by disturbing the cellular protein, fat and other metabolisms at critical periods. Fundamental investigations on these and other allied problems are needed and it is hoped that this complex subject of congenital anomalies will attract a great deal of attention from clinicians and experimental research workers alike in the years to come. It is only by increasing our knowledge of their etiology that we can hope to prevent at least some of the developmental anomalies which cause " the death of about 23 per cent of the human race before or shortly after the time of birth and handicap a certain proportion of the survivors throughout their lives" (Stockard 1909).

\section{SUMMARY AND CONCLUSIONS}

1. The magnitude of the problem of congenital anomalies becomes evident when one takes into consideration the fact that they cause the death of approximately one quarter of the human race either before or shortly after birth, and handicap an appreciable proportion of the survivors throughout their lives. Further, a significant percentage of infants judged to be normal at birth are found in later life to suffer from "disguised" anomalies of the skeleton and soft tissues. Though the study of genetic factors leading to congenital defects has attracted a great deal of attention during the last few decades, the importance of environmental causes of human malformations has received relatively less emphasis. The association of congenital anomalies such as cataract and cardiac septal defects with maternal intercurrent infection of rubella during the early months of pregnancy demonstrates clearly that changes in the germplasm cannot always be invoked as the cause of developmental abnormalities. Congenital malformations that are sometimes genetically determined, such as microphthalmos, cleft palate, and certain skeletal abnormalities, can be caused in the offspring not only by maternal nutritional deficiencies and $\mathrm{x}$-radiation but also, at least in some animals, such as chickens, rats and rabbits, by the introduction of certain substances like insulin into the environment of the embryo during its development.

2. Since very little is known of the detailed histology of the early human embryo, the histological examination of cases of perverted growth is mainly limited to aborted foetuses which, unfortunately, tend to present varying degrees of post-mortem degeneration before accurate histological methods can be applied. It is exactly in this field that animal experiments can offer valuable help. According to Mall and other embryologists the pathological changes that take place in human foetuses and those obtained experimentally in animals are not merely " analogous or similar but identical."

3. An attempt has been made to review, in some detail, the more important work which has been carried out on experimental teratogenesis, on the epidemiological implications of developmental arrests in humans, and on foetal abnormalities associated with maternal metabolic and hormonal disorders during pregnancy.

Vol. $34 \mathrm{~B}$ No. 4 , NOVEMBer 1952 
4. The technique employed for injection of insulin into the egg yolk has been described. Methods used for the estimation of blood sugar in chick embryos at various stages after injection of insulin and special histochemical techniques for localising polysaccharides in cartilage have been outlined.

5. A few salient experimental results have been tabulated, and some of the insulin-induced abnormalities have been illustrated.

6. The possible mechanism of action of insulin in the causation of the various developmental anomalies has been discussed. Broadly speaking, insulin seems to affect primarily the part or tissue which is in the most active stage of growth or differentiation at the time of the injection. Within the range of 0.05 to 6 units of insulin employed, the incidence, severity and distribution of the deformities appear to increase with the dose of the hormone. It has been observed that the hypoglycaemia caused by insulin injection is not counteracted till about the twelfth day of incubation, presumably because of excessive accumulation of glycogen in the yolk-sac membrane immediately after the injection, and because of lack of glycogen storage in the embryonic liver and the absence of active secretion in the endocrine glands concerned with the carbohydrate metabolism of the embryo. It has been suggested that this unchecked hypoglycaemia may deprive the mesenchyme, pre-cartilage and cartilage of glycogen and mucopolysaccharides (chondroiten-sulphuric acid complexes), depending on the time of injection and the dose of insulin, and thus not only give rise to a variety of single and multiple deformities in the cartilaginous skeleton but also interfere with the normal endochondral ossification, resulting in a generalised developmental disturbance of bone resembling osteogenesis imperfecta in the human.

7. Insulin-induced abnormalities can be prevented to a remarkable extent by injecting nicotinamide and riboflavin into eggs along with insulin.

8. The question of the practical application of the knowledge gained from experimental observations on insulin-induced developmental abnormalities in explaining the possible causation of congenital anomalies in humans by genetic and environmental teratogenic factors, has been discussed. It is suggested that the orderly progression from the mesenchymatous condensation to cartilage, and then through calcified cartilage to bone, may be disturbed by these teratogenic factors at critical phases during the development of the embryo, and a variety of single and multiple skeletal deformities may thus be induced.

9. A plea is made for routine pathological and radiological examination of aborted foetuses and stillborn infants more or less on the lines followed for experimentally induced deformities with a view to applying the knowledge gained from animal experiments to a better understanding of the etiology and pathology of human congenital anomalies.

10. As regards the possible prevention of these deformities, it is not always easy to offer sound eugenic advice in the cases of congenital malformations determined partly or completely by genetic factors, for two important reasons. First, it is often difficult to distinguish between genetically determined congenital anomalies and their phenocopies. Secondly, genetically determined developmental defects sometimes show surprisingly variable expressivity and penetrance. For the conditions in which both genetic and environmental factors are involved, the most profitable immediate line of attack would be on the environmental factors. A relatively simpler problem is presented by the malformations which are, for all practical purposes, entirely caused by environmental factors. Measures to prevent congenital anomalies caused by prenatal rubella, such as exposure of girls to the disease during childhood and protection of pregnant women during the early stages of pregnancy by immune serum, are under active consideration.

11. Further energetic investigation of the causes of permaturity, stillbirths, monstrosities and congenital malformations is urgently needed, before embarking on a successful programme for prevention. "The day of successful prophylaxis is not yet, but it is much nearer than seemed possible a few years ago." 
Addendum - Figure 50 shows a chicken with " inherited " club feet. It is one of the offispring from the third generation series which show " club feet." Twenty-four brown leghorn chicken: of the second generation (page 660) had been sent from Liverpool to enable me to continue the genetic experiments in the Bowles Orthopaedic Research Laboratory, Baltimore, and thus verify if the deformity is transmitted to the third and succeeding generations. So far it has been traced to the fourth generation. Though a statistically significant percentage of the $f \in w$ hundred descendants examined show " club feet" of varying degrees of severity as compared with controls, it is absolutely necessary to confirm this

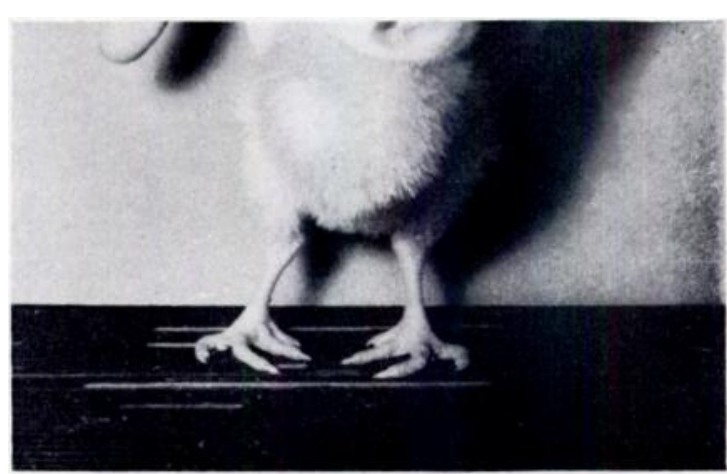

FIG. 50 observation in larger statistical series before drawing definite conclusions from these and parallel experiments with another breed of chickens, namely New Hampshire reds.

In some further recent experiments I have observed that if cortisone (Merck's cortone acetate $\mathrm{R}$ ) is injected into the yolks of hens' eggs in the same way as insulin, it gives rise to varying degrees of ectopia iscerae (exomphalos with or without ectopia cordis), tight amniotis sacs, amniotic bands and blister-like blebs. These experimental findings clearly disprove the "Amniotic Theory" and the "Bleb Theory" which have been put forward to explain the etiology of congenital defects. The blebs and amniotic bands are, in point of fact, caused by the same teratogenic agents which induce the defects. Further, the specificity of action of each of the various teratogenic agents such as insulir, soluseptasine, thallium nitrate, 3-acetylpyridine, and lead nitrate (which last substance, incidentally, induces hydrocephalus, meningoencephaloceles, and meningo-myeloceles in chick embryos), has also been demonstrated by certain experiments which involved the injection of cortisone with each of the above-mentioned substances. For example, if insulin and cortisone are injected into the yolk on the fourth day of incubation of the egg, insulin induces typical limb deformities as usual, while cortisone gives rise to ectopia viscerae. Analogous observations have been made with respect to the other combinations also. (An abstract of my paper on these and other observations read before the Johns Hopkins Medical Society has been published in the Bulletin of the .Johns Hopkins Hospital, 90, 447.)

Acknowledgement is made to the British Nedical Journal, in which Figures 2. 3, 4, 8, 10, 14, 16, 23 and 35 have been published previously.

\section{REFERENCES}

Ackerman, W. W., and TAYlor, A. (1948): Application of a Metabolic Inhibitor to the Developing Chick Embryo. Proceedings of the Society for Experimental Biology and Medicine, 67, 449.

Allotr, E. N., and Holmax, C. A. (1949): The Rhesus Factor. Lancet, i, 209.

Ancel, P., and Lallemand, S. (1942): Sur une malformation du bec et des membres obtenue, chez l'embryon de ponlet, à l'aide de sulfamides. Comptes Rendus des Séances et liémoires de la Société de Biologie, 136, 255.

ANdersen, D. H. (1941): Paper read at the 13th annual meeting of the Society for Pediatric Research, Atlantic City, X.J., May 5, 1941

AYcock, W. L., and INGalls, T. H. (1946): Maternal I)isease as a Principle in the Epidemiology of Congenital Anomalies. American Journal of the Medical Sciences, 212, 368.

BAGG, H. J. (1920): Pathological Changes Accompanying Injections of an Active Deposit of Radium Emanation. Journal of Cancer Research, 5, 1.

BAGG, H. J. (1920): The Response of the Animal Organism to Repeated Injections of an Active leposit of Radium Emanation. Journal of Cancer Research, 5, 301 .

BAGG, H. J. (1922): Disturbances in Mammalian Development Produced by Radium Emanation. American Journal of Anatomy, 30, 133.

vol. $34 \mathrm{~B}$, No. 4, NOYEMBER 1952 
BAGG, H. J. (1929): Hereditary Abnormalities of the Limbs: Their Origin and Transmission. American Journal of Anatomy, 43, 167.

BAGg, H. J., and Litrle, C. C. (1924): Hereditary Structural Defects in the Descendants of Mice Exposed to Roentgen Ray Irradiation. American Journal of Anatomy, 33, 119.

Ballantyne, J. W. (1895): The Diseases and Deformities of the Foetus. Two Volumes. Edinburgh: Oliver \& Boyd.

Ballantyne, J. W. (1904): Manual of Antenatal Pathology and Hygiene. Edinburgh: W. Green \& Sons. Bardeleben, A. (1874): Lehrbuch der Chirurgie und Operationslehre. Berlin. (Quoted by Steindler.) BARFURTH, D. (1885): Vergleichend-histochemische Untersuchungen über das Glycogen. Archiv für Mikroskopische Anatomie, 25, 259. (Quoted by H. A. Harris.)

BAUer, J. T., and Royster, H. A. Jun. (1937): Hypoglycemia; Hypertrophy and Hyperplasia of the Islands of Langerhans in the Newborn Infant Following Maternal Diabetes. Bulletin of the Ayer Clinical I.aboratory of the Pennsylvania Hospital, 3, whole number 14, 109.

Blattene, R. J., and Williamson, A. P. (1951): Developmental Abnormalities in the Chick Embryo Following Infection with Newcastle Disease Virus. Proceedings of the Society for Experimental Biology and Medicine, 77, 619.

Bleyer, A. (1938): Role of Advanced Maternal Age in Causing Mongolism. American Journal of Diseases of Children, 55, 79.

Bonnevie, K. (1934): Journal of Experimental Zoology, 67, 443.

Bovrouin, J. B. (1948): Les malformations du nouveau-né causées par des viroses de la grossesse et plus particulièrement par la Rubéole (Embryopathie rubéoleuse). Thèse, Genève. (Quoted by Tondury, Gr.) BRAILSFORD, J.F. (1948): The Radiology of Bones and Joints. Fourth edition. London: J. \& A. Churchill Ltd. Browne, D. (1936): Congenital Deformities of Mechanical Origin. Proceedings of the Royal Society of Medicine (Section for the Study of Disease in Children), 29, 1409.

Byerly, T. C., Titus, H. W., Eli.is, N. R., and Landauer, W. (1935): A New Nutritional Disease of the Chick Embryo. Proceedings of the Society for Experimental Biology and Medicine, 32, 1542.

Cappell, D. F. (1948): Recent Advances in Our Knowledge of the Rh Factor. British Medical Journal, $11,323$. Cassidy, G. J., Dworkin, S., and Finney, W. H. (1926): The Action of Insulin on the Domestic Fowl. American Journal of Physiology, 75, 609.

Charles, A. F., and Scott, D. A. (1931): Action of Acid Alcohol on Insulin. Journal of Biological Chemistry, 92, 289.

CORDA, G. M. (1932): Ricerche sperimentali sulla influenza della iperglicemia e della ipoglicemia materna sul decorso della gravidanza e sullo sviluppo dei feti. Annali di Ostetricia e Ginecologia, 54, 143. (Quoted by Warkany (1947).)

Cordes, F. C., and BARber, A. (1946): Changes in Lens of Embryo After Rubella. Archives of Ophthalmology, N.S. 36, 135.

Corner, G. W: (1944): Ourselves Unborn. New Haven: Yale University Press.

Couch, J. R., Cravens, W. W., Elvehjem, C. A., and Halpin, J. G. (1948): Anatomical Record, $100,29$. DARESTE, C. (1882): Mémoire sur les anomalies des membres et sur le rôle de l'amnios dans leur production. Journal de l'Anatomie et de Physiologie, 18, 524.

DWyer, H. L. (1932): Dyschondroplasia Foetalis. American Journal of Diseases of Children, 44, 776.

ENGrL, D. (1940): Etiology of Multiple Deformities. American Journal of Diseases of Children, 60, 562.

Evgre, D. (1943): The Etiology of the Undescended Scapula and Related Syndromes. Journal of Bone and Joint Surgery, 25, 613.

Follis, R. H., Jun. (1949a): Some Histochemical Observations on Normal and Diseased Cartilage and Bone. Transactions of the Josiah Macy Foundation Conference on Metabolic Interrelations. February 7-8, 1949, p. 27. Follis, R. H., Jun. (1949b): Glycogen in Rachitic Cartilage and its Relation to Healing. Proceedings of the Society for Experimental Biology and Medicine, 71, 441.

Follis, R. H., Jun., and Berthrong, M. (1949): Histochemical Studies on Cartilage and Bone. Bulletin of the Johns Hopkins Hospital, 85, 281.

Fox, M. J., and Bortin, M. M. (1946): Rubella in Pregnancy Causing Malformations in Newborn. Journal of the American Medical Association, 130, 568.

Fox, M. J., Krumbiegel, E. R., and Teresi, J. L. (1948): Maternal Measles, Mumps, and Chickenpox as a Cause of Congenital Anomalies. Lancet, i, 746.

Gates, R. R. (1946): Human Genetics. Two Vols. New York: The Macmillan Company.

Gegenbauer (1864): Jenaische Zeitschrift für Medizen und Naturwissenschaft, p. 1. (Quoted by Steindler.) Gillman, J., Gilbert, C., and Girlman, T. (1948): A Preliminary Report on Hydrocephalus, Spina Bifida and Other Congenital Anomalies in the Rat Produced by Trypan Blue. South African Journal of Medical Science, 13, 47.

(iOAR, E. L., and Potrs, C. R. (1946): The Relationship of Rubella in the Mother to Congenital Cataracts in the Child. American Journal of Ophthalmology, 29, 566. 
Goldschmidt, R. (1935): Zeitschrift für Induktive Abstammungs-und Vererbungslehre. (Quoted by J. Needham.)

Gray, P., and Worthing, H. (1941): Experiments on Chemical Interference with Early Morphogenesis of Chick; Effects of Tetanus Toxin on Morphogenesis of Central Nervous System. Journal of Experimental Zoology, 86, 423.

GregG, N. M. (1941): Congenital Cataract Following German Measles in the Mother. Transactions of the Ophthalmological Society of Australia, 3, 35.

GregG, N. M. (1945): Rubella During Pregnancy of the Mother, with its Sequelae of Congenital Defects in the Child. Medical Journal of Australia, 1, 313.

Grüneberg, H. (1935): A New Sub-lethal Colour Mutation in the House Mouse. Proceedings of the Royal Society B, 118, 321.

GrüNeberG, H. (1936): Two Independent Inherited Tooth Anomalies in One Family. Journal of Heredity, 27, 225.

GRÜNEBERG, H. (1938): Journal of Genetics, 36, 153.

Gutman, A. B., and Gutman, E. B. (1941): A Phosphorylase in Calcifying Cartilage. Proceedings of the Society for Experimental Biology and Medicine, 48, 687.

Gutman, A. B., and T'Sai Fan Yu (1949): Further Studies of the Relation Between Glycogenolysis and Calcification of the Cartilage. Transactions of the Josiah Macy Jun. Foundation Conference on Metabolic Interrelations. February 7-8, 1949, p. 11.

HALE, F. (1935): The Relation of Vitamin A to Anophthalmos in Pigs. American Journal of Ophthalmology, $18,1087$.

HaNAN, E. B. (1925): Experimental Hypoglycemia and Hyperglycemia in the Chick Embryo. Proceedings of the Society for Experimental Biology and Medicine, 22, 501 .

HARRIS, H. A. (1932): Glycogen in Cartilage. Nature, 130, 996.

Harris, H. A. (1933): Bone Growth in Health and Disease. London: Humphrey Milford Oxford University Press.

Harris, H. F. (1919): Pellagra. New York: The Macmillan Company.

HATA, K. (1927): Journal of the Imperial Fisheries Institute, Tokyo, 13, 50.

Hein, W. (1907): Bayerischen Biologischen Versuchsstation, München, 22. (Quoted by I. Needham.) Hrin, W. (1911): Allgemeine Fischereizeitung, 32, 334. (Quoted by J. Needham.)

Hertig, A. T. (1948): Discussion on Nutrition in Pregnancy. Obstetrical and Gynecological Survey, 3, 701. Higurashi, T., and Nakai, N. (1925): Journal of the Imperial Fisheries Institute, Tokyo, 21, 5.

Hoffmann, A., Lehmann, G., and Wertheimer, E. (1928): Der Glykogenbestand des Knorpels und seine Bedeutung. Pflüger's Archiv für die gesamte Physiologie, 220, 183.

Hотснкiss, R. D. (1948): Microchemical Reaction Resulting in Staining of Polysaccharide Structures in Fixed Tissue Preparations. Archives of Biochemistry, 16, 131.

Hut, F. B., and Greenwood, A. W. (1929): Proceedings of the Royal Society of Edinburgh, 49, 145.

IDZUMI, S. (1924): Biochemische und serologische Untersuchungen von bebrüteten Hühnereiern. Mitteilungen aus der Medizenischen Fakultät der Kaiserlichen Universität zu Tokyo, 32, 197. (Quoted by J. Needham.) INGALLS, T. H. (1947): Etiology of Mongolism. American Journal of Diseases of Children, 74, 147.

INGALLs, T. H., and GoRDon, J. E. (1947): Epidemiologic Implications of Developmental Arrests. American Journal of the Medical Sciences, 214, 322.

Ingalls, T. H., and Prindle, R. A. (1949): Esophageal Atresia with Tracheoesophageal Fistula. New England Journal of Medicine, 240, 987.

Ingalls, T. H., Curley, F. J., and Prindle, R. A. (1950): Anoxia as a Cause of Fetal Death and Congenital Defect in the Mouse. American Journal of Diseases of Children, 80, 34.

Ivanovsky, A. (1923): American Journal of Physical Anthropology, 6, 331.

Jansen, M. (1912): Achondroplasia, Its Nature and Its Cause. London: Baillière, Tindall \& Cox.

Jansen, M. (1934): Uber atypische Chondrodystrophia (Achondroplasie) und über eine noch nicht beschriebene angeborene Wachstumtörung des Knochensystems: Metaphysäre Dysostosis. Zeitschrift für Orthopädische Chirurgie, 61, 253.

Joslin, E. P., Root, H. F., White, P., and Marble, A. (1940): The Treatment of Diabetes Mellitus. Seventh edition. London: Henry Kimpton.

Karnofsky, D. A., Patterson, P. A., and Ridgway, L. P. (1949): Effect of Folic Acid, " 4-Amino " Folic Acids and Related Substances on Growth of Chick Embryo. Proceedings of the Society for Experimental Biology and Medicine, 71, 447.

Karnofsky, D. A., Ridgway, L. P., and Patterson, P. A. (1950): Proceedings of the Society for Experimental Biology and Medicine, 73, 225.

Karnofsky, D. A., Stock, C. C., Ridgway, L. P., and Patterson, P. A. (1950): The Toxicity of Vitamin B, 4-Desoxypyridoxine and 4-Methoxymethylpyridoxine, Alone and in Combination, to the Chick Embryo. Journal of Biological Chemistry, 182, 471.

Vol. 34 B, No. 4, NOVEMBER 1952 
Karnofsky, D. A., Ridgway, L. P., and Patterson, P. A. (1951): Growth-Inhibiting Effect of Cortisone Acetate on the Chick Embryo. Endocrinology, 48, 596.

KEITH, Sir A. (1940): Concerning the Origin and Nature of Certain Malformations of the Face, Hearl and Foot. British Journal of Surgery, 28, 173.

LANDAUER, W. (1945): Journal of Experimental Zoology, 98, 65.

LANDAUER, W. (1947): Journal of Experimental Zoology, 105, 145.

LANDAUER, W., and BaumanN, L. (1943): Journal of Experimental Zoology, 93, 51.

LANDAUER, W., and LANG, E. H. (1946): Journal of Experimental Zoology, 98, 65.

Lavinder, C. H., and Babcock, J. W. (1910): “ Pellagra." State Co., Publishers, Columbia, D.C.

Lawrence, R. D., and Oakley, W. (1942): Pregnancy and Diabetes. Quarterly Journal of Medicine, N.S. 11, 45.

Le Damany, P. (1923): La Luxation congénitale de la Hanche. Paris: Flammarion.

Lichtenstein, H., Guest, G. M., and Warkany, J. (1951): Paper read at the xiii Congrès des pédiatres de lange française, Algiers, May 7, 1951. (Private communication.)

Lindbom, A. (1942): Zwei Neue Fälle mit " Streifenförmiger Osteopoikilie " (Voorhoeve). Acta Radiologica, 23, 296.

Lison, L. (1935): La signification histochimique de la métachromasie. Comptes Rendus des Séances et Mémoires de la Société de Biologie, 118, 821.

Loeb, J., and Bancroft, F. W. (1911): Some Experiments on the Production of Mutants in Drosophila. Science, N.S. 33, 781.

Lowe, R. F. (1949): The Eyes in Mongolism. British Journal of Ophthalmology, 33, 131.

Lyon, E. P. (1902): Effects of Potassium Cyanide and of Lack of Oxygen upon the Fertilized Eggs and the Embryos of the Sea Urchin (Arbacia Punctulata). American Journal of Physiology, 7, 56.

Lyons, M., and Inkso, W. M., Jun. (1937): Kentucky Agricultural Experiment Station Bulletin, p. 371. MacGregor, A. R. (1946): The Pathology of Still-Birth and Neonatal Death. British Medical Bulletin, 4, 174. McManus, J. F. A. (1946): Histological Demonstration of Mucin after Periodic Acid. Nature, 158, 202.

MACKLIN, M. T. (1936): Heredity as the Cause of Congeniral Malformations. American Journal of Obstetrics and Gynecology, 32, 258.

Mall, F. P. (1908): A Study of the Causes Underlying the Origin of Human Monsters. Journal of Morphology, $19,1$.

MALL, F. P. (1917): On the Frequency of Localized Anomalies in Human Embryos and Infants at Birth. American Journal of Anatomy, 22, 49.

Marchand, F. (1885): Ueber eine Geschwulst aus quergestreiften Muskelfasern mit ungewöhnlichem Gehalte an Glykogen, nebst Bemerkungen über das Glykogen in einigen fötalen Geweben. Virchow's Archiv für Pathologische Anatomie, 100, 42.

Marks, P. A., and Shorr, E. (1950): Factors Which Regulate the Deposition of Calcium and Strontium in Rachitic Cartilage in vitro. Transactions of the Josiah Macy, Jun., Foundation Conference on Metabolic Interrelations. January 9-10, 1950, New York, p. 175.

Mavor, J. W. (1922): The Elimination of the Sex-Chromosome by X-rays: A Modification of the Germ Plasm Produced by an External Agent. Anatomical Record, 23, 99.

Middleton, D. S. (1934): Studies on Prenatal Lesions of Striated Muscle as a Cause of Congenital Deformity. Edinburgh Medical Journal, N.S. 41, 401.

Miller, H. C. (1945): Cardiac Hypertrophy and Extramedullary Erythropoiesis in Newborn Infants of Prediabetic Mothers. American Journal of the Medical Sciences, 209, 447.

Miller, H. C. (1946): The Effect of Diabetic and Prediabetic Pregnancies on the Fetus and Newborn Infant. Journal of Pediatrics, 29, 455.

Miller, H. C., and Wilson, H. M. (1943): Macrosomia, Cardiac Hypertrophy, Erythroblastosis, and Hyperplasia of the Islands of Langerhans in Infants Born to Diabetic Mothers. Journal of Pediatrics, 23, 251. Miller, H. C., Johnson, R. D., and Durlacher, S. H. (1944): A Comparison of Newborn Infants with Erythroblastosis Fetalis with Those Born to Diabetic Mothers. Journal of Pediatrics, 24, 603.

Mollison, P. L., Mourant, A. E., and Race, R. R. (1948): The Rh Blood Groups and their Clinical Effects. Medical Research Council Memorandum No. 19.

Moore, L. A., Huffman, C. F., and Duncan, C. W. (1935): Blindness in Cattle Associated with a Constriction of the Optic Nerve Probably of Nutritional Origin. Journal of Nutrition, 9, 533.

Morgan, T. H. (1904): Archiv für Entwicklungsmechanik, 19, 570. (Quoted by J. Needham.)

Morgan, T. H. (1905): Archiv für Entwicklungsmeckanik, 19, 581. (Quoted by J. Needham.)

Murphy, D. P. (1933): The Excretion of Ovary Stimulating Hormone in the Urine During Pregnancy. Surgery, Gynecology and Obstetrics, 56, 914.

Murphy, D. P. (1947): Congenital Malformations. Philadelphia: J. B. Lippincott Company.

Needham, J. (1926a): The Energy Sources in Ontogenesis. British Journal of Experimental Biology. 3, 189. Needham, J. (1926b): The Energy Sources in Ontogenesis, British Journal of Experimental Biology, 4, 114;145. 
Needhal, J. (1931): Chemical Embryology. Three vols. Cambridge: University Press.

Needham, J. (1942): Biochemistry and Morphogenesis. Cambridge: University Press.

OAkley, W., and Peel, J. (1949): Proceedings of the 12th British Congress of Obstetrics and Gynaecology. (Quoted by F. J. Browne.)

Oтто, A. G. (1841): Monstrorum Sexcentorum Descriptio Anatomica Vratislaviae. F. Hirt. p. 322. (Quoted by Middleton.)

PARsoxs, L. G. (1936): The British Encyclopaedia of Medical Practice. Editor, Sir H. Rolleston. London: Butterworth \& Co. (Publishers) Ltd.

PARsoss, L. G. (1946): Antenatal Paediatrics. Journal of Obstetrics and Gynaecology of the British Empire, 53, 1.

People's League of Health (1946): The Nutrition of Expectant and Nursing Mothers in Relation to Maternal and Infant Mortality and Morbidity. Journal of Obstetrics and Gynaecology of the British Empire, 53, 499.

Plagess, G. M. (1933): An Embryological Study of a Special Strain of Deformed X-rayed Mice, with Special Reference to the Etiology and Morphogenesis of the abnormalities. Journal of Morphology, 55, 151. Potvin, R., and ARON, M. (1927): Recherches sur l'évolution embryonnaire des îlots pancréatiques endocrines chez le poulet. Comptes Rendus Hebdomadaires des Séances et Mémoires de la Société de Biologie, 96, 267.

Prentiss, C. W. (1910): A Case of Polydactylism Correlated with Defect of the Fronto-Nasal Process. Quarterly Bulletin of Northwestern University Medical School, 12, 10.

RidDle, O. (1922): Identical Twins in Pigeons Arise from Ova of Markedly Aberrant Size. Proceedings of the Society for Experimental Biology and Medicine, 19, 122.

Riddle, O. (1923): Resistance of Pigeons to the Lethal Action of Iletin (Insulin) with Observed Effects on Reproduction. Proceedings of the Society for Experimental Biology and Medicine, 20, 244.

Ridgway, L. P., Patterson, P. A., and Karnofsky, D. A. (1950): Effect of Thallium, Lead and other Metals on Development of Chick Embryo. Federation Proceedings, 9, 341.

Robisox, R. (1923): The Possible Significance of Hexosephosphoric Esters in Ossification. Biochemical Journal, 17, 286.

Romanoff, A. L., and Bauernfeind, J. C. (1942): Influences of Riboflavin-Deficiency in Eggs on Embryonic Development (Gallus Domesticus). Anatomical Record, 82, 11.

Ross, O. B., Philips, P. H., Bohstedt, G., and Cunha, T. J. (1944): Journal of Animal Science, $3,406$. Rouget, C. J. (1859): Des substances amyloides; de leur rôle dans la constitution des tissus des animaux. Journal de la Physiologie, 2, 83.

Rubin, P. S., and Howard, J. E. (1950): Histochemical Studies on the Role of Acid Muco-Polysaccharides in Calcifiability and Calcification. Transactions of the Second Josiah Macy, Jun., Foundation Conference on Metabolic Interrelations, January 9-10, p. 155.

Ruggles, H. E. (1931): Dwarfism Due to Disordered Epiphyseal Development. American Journal of Roentgenology, 25, 91.

SABin, A. B., and Feldman, H. A. (1949): Chorioretinopathy Associated with Other Evidence of Cerebral Damage in Childhood. Journal of Pediatrics, 35, 296.

Scotr, J. W. (1903): Periods of Susceptibility in the Differentiation of Unfertilized Eggs of Amphitrite. Biological Bulletin, 5, 35.

Silberberg, M., Levy, B. M., and Younger, F. (1948): Skeletal Changes in Growing Vitamin B Complex Depleted Rats and the Course of Repair. Proceedings of the Society for Experimental Biology and Medicine, 67, 185.

SilfVERSKIÖLD, N. (1925): A "Forme Fruste" of Chondrodystrophia with Changes Simulating Several of the Known "Local Malacias." Acta Radiologica, 4, 44.

Smith, G. E. (1917): Fetal Athyrosis. A Study of the Iodine Requirement of the Pregnant Sow. Journal of Biological Chemistry, 29, 215.

Smyth, F. S., and Olney, M. B. (1938): Diabetes and Pregnancy: Observations on the Offspring with a Pathologic Report. Journal of Pediatrics, 13, 772.

SNOKE, P. O. (1933): Chondrodystrophia Fetalis. American Journal of Roentgenology, 29, 31.

Spemans, H. (1938): Embryonic Development and Induction. New Haven: Yale University Press.

SPRATT, X. T., Jun. (1948): Journal of Experimental Zoology, 107, 39.

Steindler, A. (1950): Post-Graduate Lectures on Orthopedic Diagnosis and Indications. Springfield, Illinois: Charles C. Thomas.

Stockard, C. R. (1907): Archiv für Entwicklungsmeckanik, 23. (Quoted by J. Needham.)

Stockard, C. R. (1909): The Origin of Certain Types of Monsters. American Journal of Obstetrics, 59, 582. Stockard, C. R. (1909): Journal of Experimental Zoology, 6, 285.

Stockard, C. R. (1910) The Independent Origin and Development of the Crystalline Lens. American Journal of Anatomy, 10, 393.

VOL. $34 \mathrm{~B}$, No. 4 , NOVEMBER 1952 
Stockard, C. R. (1913): An Experimental Study of the Position of the Optic Anlage in Amblystoma Punctatum, with a Discussion of Certain Eye Defects. American Journal of Anatomy, 15, 253.

Stockard, C. R. (1913): Proceedings of the New York Pathological Society, 13.

Stockard, C. R. (1914): A Study of Further Generations of Mammals from Ancestors Treated with Alcohol. Proceedings of the Society for Experimental Biology and Medicine, 11, 136.

StockaRD, C. R. (1919): Developmental Rate and the Formation of Embryonic Structures. Proceedings of the Society for Experimental Biology and Medicine, 16, 93.

Stockard, C. R. (1920) : Developmental Rate and Structural Expression: an Experimental Study of Twins,

"Double Monsters," and Single Deformities, and the Interaction Among Embryonic Organs During their Origin and Development. American Journal of Anatomy, 28, 115.

Streeter, G. L. (1930): Focal Deficiencies in Fetal Tissues and their Relation to Intra-Uterine Amputation. Contributions to Embryology, 22, 1.

Swan, C. (1944): A Study of Three Infants Dying from Congenital Defects Following Maternal Rubella in the Early Stages of Pregnancy. Journal of Pathology and Bacteriology, 56, 289.

Swan, C. (1949): Rubella in Pregnancy as an Aetiological Factor in Congenital Malformation, Stillbirth, Miscarriage and Abortion. Journal of Obstetrics and Gynaecology of the British Empire, 56, 341; 591.

Swan, C., Tostevin, A. L., Moore, B., Mayo, H., and Black, G. H. B. (1943): Congenital Defects in Infants Following Infectious Diseases During Pregnancy. Medical Journal of Australia, ii, 201.

Swan, C., Tostevin, A. L., and Black, G. H. B. (1946): Final Observations on Congenital Defects in Infants Following Infectious Diseases During Pregnancy, with Special Reference to Rubella. Medical Journal of Australia, ii, 889.

Swan, C., and Tostevin, A. L. (1946): Congenital Abnormalities in Infants Following Infectious Diseases During Pregnancy with Special Reference to Rubella: A Third Series of Cases. Medical Journal of Australia, i, 645 .

Terry, T. L. (1943): Fibroblastic Overgrowth of Persistent Tunica Vasculosa Lentis in Premature Infants. Archives of Ophthalmology, 29, 36.

Tondury, G. (1951): Bulletin der Schweizerischen Akademie der Medizinischen Wissenschaften, 7, 325.

Vladimirov, G. (1931): The Effect of Some Factors upon the Blood Sugar of Embryo Chicks. Journal of Physiology, 72, 411.

Wakeley, C. P. G. (1931): Marble Bones (Albers-Schönberg Disease). Proceedings of the Royal Society of Medicine (Clinical Section), 25, 145.

Warkany, J. (1945): Manifestations of Prenatal Nutritional Deficiency. Vitamins and Hormones, $3,73$. Warkany, J. (1947): Etiology of Congenital Malformations. Advances in Pediatrics, 2, 1.

Warkany, J., and Mitchell, A. G. (1934): Atypical Chondrodystrophy. Journal of Pediatrics, 4, 734.

Warkany, J., and Nelson, R. C. (1940): Appearance of Skeletal Abnormalities in the Offspring of Rats Reared on a Deficient Diet. Science, 92, 383.

Warkany, J., and Nelson, R. C. (1941): Skeletal Abnormalities in the Offspring of Rats Reared on Deficient Diets. Anatomical Record, 79, 83.

Warkany, J., and Nelson, R. C. (1942): Skeletal Abnormalities Induced in Rats By Maternal Nutritional Deficiency. Archives of Pathology, 34, 375.

Warkany, J., Nelson, R. C., and Schraffenberger, E. (1942): Congenital Malformations Induced in Rats by Maternal Nutritional Deficiency. American Journal of Diseases of Children, 64, 866.

Warkany, J., Nelson, R. C., and Schraffenberger, E. (1943): Congenital Malformations Induced in Rats by Maternal Nutritional Deficiency. American Journal of Diseases of Children, 65, 882.

Warkany, J., Nelson, R. C., and Schraffenberger, E. (1943): Congenital Malformations Induced in Rats by Maternal Nutritional Deficiency. Journal of Bone and Joint Surgery, 25, 261.

Warkany, J., Roth, C. B., and Wilson, J. G. (1948): Multiple Congenital Malformations: a Consideration of Etiologic Errors. Pediatrics, 1, 462.

Watchorn, E. (1938): Some Biochemical Data on the Grey-Lethal Mouse. Journal of Genetics, 36, 171. Wesselhoeft, C. (1947): Rubella (German Measles). New England Journal of Medicine, 236, 943; 978.

White, P., Titus, R. S., Joslin, E. P., and Hunt, H. (1939): Prediction and Prevention of Late Pregnancy Accidents in Diabetes. American Journal of the Medical Sciences, 198, 482.

Wolf, A., Cowen, D., and Paige, B. H. (1939a): Human Toxoplasmosis: Occurrence in Infants as an Encephalomyelitis. Verification by Transmission to Animals. Science, 89, 226.

Wolf, A., Cowen, D., and Paige, B. H. (1939b): Toxoplasmic Encephalomyelitis. American Journal of Pathology, 15, 657.

Yannet, H. (1950): Mental Deficiency Due to Prenatally Determined Factors. Pediatrics, 5, 328.

YanNet, H., and Lieberman, R. (1948): Mother-Child ABO Incompatibility. American Journal of Diseases of Children, 76, 176.

Zwill.ing, E. (1948): Journal of Experimental Zoology, 109, 197.

Zwilling, E. (1951): Journal of Experimental Zoology, 117, 65. 